\title{
SHIPBOARD AND SATELLITE OBSERVATIONS OF UPPER OCEAN VELOCITY AND TRANSPORT VARIABILITY IN THE GULF STREAM
}

\author{
by \\ David Michael Schubert, Jr. \\ B.S. United States Naval Academy \\ (1977) \\ Submitted in partial fulfillment of the \\ requirements for the degree of \\ Master of Science \\ at the \\ MASSACHUSETTS INSTITUTE OF TECHNOLOGY \\ and the \\ WOODS HOLE OCEANOGRAPHIC INSTITUTION
}

September 1990

()David M. Schubert, Jr. 1990

The author hereby grants to MIT and to WHOI permission to reproduce and to distribute copies of this thesis document in whole or in part.

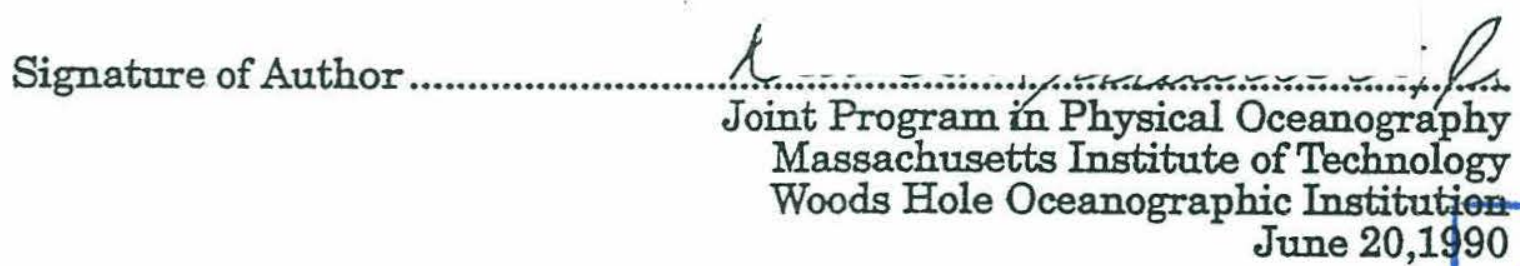

Certified by

MARINE BIOLCG!CAL LABORATORY

Certifed by

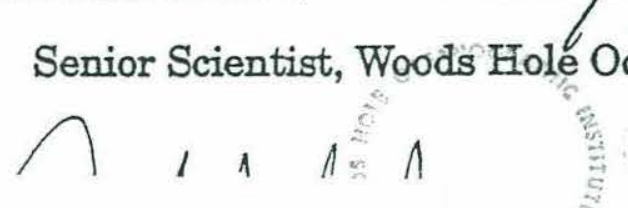

Dr. Terrence M. JofceLIB RARY

Thesis Superviporoos HOLE, MASS.

Accepted by 


\section{Table of Contents}

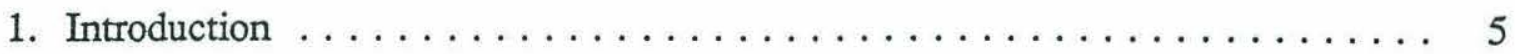

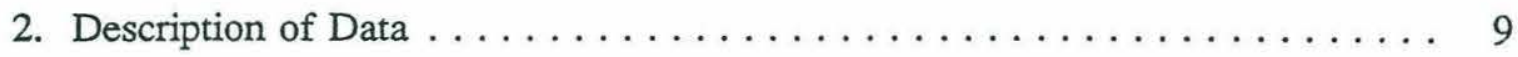

2.1 Acoustic Doppler Current Profiler 9

2.2 Expendable Bathythermograph 14

3. Estimation of the Absolute Velocity Field $\ldots \ldots \ldots \ldots \ldots \ldots \ldots \ldots 26$

3.1 ADCP and Geostrophic Profiles 26

3.2 Direct Combination of ADCP and Geostrophic Velocities 28

3.3 Transport Variability 42

4. Velocity by Combined Inversion Techniques $\ldots \ldots \ldots \ldots \ldots \ldots \ldots .45$

4.1 The Inverse Problem 45

4.2 The Singular Value Decomposition 50

4.3 Resolution and Variance 52

4.4 Inverse Results for Cruise OC216 53

4.5 Inverse Results for Cruise OC205 64

5. Temporal Variability between Bermuda and Cape Cod $\ldots \ldots \ldots \ldots .73$

5.1 Gulf Stream Variability 73

5.2 Ageostrophic effects 76

6. Comparison of Sea Surface Height and Velocity to Satellite Data . . . . . . 92







\title{
Shipboard and Satellite Observations of Upper Ocean Velocity and Transport Variability in the Gulf Stream
}

\author{
by \\ David Michael Schubert, Jr. \\ Submitted in partial fulfillment of the requirements for the degree of \\ Master of Science in Physical Oceanography \\ at the Massachusetts Institute of Technology and the \\ Woods Hole Oceanographic Institution \\ June 30, 1990
}

\begin{abstract}
Acoustic doppler velocities are combined with velocity profiles generated from XBT measurements to produce estimates of the flow field between Bermuda and the eastern coast of the United States. Repeated shipboard measurements along an ascending GEOSAT subtrack between Bermuda and Cape Cod allow study of rapid Gulf Stream Variability along the track, and comparison of sea surface and velocity measurements with those computed from the GEOSAT altimeter. The shipboard data were taken during two separate cruises on the R/V Oceanus in April and December, 1989. Using mass conservation constraints and inverse techniques, the transport across the Cape CodBermuda track has been balanced with transport across additional ship tracks between Bermuda and Cape Hatteras, and between Bermuda and Nova Scotia. The shipboard results show evidence of a rapid barotropic mode which caused changes in transport along the Cape Cod-Bermuda track on the order of 8 Sverdrups in a week period. Comparisons of sea surface velocity and dynamic height determined from the ship's data with measurements made from the GEOSAT altimeter showed a consistent picture of the Gulf Stream location and were also consistent in showing smaller scale variations in flow. The dynamic height difference across the Gulf Stream was approximately $10 \%$ higher for the GEOSAT measurements than for the shipboard measurements, which is within the expected errors of the analysis techniques.
\end{abstract}

Thesis Supervisor: Dr. Terrence M. Joyce

Senior Scientist, Woods Hole Oceanographic Institution 


\section{Acknowledgements}

I would like to thank the following persons for their contributions to my thesis:

My advisor, Dr. Terrence Joyce, who inspired this work by his guidance and encouragement.

Jane Dunworth, who guided me through many frustrating experiences in learning computer progranmming.

Lorraine Barbour, who drafted many of the figures in this thesis, provided moral support, and lent a willing hand in countless other ways.

Dr. Kathryn Kelly, who taught me about satellite oceanography.

The crew of R/V Oceanus, for their professionalism and hospitality during the two cruises. 


\section{Chapter 1}

\section{Introduction}

Many studies have been made over the years of water transport in the Gulf Stream. Studies done in the 1950's and earlier used the dynamic method, which measures the horizontal pressure gradient, and uses the geostrophy to calculate velocities assuming the force caused by horizontal pressure gradients in the water is balanced by Coriolis force. Classically, water velocities were calculated relative to some deep level of no motion. Worthington (1976) analyzed a large group of hydrographic sections across the Gulf Stream to investigate the seasonal variation in Gulf Stream transport relative to a level of no motion at 2000 meters. It is now well known that significant velocities exist at 2000 meters and deeper, making estimates such as those by Worthington questionable as representative of the total mass flux. In the 1960's, deep current measurements were made using neutrally buoyant floats in connection with CTD sections, which showed currents of speeds between 6 and $11 \mathrm{~cm} / \mathrm{s}$ at depths of approximately 2500 meters (Warren and Volkman, 1968). Recently, Halkin and Rossby (1985) have made a study of Gulf Stream transport using the Pegasus free-falling velocity profiler, which measures absolute horizontal velocity profiles. The Pegasus technique is quite labor-intensive, requiring an ocean bottom transponder array to acoustically track the profiler, and requiring a dedicated research vessel to deploy the profiler. An alternate method using

hydrographic data and an Acoustic Doppler Current Profiler (ADCP) for direct shallow water velocity measurements was reported by Joyce, Wunsch, and Pierce (1986) and 
Pierce and Joyce (1988). This method also requires the use of a dedicated research vessel, but does not require as much ship time nor any external transducer network. The work presented in this thesis uses a variation of the $\mathrm{ADCP} / \mathrm{CTD} /$ inverse method used by Joyce, Wunsch, and Pierce, using expendable bathythermographs (XBT's) and acoustic doppler measurements from a moving research vessel. This method limits measurements to the upper ocean, but allows faster transits to be made, since the ship does not need to stop for CTD stations. Data were taken along a GEOSAT Altimeter track in order to investigate the possibility of using direct sea surface height measurements made by satellite to provide a sea surface velocity reference for geostrophically determined velocity profiles. This method could be used by ships of opportunity in the future, eliminating the need for a dedicated research vessel.

The measurements used in this report were made during two separate cruises on the R/V Oceanus. The first cruise, OC205, conducted in April, 1989 consisted of two triangular tracks with legs running from Bermuda to the 200 meter isobath off Cape Hatteras, Cape Cod, and Nova Scotia (Figure 1.1, top) The central leg of this track was chosen to coincide with an ascending subtrack of the GEOSAT altimeter. This leg was traversed three times during the April cruise, at time intervals of about one week. The second, somewhat shorter cruise, OC216, was conducted in December, 1989, and covered the same area as the lower triangle in the April cruise (Figure 1.1, bottom). During the cruises, $\mathrm{ADCP}$ measurements were made continuously and XBT's were launched approximately once an hour. The GEOSAT altimeter is in an orbit which causes it to repeat its track over the earth every 17 days. During the April cruise, the GEOSAT pass occurred between the second and third ship passage along the track. During the December cruise, the ship's track was planned so that the Gulf Stream crossing on the final leg of the cruise would coincide in time with a satellite pass. Unfortunately, due to equipment malfunctions associated with the satellite's age, no altimeter data were received for the pass during the OC216 cruise.

The geostrophic velocity profiles generated from the XBT data and the shallow 

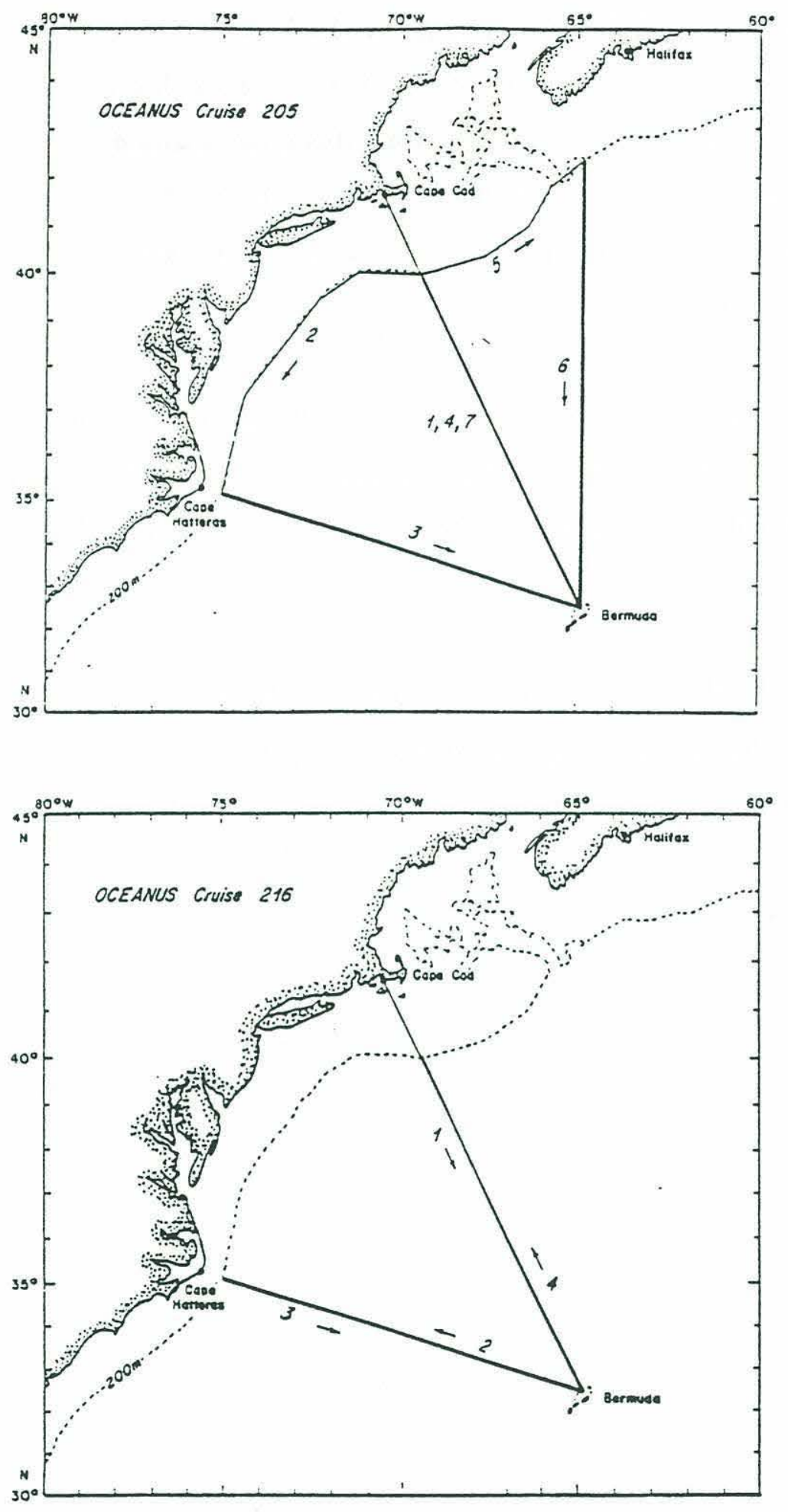

Figure 1.1 Tracks for RV Oceanus cruises in April 1989 (top) and December 1989 (bottom) 
acoustic doppler velocity profiles will be combined to produce an absolute velocity field for the upper 760 meters along the ship's track. The direct use of acoustic doppler velocities to provide a reference for the geostrophic profiles will be examined first. Errors in the doppler velocities using this direct method can lead to substantial errors in total transport. The geometry of the sections allows us to impose mass budgeting constraints on the transport and use linear inverse theory to yield a more accurate picture of the flow field.

The repeated ship legs along the altimeter track allow us to examine variability along this track. The variability section uses the $\mathrm{ADCP}$ measurements to estimate the ageostrophic components in the momentum equation, and show how the Gulf Stream varies with time.

Finally, the sea surface dynamic heights and velocities computed from shipboard measurements are compared to those computed from the altimeter in order to validate the use of altimeter data as a velocity reference for hydrographic data. 


\section{Chapter 2}

\section{Description of Data}

The shipboard data consists of Acoustic Doppler Current Profiler (ADCP) velocities, Expendable Bathythermograph (XBT) temperature profiles, and navigation positions which were recorded for each XBT launch. The Acoustic Doppler system produces profiles of horizontal velocity from the surface down to a depth of 200 to 400 meters. The XBT temperature profiles are combined with estimated values for salinity to produce density profiles, from which geostrophic velocity profiles can be obtained.

Two types of satellite data will be presented. Sea surface height measured by the GEOSAT altimeter will be differentiated to compute sea surface velocities. Infrared pictures of sea surface temperature obtained from the AVHRR satellite will also be used qualitatively to examine the large scale features of the Gulf Stream during the times of the other observations.

\subsection{Acoustic Doppler Current Profiler}

The Acoustic Doppler system computes horizontal velocity components by measuring the doppler frequency shift of sound which is reflected by small particles in the water. Short $153.6 \mathrm{khz}$ pulses are transmitted in four narrow acoustic beams, which are oriented fore, aft, port, and starboard of the ship. Backscattered sound from plankton 
and other small particles in the water is received by the transducer with a frequency shift proportional to the relative velocity between the ship and the scatterers. In order to compute the velocity of the water, the ship's velocity must be accurately known and added to the signal.

The ADCP equipment used aboard OCEANUS is the RD Instruments Model VM0150 Current Profiler. In order to reduce the effects of ship's pitch and roll on the measurements, the pings, which have a pulse repetition frequency of one second, are averaged over a two minute interval. The advertised maximum depth for the ADCP system operating in this mode is 350 meters. During the cruises, the maximum depth at which a good signal ( $>25 \%$ of pings good) was received varied between 200 and 400 meters, depending on the roughness of the weather and the concentration of scatterers in the water.

Water velocities are determined by adding the ship's velocity to the doppler velocity. Since the velocity of the ship is typically much larger than the velocity of the water, errors in ship velocity can lead to large errors in the water velocity. The ship's velocity is determined by dividing the change in ship's position by the elapsed time. The accuracy of this velocity depends on precise navigation. During the cruises, the ship's position was determined using both the global positioning system (GPS) and the Loran-C navigation system.

In order to compare $\mathrm{ADCP}$ velocities with geostrophic velocities computed from the XBT data, the ADCP data were vector averaged between XBT positions. A typical navigation error of $.2 \mathrm{~km}$ between 2 XBT positions taken one hour apart would cause a $5 \mathrm{~cm} / \mathrm{s}$ error in the doppler velocity. An error in XBT position will introduce equal and opposite velocity errors in the doppler velocity vectors on either side of the XBT. To reduce these errors, the absolute velocities were filtered using a triangular filter. 


$$
\begin{gathered}
v_{n}^{\prime}=\frac{1}{4}\left(v_{n-1}+2 v_{n}+v_{n+1}\right), \text { for all but end velocities. } \\
v_{\text {end }}^{\prime}=\frac{1}{3}\left(2 v_{\text {end }}+v_{\text {end } \pm 1}\right), \text { for end velocity vectors }
\end{gathered}
$$

The effect of this filter is to reduce the navigational noise by $1 / 3$ for the end velocity vectors and by half for all the rest of the vectors. This filter also smoothes the actual velocities, reducing the peak and broadening the width of the Gulf Stream.

Another source of error in the $A D C P$ velocities arises from misalignment of the transducer with the ship's gyrocompass. A calibration run (Joyce, 1988) was performed during each cruise in an effort to eliminate this problem, but misalignment effects caused a significant bias in the velocities, especially during the April cruise. With the ship moving forward at a speed $U$, a small error, $\delta \theta$ in the transducer angle will generate an apparent velocity perpendicular to the ship's track of Usin $\delta \theta$. This error will be systematic, appearing as a consistent velocity error to one side of the ship. A transducer misalignment of $.5^{\circ}$ with a typical ship's velocity of $5 \mathrm{~m} / \mathrm{s}$ would generate a cross-track velocity error of $4.4 \mathrm{~cm} / \mathrm{s}$.

The doppler vectors for cruise OC205 are shown in Figure 2.1 In this Figure, only the second of the three central track legs is shown. The magnitude and direction of the velocity vectors along the 200 meter isobath lead one to suspect a systematic bias. The vectors for leg 2, which was traveled from north to south, point consistently off the shelf, while the vectors for leg 5, which was traveled from south to north, show velocities onto the shelf. In each case, there is a bias to the left of the ship's track. This bias will be quantified and its effects removed in the next chapter. The Gulf Stream is clearly seen in the doppler vectors of the three tracks which run from Bermuda to the 200 meter isobath. A large cold core ring is also observed south of the Gulf Stream on leg 6 between Bermuda and Nova Scotia. 
OC205 LEGS 2-6 SMOOTHED DOPPLER VECTORS

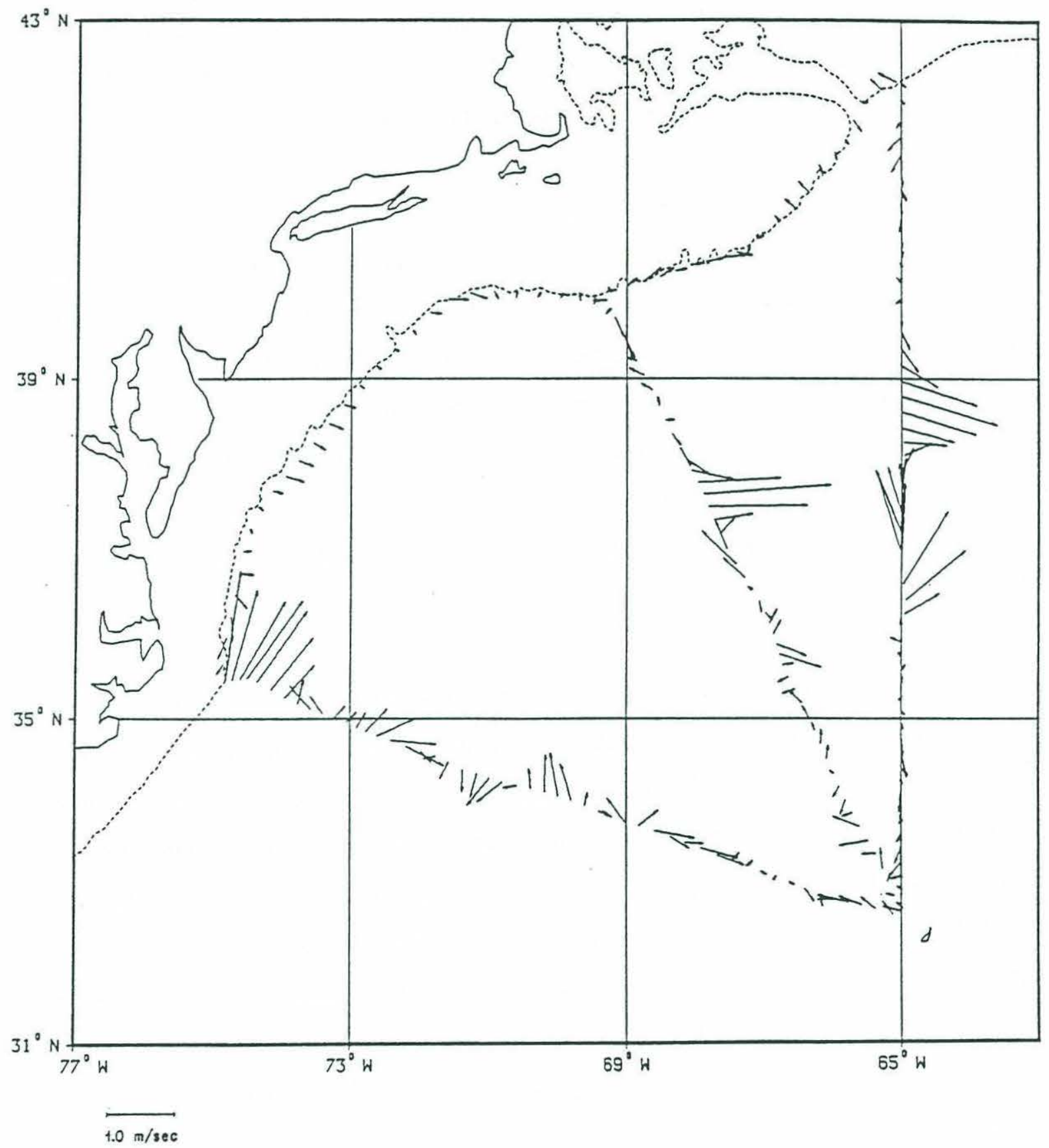

Figure 2.1 Doppler vectors for cruise OC205 at 100 meters depth. The vectors for the Bermuda to Cape Cod track are the leg 4 vectors. 



Figure 2.2 Doppler vectors for cruise OC216 at 100 meters depth. Legs 1 and 2 (top), legs 3 and 4 (bottom). 
The doppler vectors for the December cruise are shown in Figure 2.2. Along the Cape Cod-Bermuda satellite track, the Gulf Stream is about $100 \mathrm{~km}$ further to the North than during the April cruise. There are two large cold core rings near the track, one centered near $37^{\circ} \mathrm{N}$ which moved across the track from west to east during the time between legs one and four, and one west of Bermuda which remained at the eastern edge of legs two and three during the cruise.

\subsection{Expendable Bathythermograph}

Temperature profiles measured by expendable bathythermograph (XBT) are used to determine geostrophic velocity profiles. Sippican T-7 (765 meter) XBT's were used on both cruises except along the shelf, where shallower T-10 (200 meter) XBT's were used. In order to generate density profiles, salinity was estimated using the method of . Joyce, et al. (1988). The procedure for generating salinity is based on temperature and depth:

- Starting at the bottom of the temperature profile, $(765 \mathrm{~m})$ use the T/S relation for NW Atlantic Central Water (Armi and Bray, 1982) to estimate a salinity.

- When depth reaches 200 meters, hold salinity constant to the surface unless a temperature inversion is encountered.

- If a temperature inversion $\left(>0.5^{\circ} \mathrm{C}\right)$ is encountered, use temperature and depth and interpolate towards a value of $8^{\circ} \mathrm{C} / 32.5 \mathrm{psu}$, which is characteristic of shelf water.

This technique will be more accurate below 200 meters than above, and will be more accurate in the Sargasso Sea, where the T/S relation is accurate, than it will be on 
the slope. Joyce et al. estimate that dynamic height errors introduced with this method will be of order $2 \%$ of the signal.

Navigational errors will also affect the geostrophic velocities, but not to as great an extent as the $\mathrm{ADCP}$ velocities. The same $.2 \mathrm{~km}$ error in distance between $\mathrm{XBT}$ positions described above will produce only a $1.3 \%$ error in velocity for XBT's which are $15 \mathrm{~km}$ apart.

The velocity profiles computed from the XBT data assume geostrophy, and do not take into account centripetal acceleration due to Gulf Stream curvature or any other ageostrophic components in the momentum balance. These components can be significant and are discussed in chapters 5 and 6.

Sections of temperature and potential density are shown in Figure 2.3 through Figure 2.11. All of these sections as well as subsequent sections of velocity are shown with the shore end of the track to the left, and the Bermuda end of the track to the right. The major features shown in the doppler vectors are also apparent in the temperature and potential density sections. Cold core rings are seen in the OC205 sections at XBT 27-32 of leg 1, XBT 118-123 of leg 3, and XBT 254-258 of leg 6. There are also cold core rings on all four legs of the OC216 cruise. The shelf water was considerably colder near the surface during the April cruise with surface temperatures ranging from 8-15 ${ }^{\circ} \mathrm{C}$ compared to $16-18^{\circ} \mathrm{C}$ for the December cruise. These low surface temperatures cause apparent density inversions in the shallow shelf water due to the way salinity is estimated in the upper 200 meters. In leg 4 of cruise OC205, for example, the potential density section shows a density inversion at XBT's $190-191$, where $\sigma_{\mathrm{t}}$ at the surface is shown to be $>$ 26.3. The actual surface value of $\sigma_{\mathrm{t}}$ computed using surface temperature and salinity measured from bottle samples is 26.1 . On leg 7 of cruise OC205, there is a shallow mass of cold water between XBT's 320-325 with sea surface temperature $\approx 7^{\circ} \mathrm{C}$. Sea surface potential densities computed using the bottle salinities indicate that the $7^{\circ} \mathrm{C}$ water is actually less dense $\left(\sigma_{t}=25.8\right)$ than the surrounding $10^{\circ} \mathrm{C}$ water $\left(\sigma_{\mathrm{t}}=26.0\right)$ due to lower 

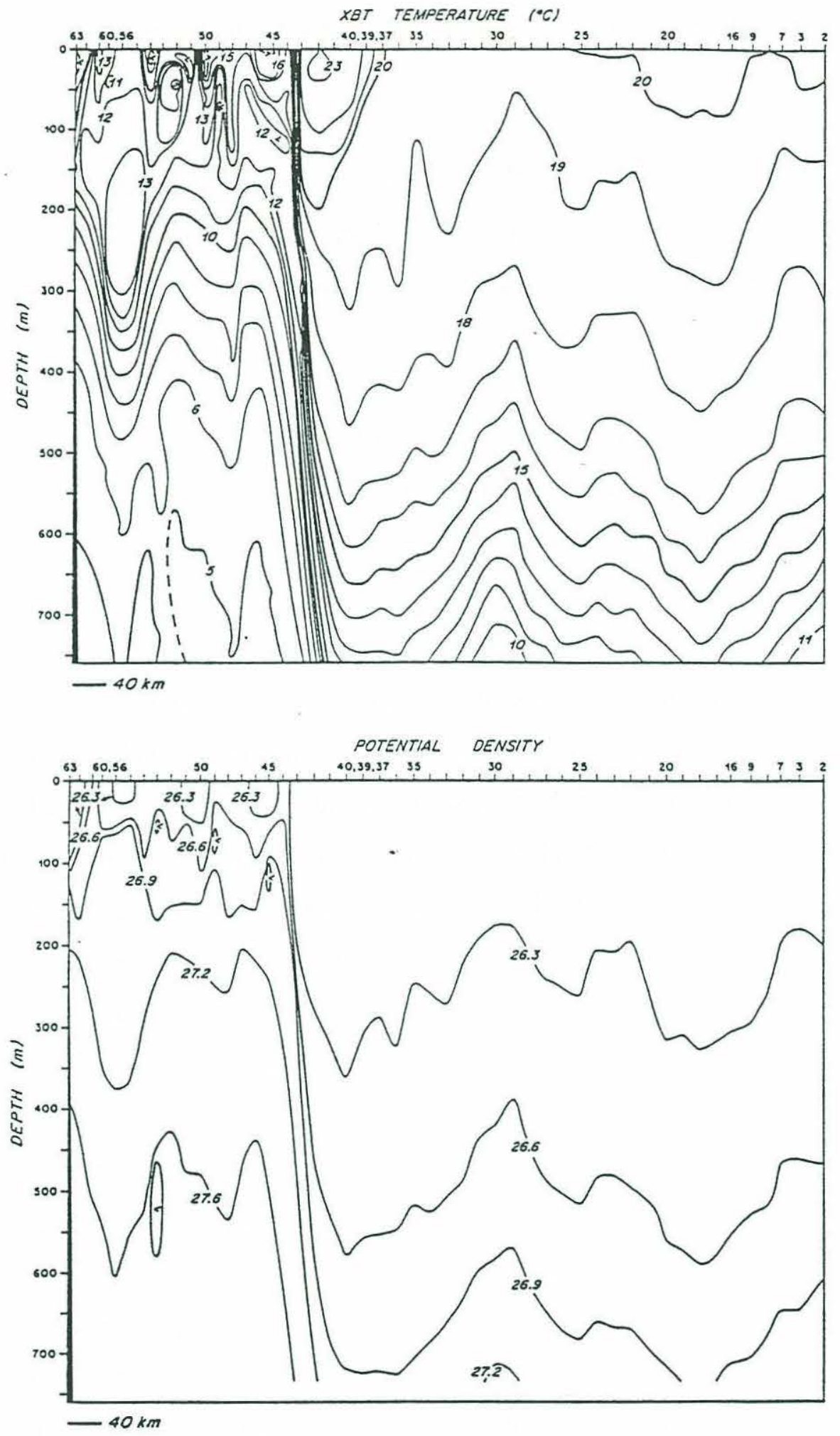

Figure 2.3. Temperature and potential density cruise OC205 section 1 . Numbers at top are XBT numbers. Distance is from 200 meter isobath. 



Figure 2.4. Temperature and potential density cruise 0C205 section 3. Distance is from 200 meter isobath. 

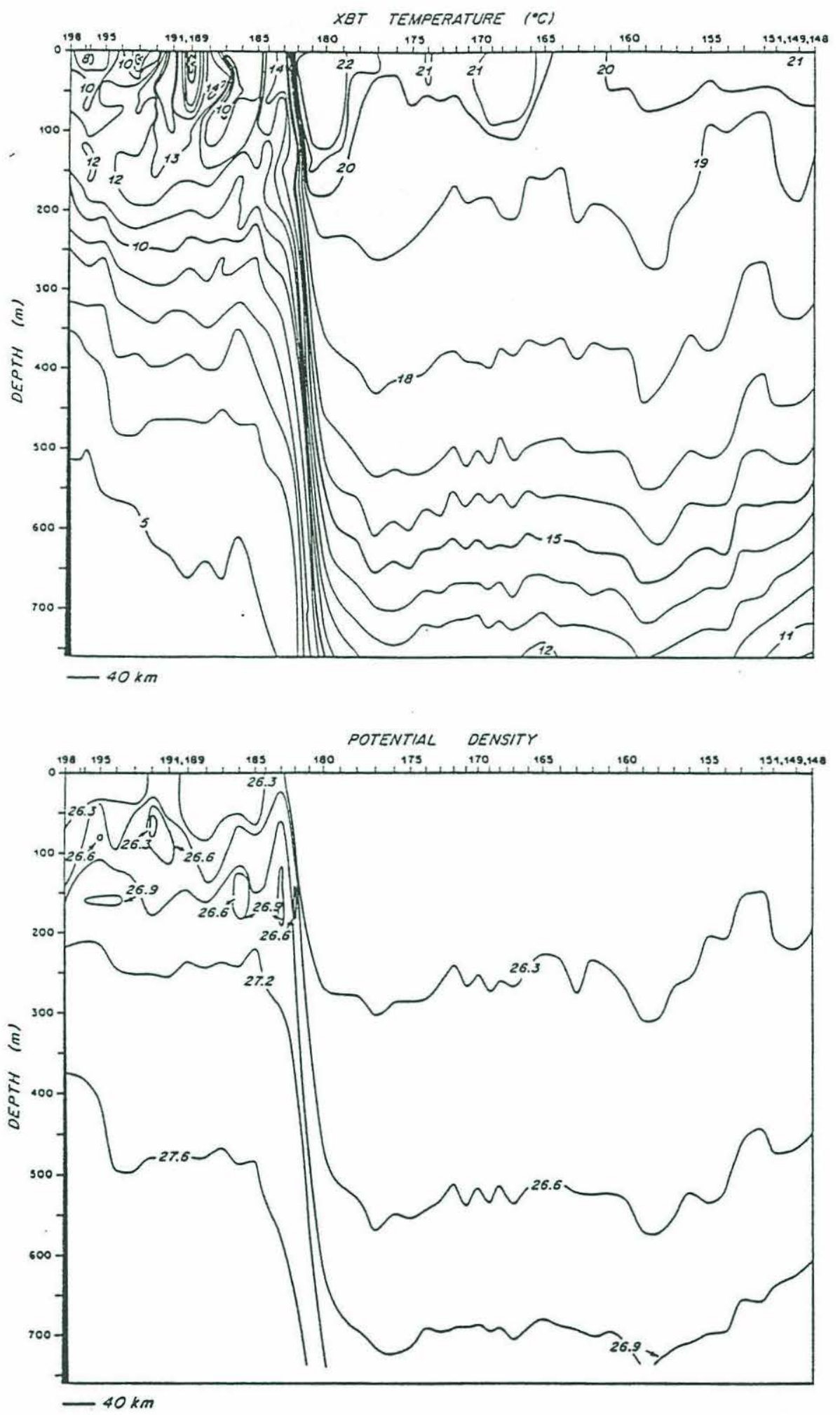

Figure 2.5. Temperature and potential density cruise $0 C 205$ section 4. Distance is from the 200 meter isobath. 

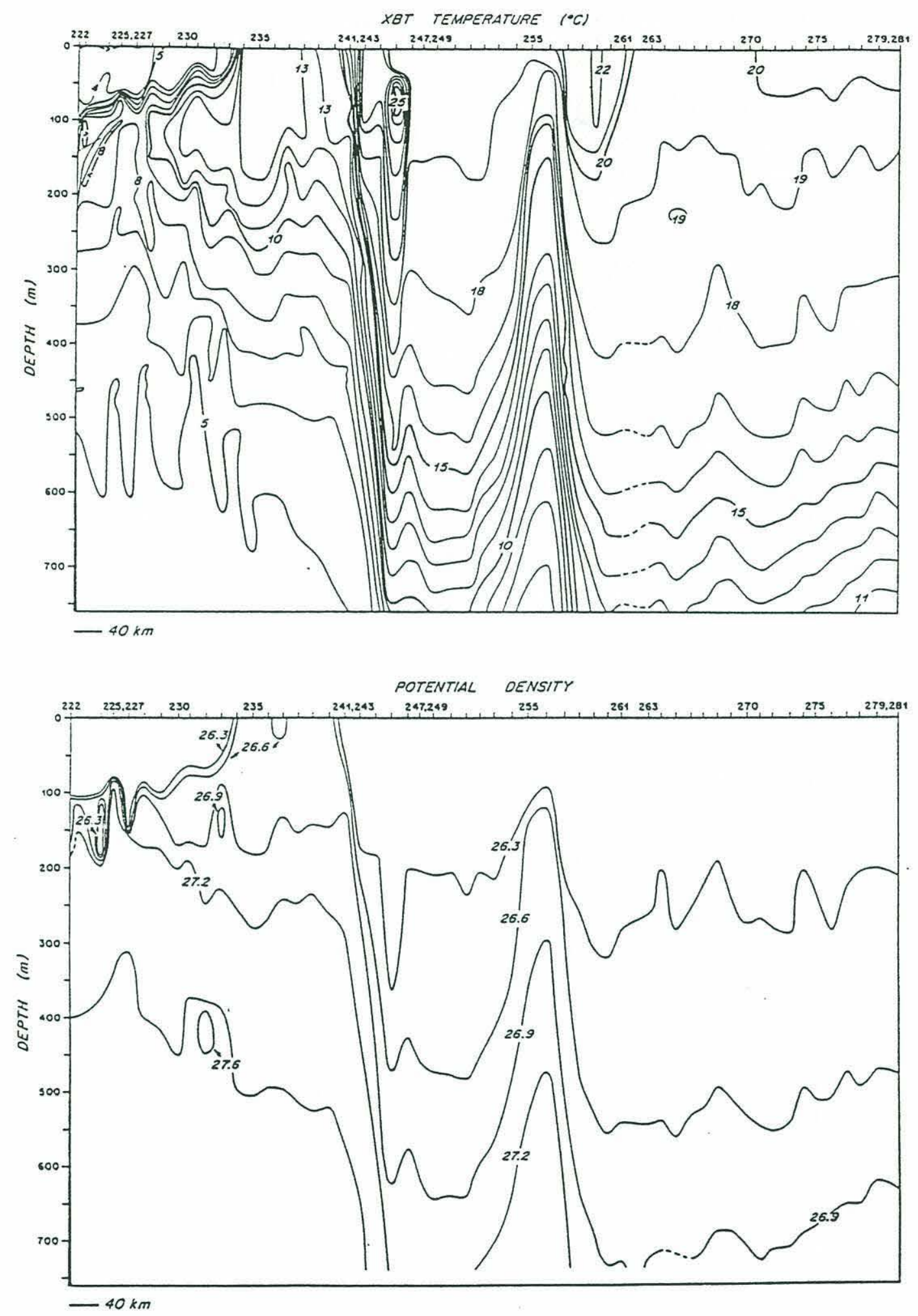

Figure 2.6. Temperarure and potential density cruise 0C205 section 6. Distance is from 200 meter isobath. 

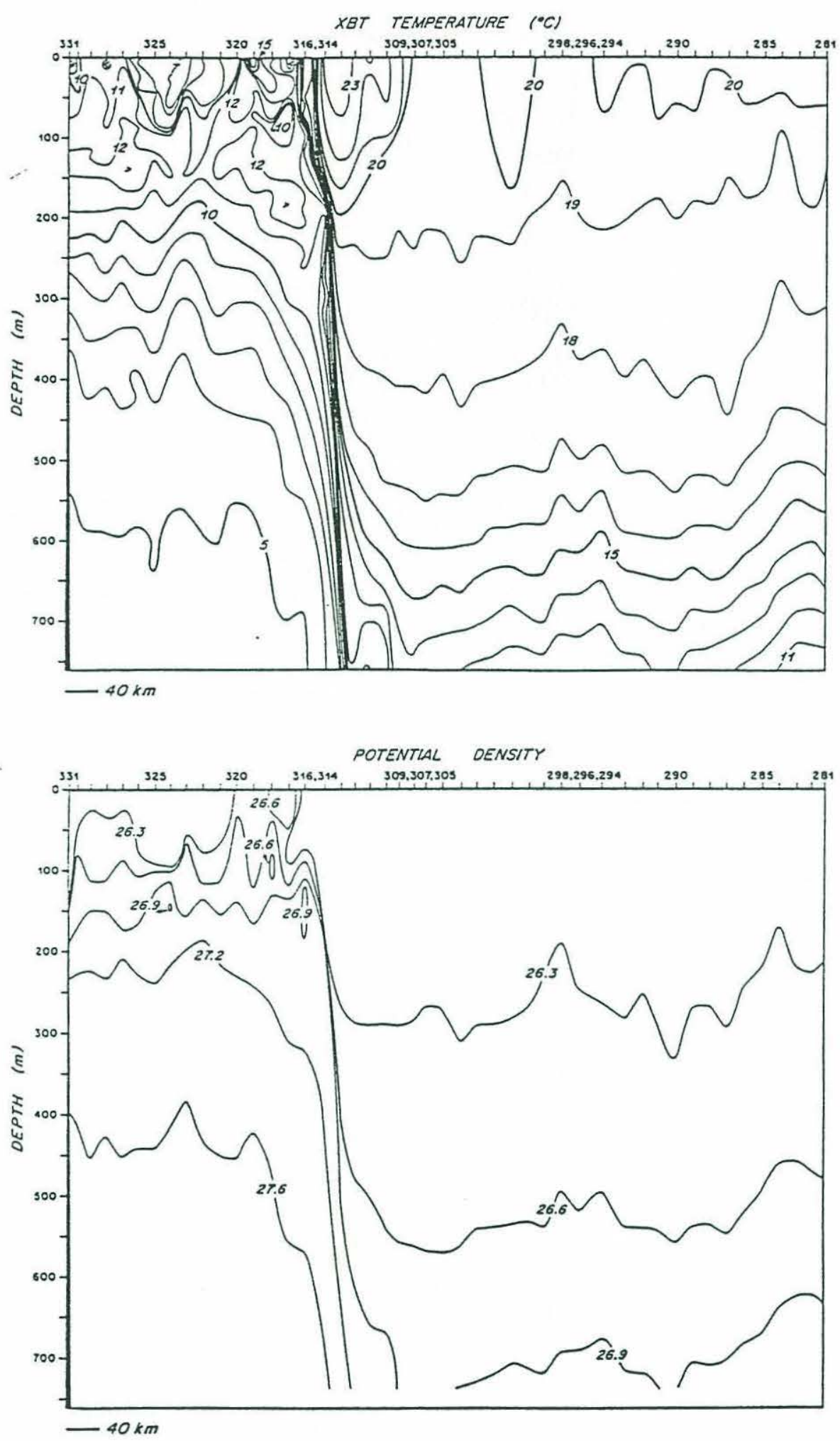

Figure 2.7. Temperature and potential density cruise 0 C205 section 7. Distance is from 200 meter isobath. 



Figure 2.8. Temperature and potential density cruise 0C216 section 1. Distance is from the 200 meter isobath. 

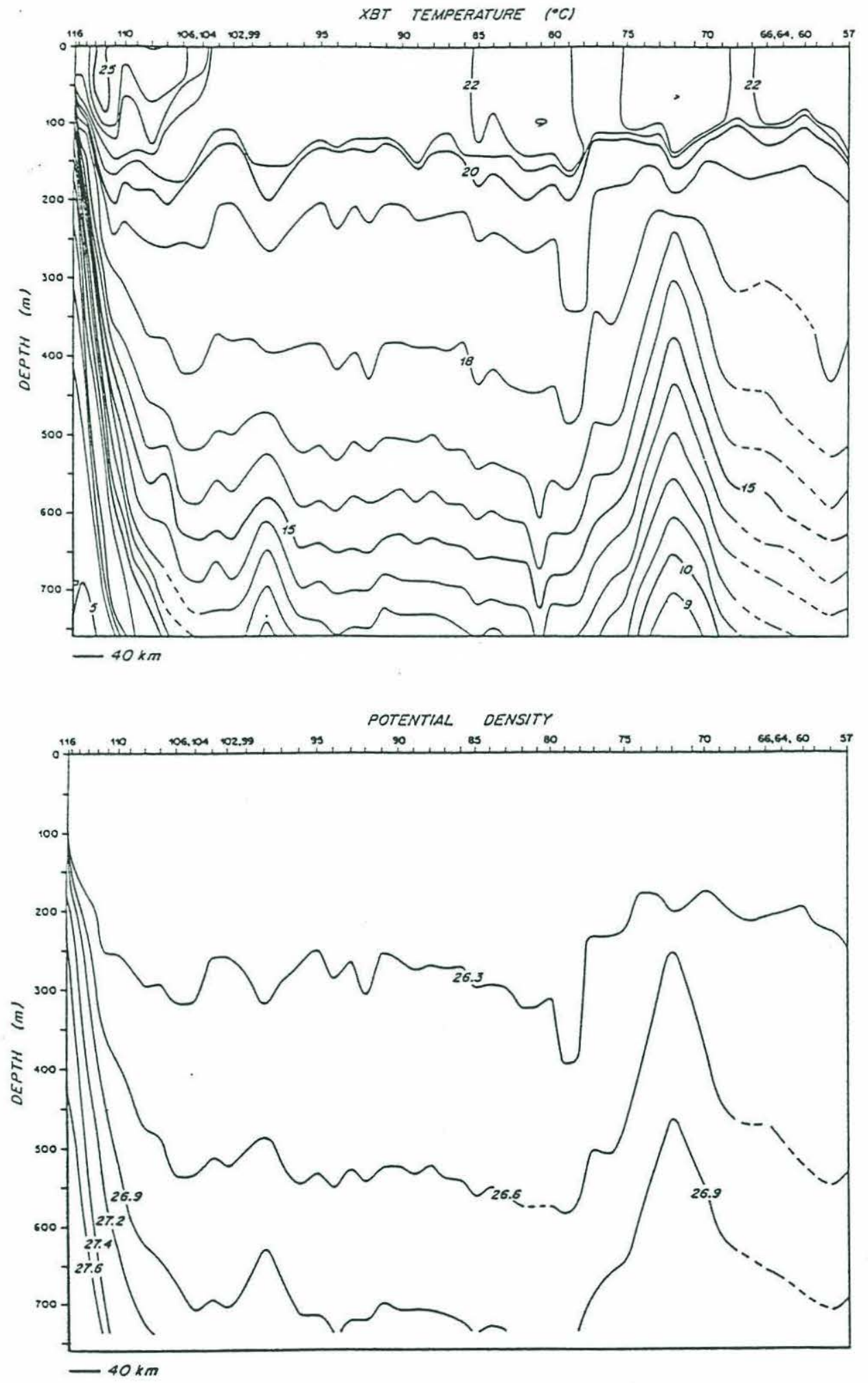

Figure 2.9. Temperature and potential density cruise $O C 216 \mathrm{leg} 2$. Distance is from the 200 meter isobath. 

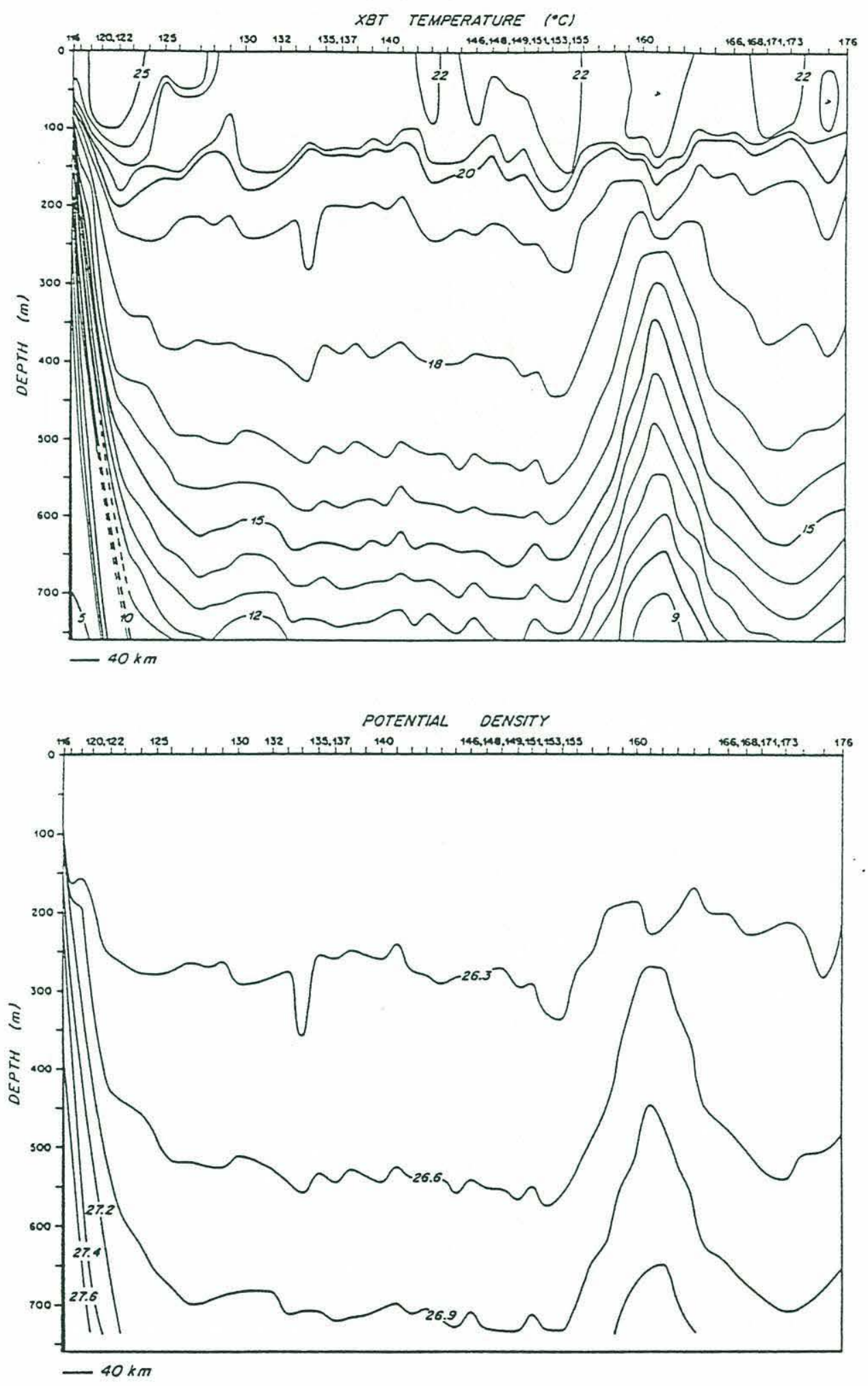

Figure 2.10. Temperature and potential density for cruise $0 \mathrm{C} 216 \mathrm{leg} 3$. Distance is from the 200 meter isobath. 

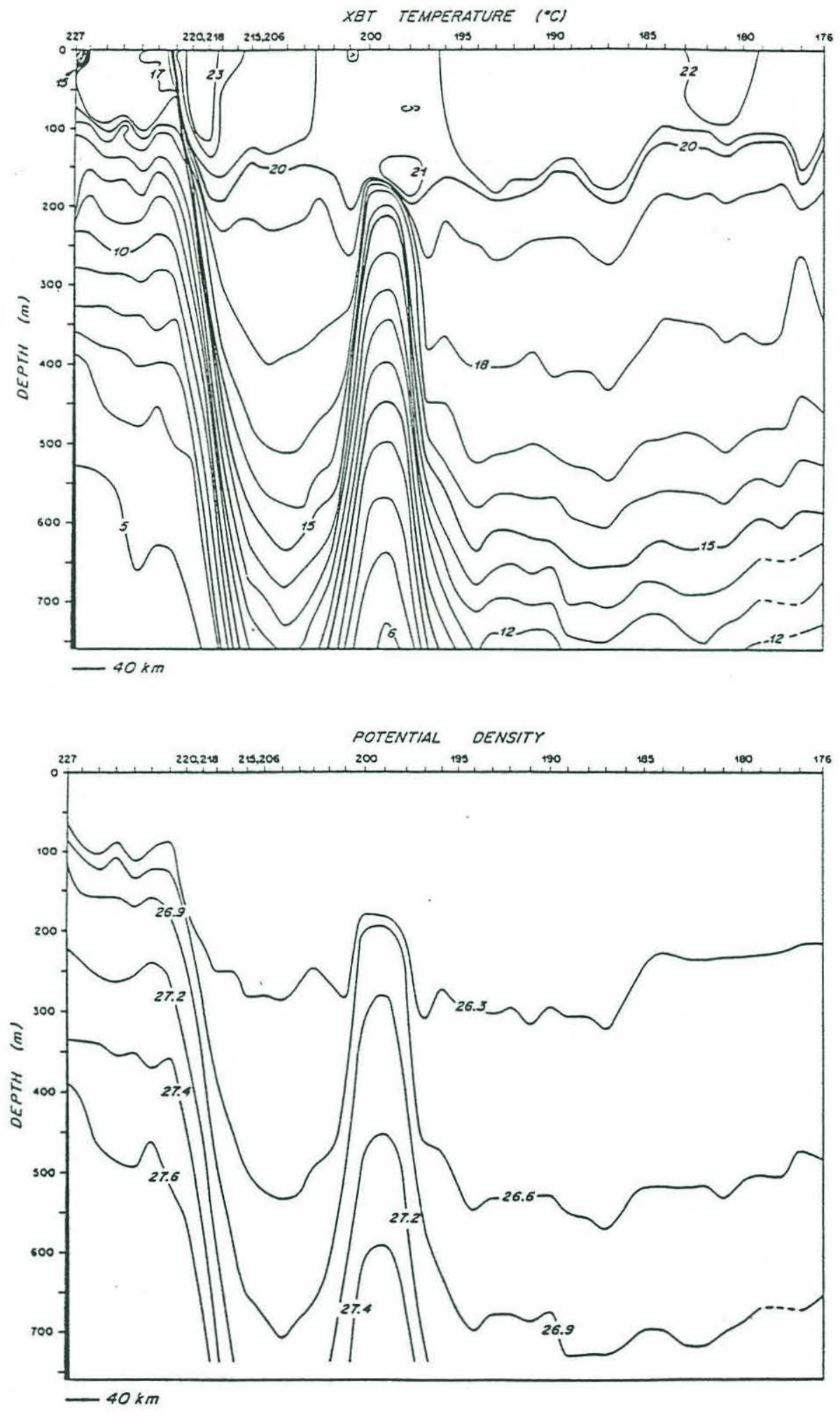

Figure 2.11. Temperature and potential density cruise $0 C 216$ leg 4. Distance is from the 200 meter isobath. 
salinity. These inversions are not observed in the OC216 sections because the nearsurface temperature gradients are smaller and the errors induced by the salinity estimation program are not as large. In the next section, $\mathrm{ADCP}$ velocity profiles will be compared to geostrophic velocity profiles for several XBT pairs. 


\section{Chapter 3}

\section{Estimation of the Absolute Velocity Field}

\subsection{ADCP and Geostrophic Profiles}

The geostrophic velocity profiles were generated relative to an assumed level of no motion at 765 meters. Following the convention of Halkin and Rossby, this will be referred to as the baroclinic velocity field, and the 765 meter velocities needed to obtain the full flow will be referred to as the reference velocity field. The velocity at 765 meters should be equal to the difference between the the profile of ADCP velocity normal to the ship's track and the geostrophic velocity profile generated from the XBT data. With no noise, the geostrophic profile would have the same shape as the ADCP profile, offset by the actual velocity at 765 meters. Errors discussed in chapter 2 account for the differences in the velocity profiles. Due to the salinity estimation technique used with the XBT profiles, the geostrophic velocities are likely to be most accurate below 200 meters depth, and least accurate at the surface. The ADCP velocities, on the other hand, are most accurate above 200 meters, with velocity dropping to zero between 200 and 400 meters as the signal is lost. The reference velocities were computed using an average of the difference between $\mathrm{ADCP}$ and geostrophic velocities at 100,150, and 200 meters depth. 


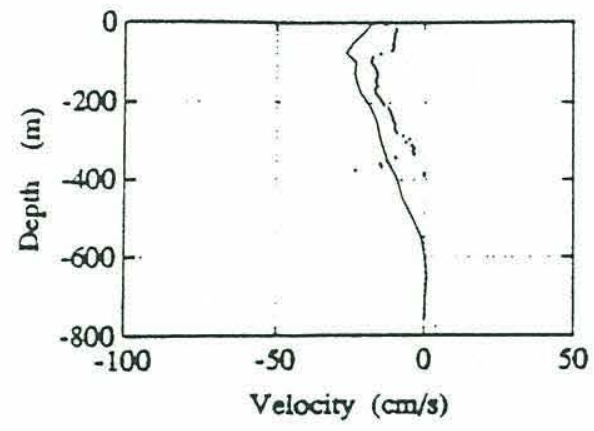

(a) North of the Gulf stresm, cruise OC216.

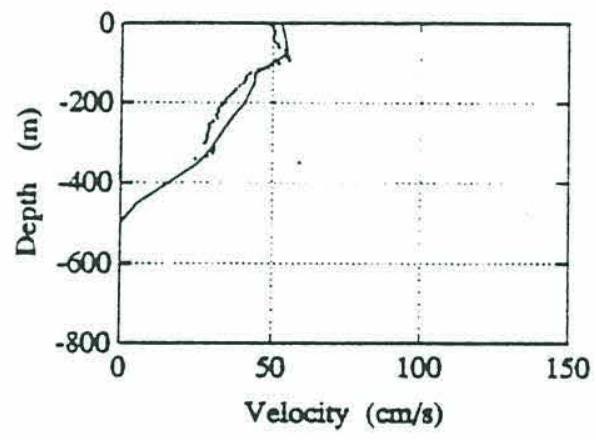

(c) North wall of the Gulf stream.

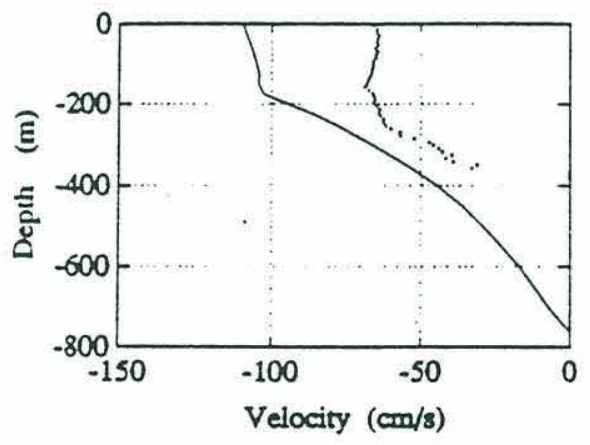

(e) Cold-core ring, cruise oc216 les 1.

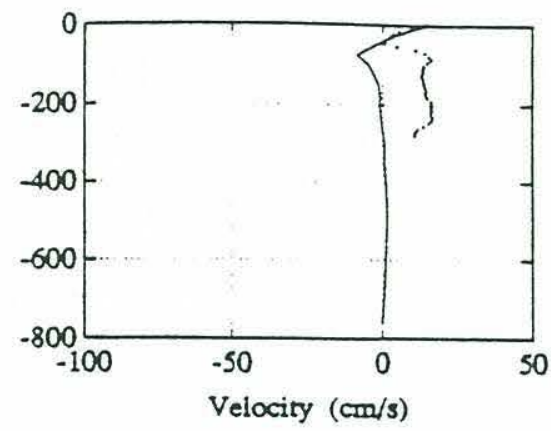

(b) North of the Gulf stream, cruise OC205.



(d) Near the center of the Gulf Stream.

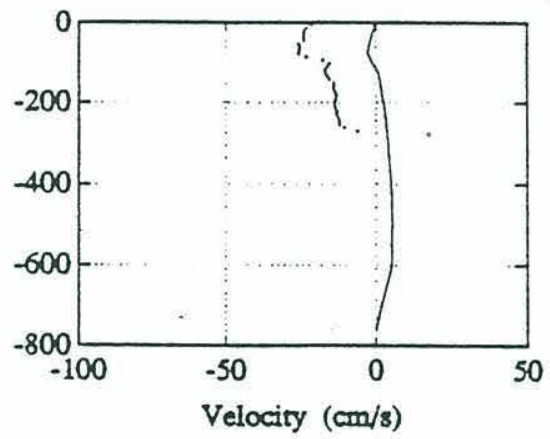

(1) Sargasso Se2.

Figure 3.1. Comparison of geostrophic and $A D C P$ profiles of velocity normal to the track. Dots are ADCP velocities, solid black line is geostrophic profile.

Velocity profiles for several station pairs are shown in Figure 3.1. The top two profiles are north of the Gulf Stream. The left profile is from leg 1 of cruise OC216 and shows good general agreement in the shapes of the ADCP and the geostrophic profiles. 
The right profile is for XBT's 190-191 of cruise OC205, where the apparent density inversion discussed in th previous chapter is observed in the XBT data. We can see that the shapes of the curves are quite different in the top 100 meters, due to errors in the geostrophic profile induced by the salinity estimation technique. Profile c (mid left) is at the north wall of the Gulf Stream, and shows very excellent agreement between ADCP and geostrophic velocity. Profile d (mid right) is near the center of the Gulf Stream, and shows a significant difference between $\mathrm{ADCP}$ and geostrophic velocity. From 200 meters up, the geostrophic velocities are decreasing toward the surface, while the ADCP velocities are increasing. This may be due to the assumption of constant salinity above 200 meters used in computing the geostrophic profile, or due to significant ageostrophic terms in the momentum balance. The bottom left profile (e) is in a cold core ring south of the Gulf Stream, and the bottom right profile (f) is from the Sargasso Sea. In general, the velocity profiles appear consistent, with the largest differences in shape occurring near the surface, where the salinity errors are the greatest, and the ageostrophic terms in the momentum equations would be expected to be largest.

\subsection{Direct Combination of ADCP and Geostrophic Velocities}

The straightforward way to compute the total velocity field once the reference and baroclinic components are calculated is simply to add them together. Since the ADCP velocities were filtered to reduce navigational noise, the geostrophic velocities were also filtered before adding the two components together. Mass transports (M) across each track are computed by multiplying the velocities (u) by the cross sectional area of the track (a) and by the density of the water ( $p)$.)

$$
M=u a \rho
$$


The sections were set up to be able to take advantage of mass conservation constraints. The transport across the sections along the 200 meter isobath should be negligible compared to the transports across the other sections. Beardsley and Boicourt (1981) estimate that the transport over the whole shelf to be $0.2 \mathrm{~Sv}$. Therefore, the net mass transports across all the sections running from the shelf to Bermuda should be the same. When the transports were calculated for the OC205 sections, it was found that the transports for legs 3 and 6 were much larger than those for legs 1, 4, and 7 (Table 3.1). Table 3.1 Cruise 0 C205 section transports. Transports are in $\mathrm{kg} / \mathrm{s} \times 10^{9} \approx$ Sverdrups.

\begin{tabular}{||c|c|c|c||}
\hline \hline Section & $\begin{array}{c}\text { Baroclinic } \\
\text { transport }\end{array}$ & $\begin{array}{c}\text { Total } \\
\text { Transport }\end{array}$ & $\begin{array}{c}\text { After bias } \\
\text { removed }\end{array}$ \\
\hline \hline 1 & 27.287 & 26.885 & 58.803 \\
\hline 3 & 25.538 & 95.752 & 61.954 \\
\hline 4 & 30.365 & 22.183 & 54.012 \\
\hline 6 & 22.269 & 82.632 & 44.484 \\
\hline 7 & 28.912 & 22.745 & 54.562 \\
\hline
\end{tabular}

The large imbalances are due to a systematic bias in the doppler velocity discussed in chapter 2. Legs 1, 4, and 7 were traversed from South to North, while legs 3 and 6 were traversed from North to South. A bias to the left side of the ship would add to the transports on legs 3 and 6 and subtract from the transports of legs 1, 4, and 7. The value of the bias velocity which most nearly balances all the legs is $4.48 \mathrm{~cm} / \mathrm{s}$ to the left of the ship. When this bias is subtracted from the reference velocity field, the transports are as given in the last column of Table 3.1. The resulting velocity sections for the direct combination of $\mathrm{ADCP}$ and geostrophic velocities after removing the bias are presented in Figure 3.2 and Figure 3.3. 

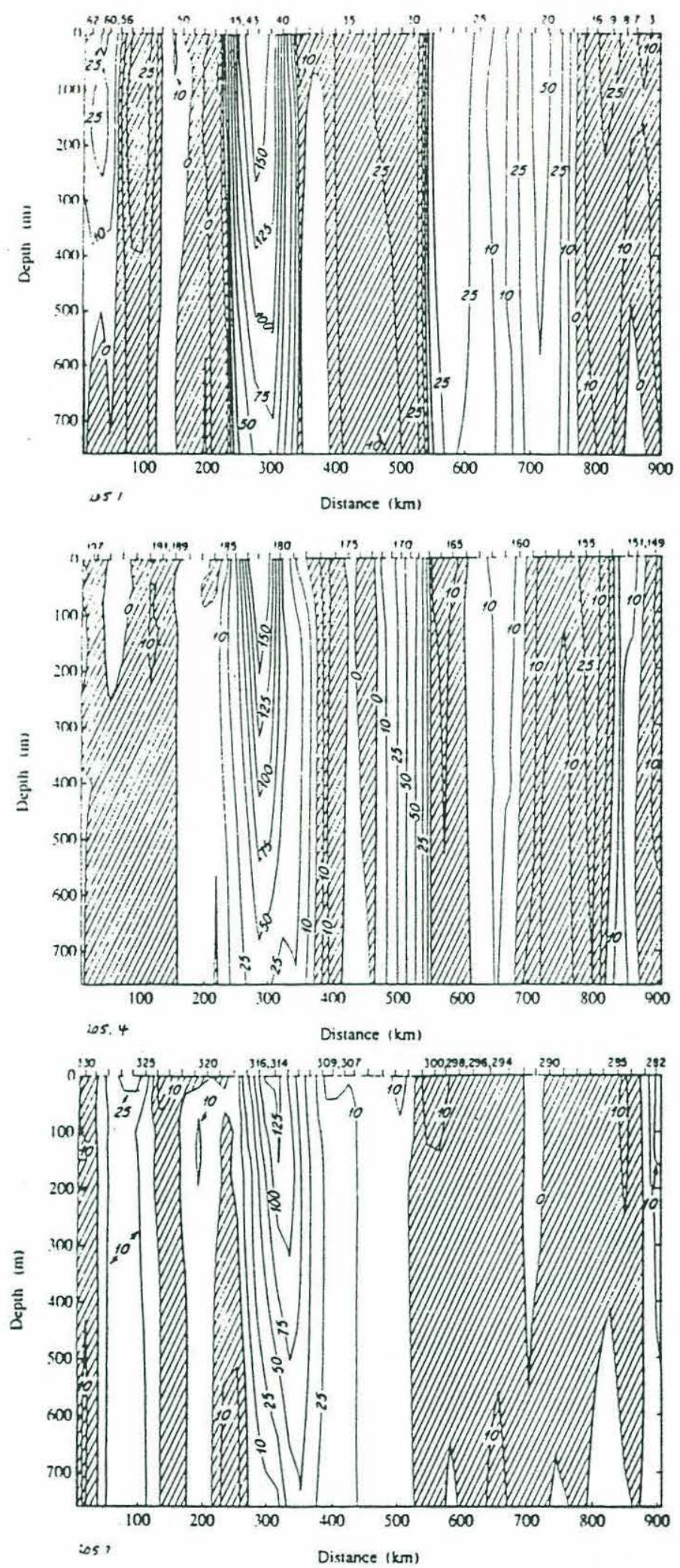

Fignare 3.2. Velocity normal to the ship's track for cruise 0 C205 sections 1,4 , and 7 by direct combination of $A D C P$ and geostrophic data. Distance is from 200 meter curve. Cross-hatched areas indicate negative velocity. 

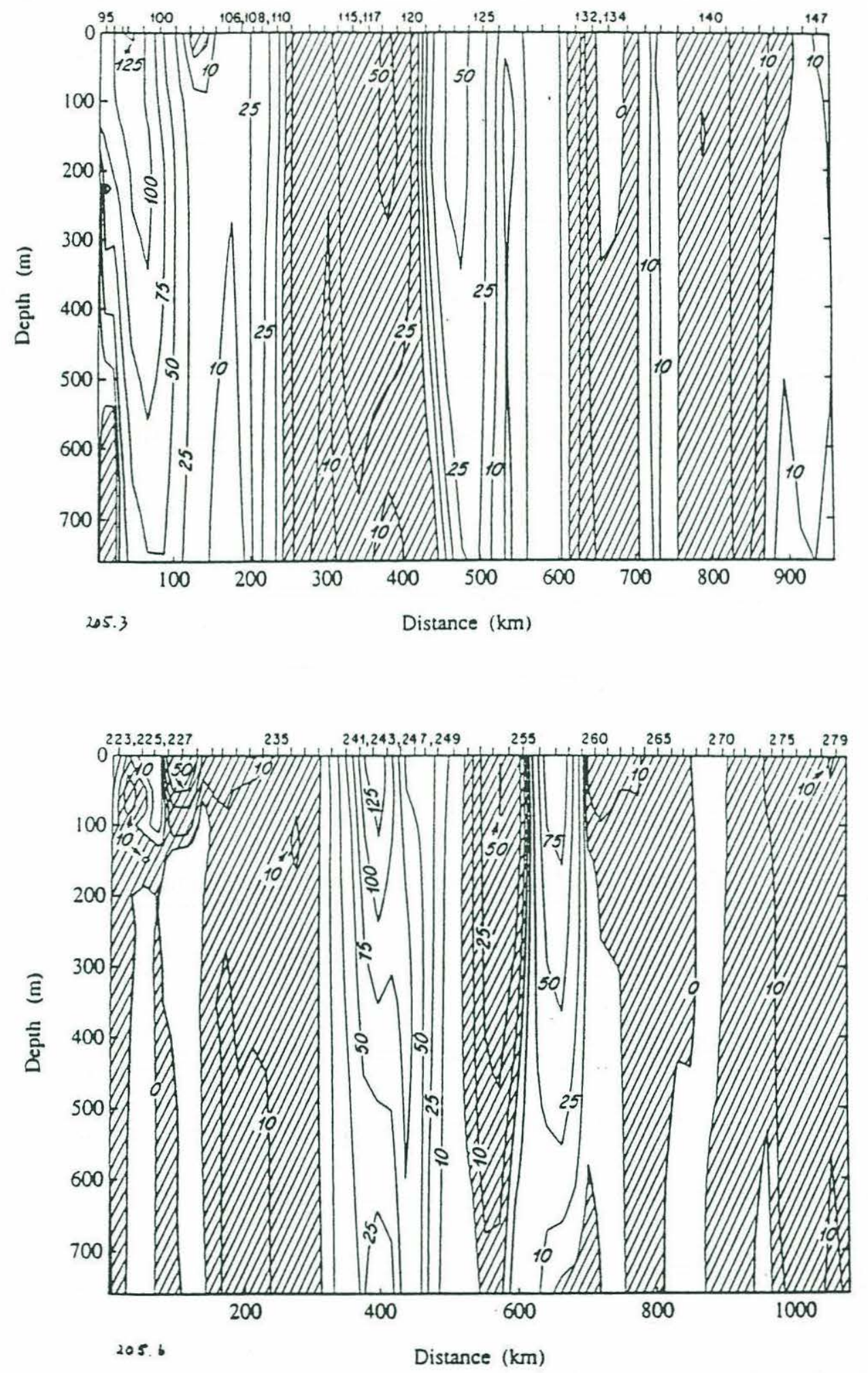

Figure 3.3. Velocity normal to ship's track for cruise OC205 sections 3 and 6 by direct combination of ADCP and geostrophic data. Distance is from 200 meter curve. Cross hatched areas indicate negative velocity. 
OC205 Leg 1 Transport and Dynamic Heights

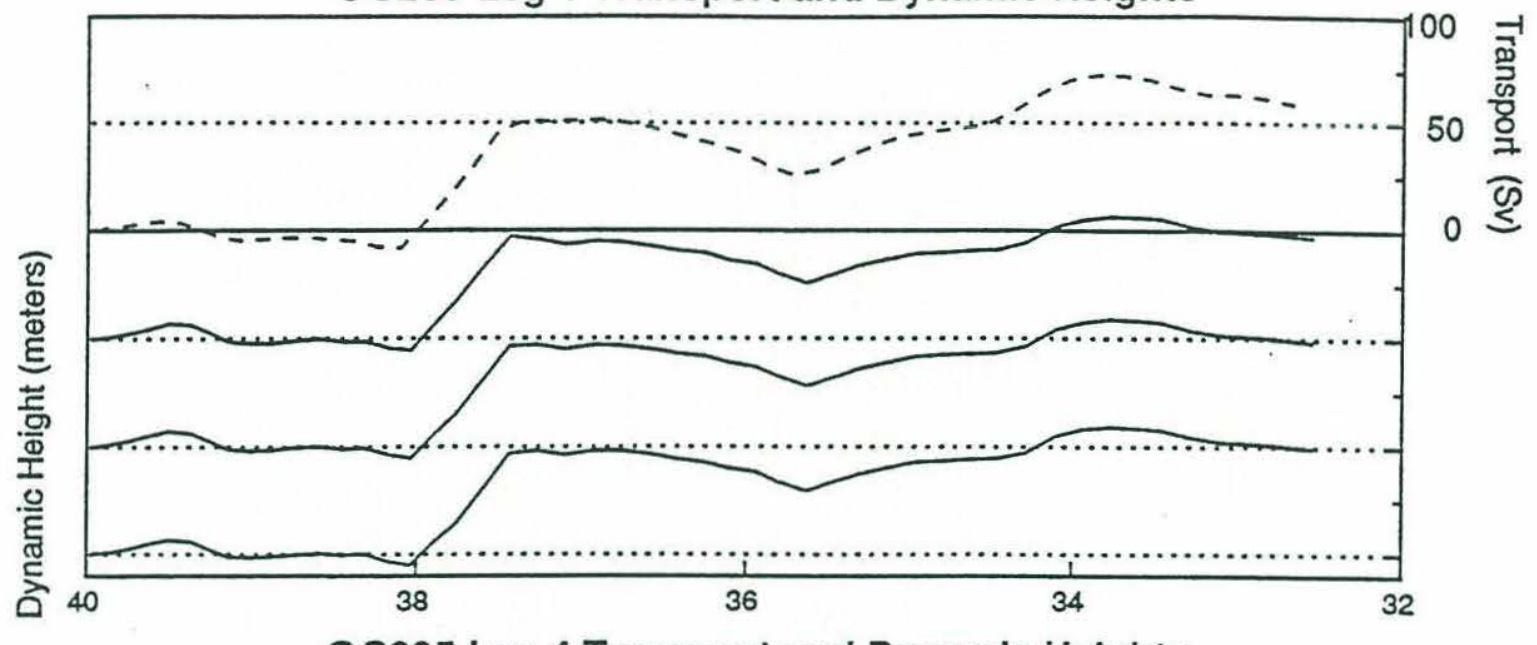

OC205 Leg 4 Transport and Dynamic Heights
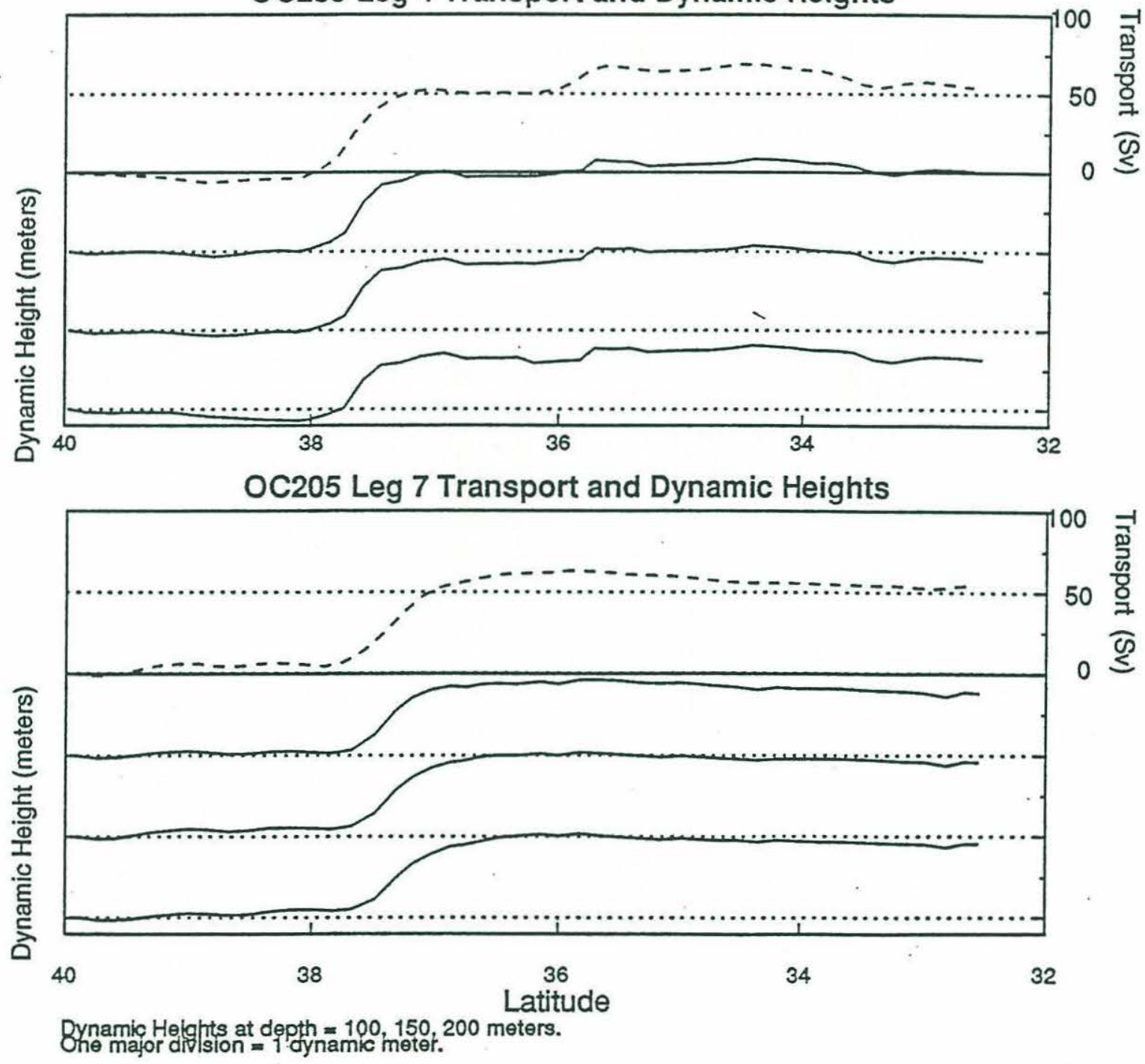

Figure 3.4. Transport and dynamic heights OC205 legs 1, 4, and 7. 
OC205 Leg 3 Transport and Dynamic Heights

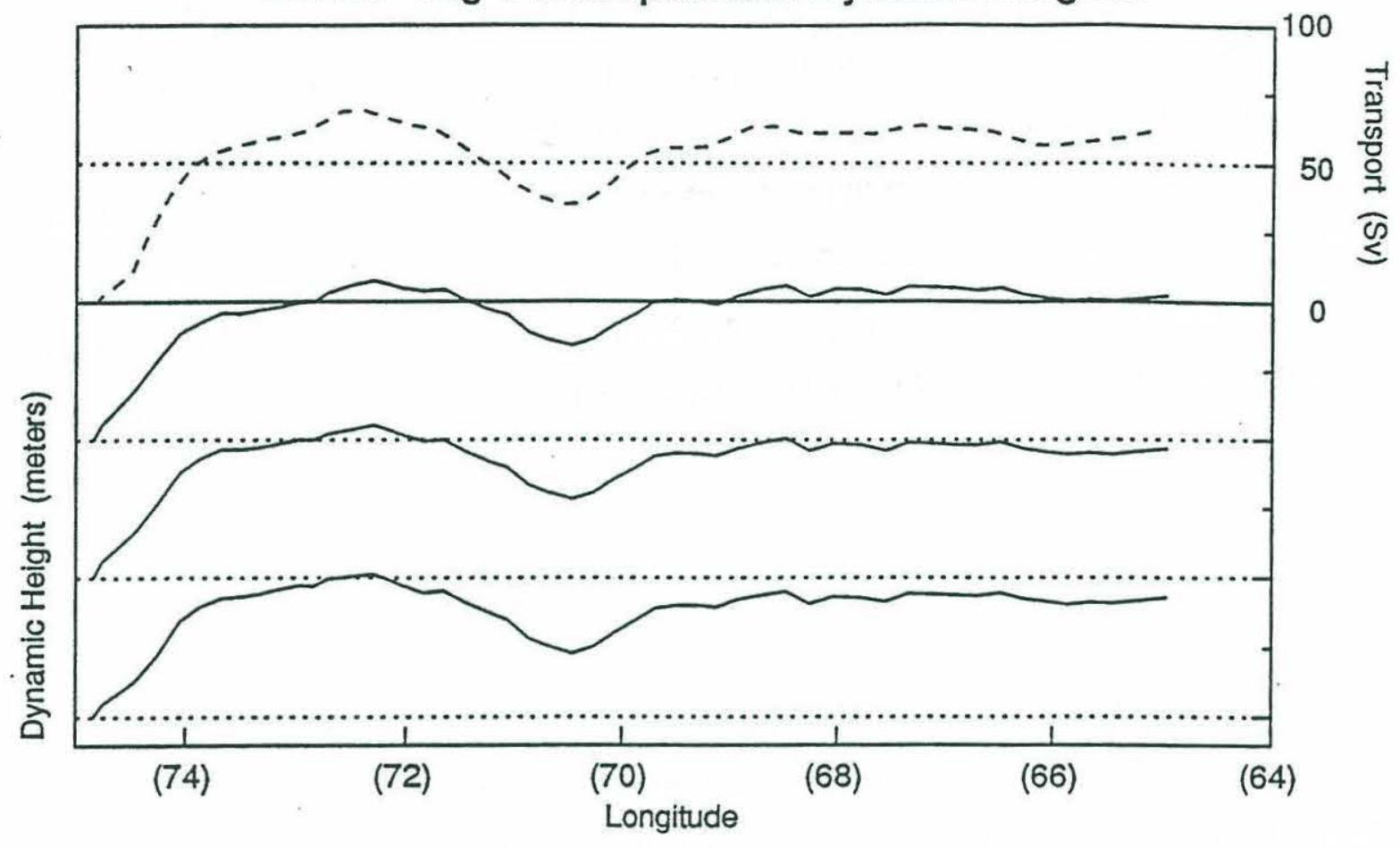

OC205 Leg 6 Transport and Dynamic Heights

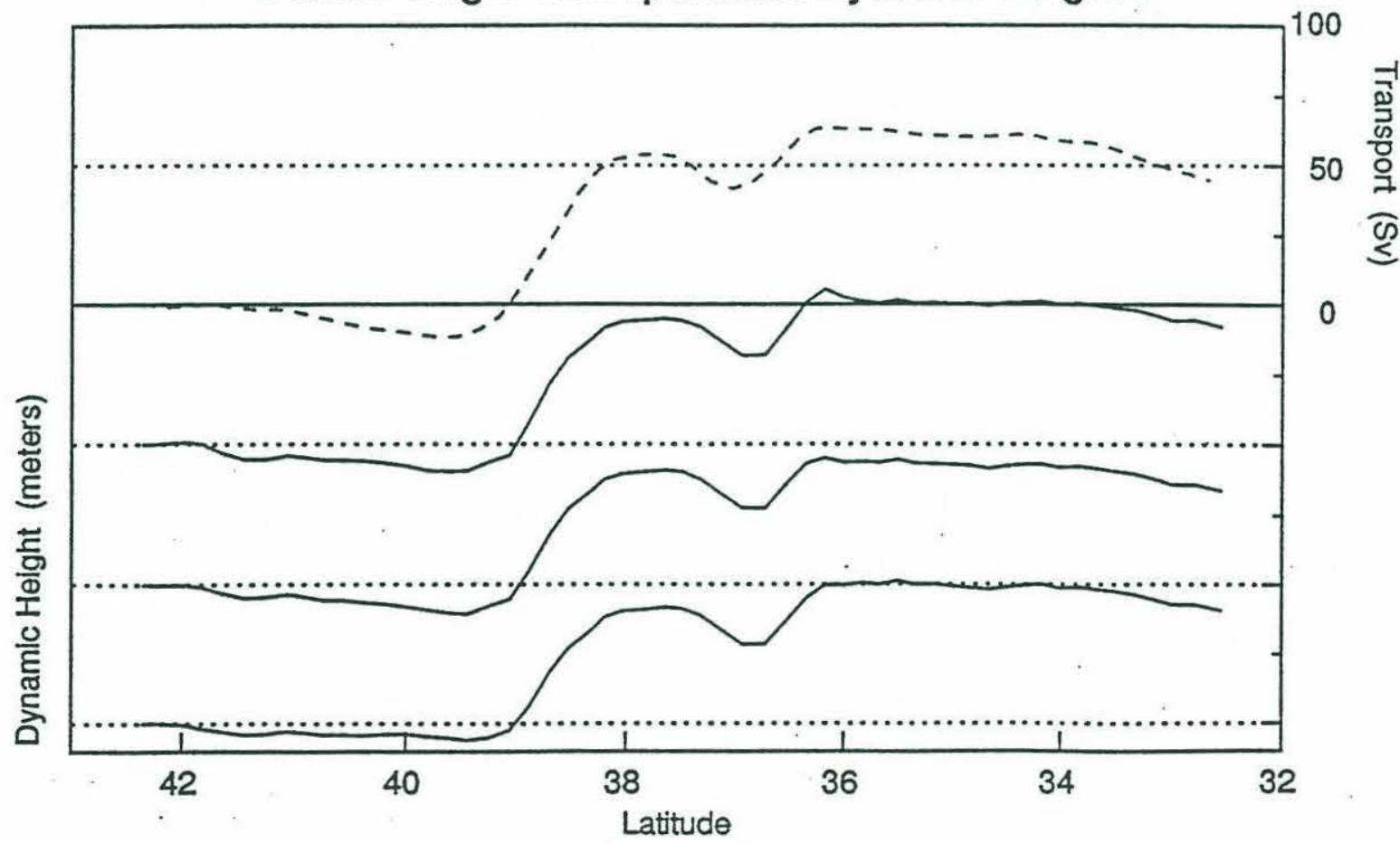

Dynamic Heights at depths $100,150,200$ meters.

One major dlvision = one dynamic meter.

Figure 3.5. Transport and dynamic heights OC205 legs 3 and 6. 
With the bias removed, significant differences in transport remain. These errors are due either to additional errors in our measurements, or to short term variability in the flow field. In order to examine the transport of each section more fully, it is necessary to evaluate the transport as a function of horizontal distance and as a function of depth. Figure 3.4 and Figure 3.5 show the transport as a function of horizontal distance, along with the dynamic height computed from the $\mathrm{ADCP}$ velocities at 100,150 , and 200 meters depth for OC205 legs 1, 3, 4, 6, and 7. The shape of the transport curves closely follow the dynamic height curves, with small differences due to changes in transport with depth.

The transport and dynamic height curves for the three legs between Bermuda and Cape Cod are quite consistent. In each case we see a rise in dynamic height across the Gulf Stream of approximately one dynamic meter resulting in an increase in transport across the Gulf Stream of approximately 57 Sverdrups. There is a cold core ring on the track during leg one, which causes the transport to dip, then rise again between $37^{\circ}$ and $35^{\circ} \mathrm{N}$. A region of positive velocity between $33^{\circ}$ and $34^{\circ} \mathrm{N}$ causes an additional rise in transport and dynamic height, which results in the leg 1 transport being about 5 Sverdrups higher than those of legs 4 and 7 . The slope of the dynamic height across the Gulf Stream in leg seven is less than for the other legs, because the Gulf Stream axis has rotated so that it is no longer nearly perpendicular to the ship's track, but the total height difference and transport is consistent with the other two legs.

Comparing the transports for the Cape Cod-Bermuda legs to the other two Gulf Stream crossings, we find that the transport for the Cape Hatteras-Bermuda leg (leg 3 ) is higher, and the transport for the Nova Scotia-Bermuda leg (leg 6) is lower than the average transport. The difference in transport between the two legs appears to be due to effects occurring near Bermuda. At approximately $100 \mathrm{~km}$ from Bermuda, both legs 3 and 6 have transports of about 55 Sverdrups (Longitude $66^{\circ} \mathrm{W}$ for leg 3, latitude $33.5^{\circ}$ $\mathrm{N}$ for leg 6 in Figure 3.5). From those points to Bermuda, the dynamic height and transport for leg 3 rises, while the dynamic height and transport for leg 6 drops sharply. 
This appears to be the result of temporal variability in the currents near Bermuda. The difference in time between the turn from leg 3 to leg 4 and the turn from leg 6 to leg 7 was 162 hours, approximately one week. Comparing the Bermuda ends of legs 3 and 4, we see a dip then a rise in transport coming towards Bermuda. Legs 6 and 7 both show a steady decrease in transport south of $34^{\circ} \mathrm{N}$, although the effect is much more pronounced in leg 6.

The transports for the December cruise, OC216, are presented in Table 3.2. The calibration performed for this cruise appears to have been more accurate than the April cruise, the bias which minimizes the difference in transport between all four legs being $0.87 \mathrm{~cm} / \mathrm{s}$ to the left. Again, removing the bias does not balance the transports, leaving a difference of 10.5 Sverdrups between the highest transport (leg 3) and the lowest transport (leg 1). It appears that something happened between leg 2 and leg 3 which appreciably increased the transport of both of the latter two legs compared to legs 1 and 2. The velocity sections for cruise OC216 after removing the bias are presented in Figure 3.6 and Figure 3.7.

Table 3.2 Cruise OC216 Section Transports. Transports are in $\mathrm{kg} / \mathrm{s} \times 10^{9} \approx$ Sverdrups.

\begin{tabular}{||c|c|c|c||}
\hline \hline Section & $\begin{array}{c}\text { Baroclinic } \\
\text { Transport }\end{array}$ & $\begin{array}{c}\text { Total } \\
\text { Transport }\end{array}$ & $\begin{array}{c}\text { After bias } \\
\text { removed }\end{array}$ \\
\hline \hline 1 & 32.60 & 59.40 & 53.20 \\
\hline 2 & 34.00 & 49.49 & 55.96 \\
\hline 3 & 27.63 & 70.28 & 63.74 \\
\hline 4 & 31.93 & 54.96 & 61.14 \\
\hline
\end{tabular}



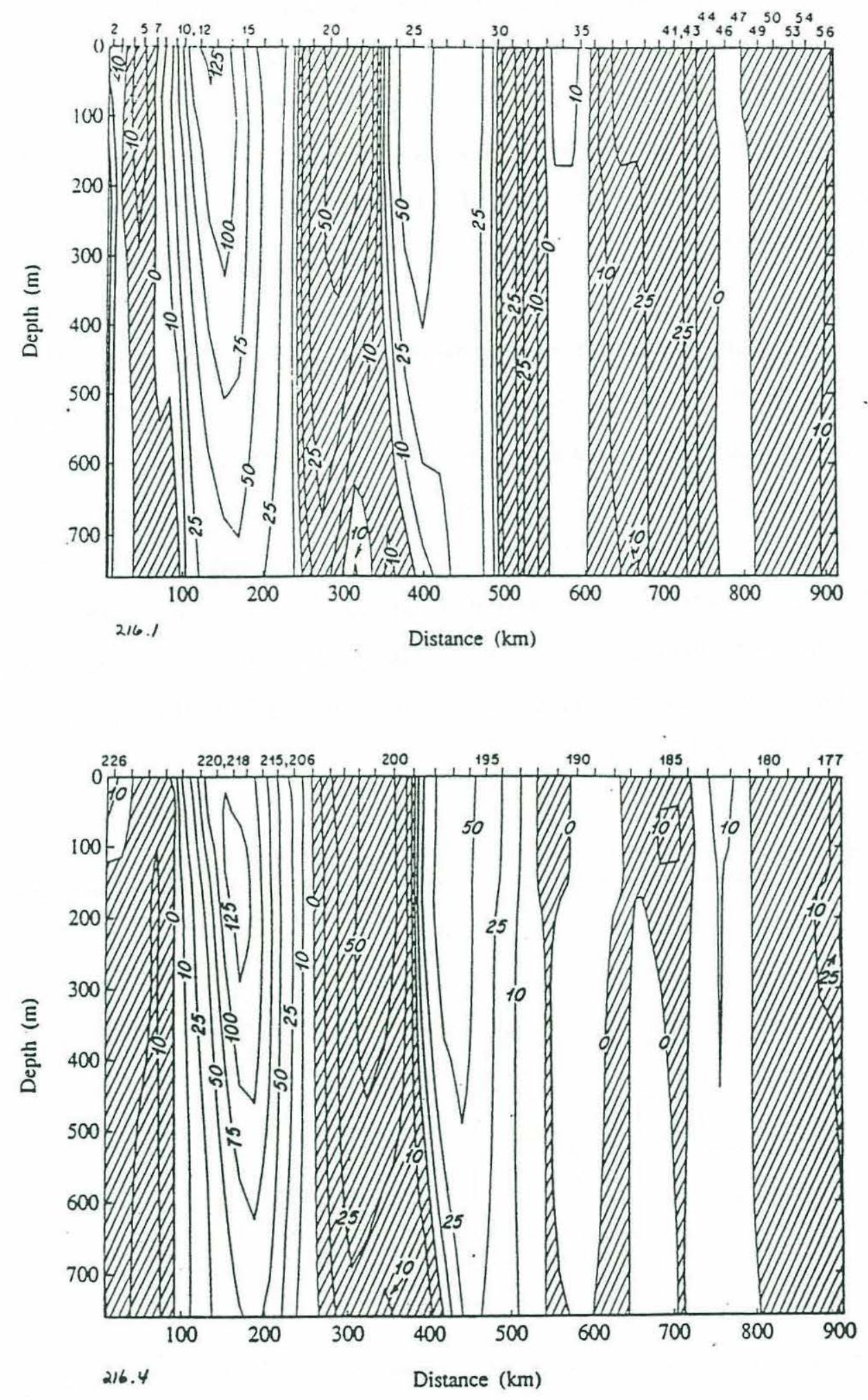

Figure 3.6. Velocity normal to ship's track for cruise OC216 sections 1 and 4 by direct combination of ADCP and geostrophic data. Distance is from the 200 meter isobath. Cross-hatched areas indicate negative velocity. 

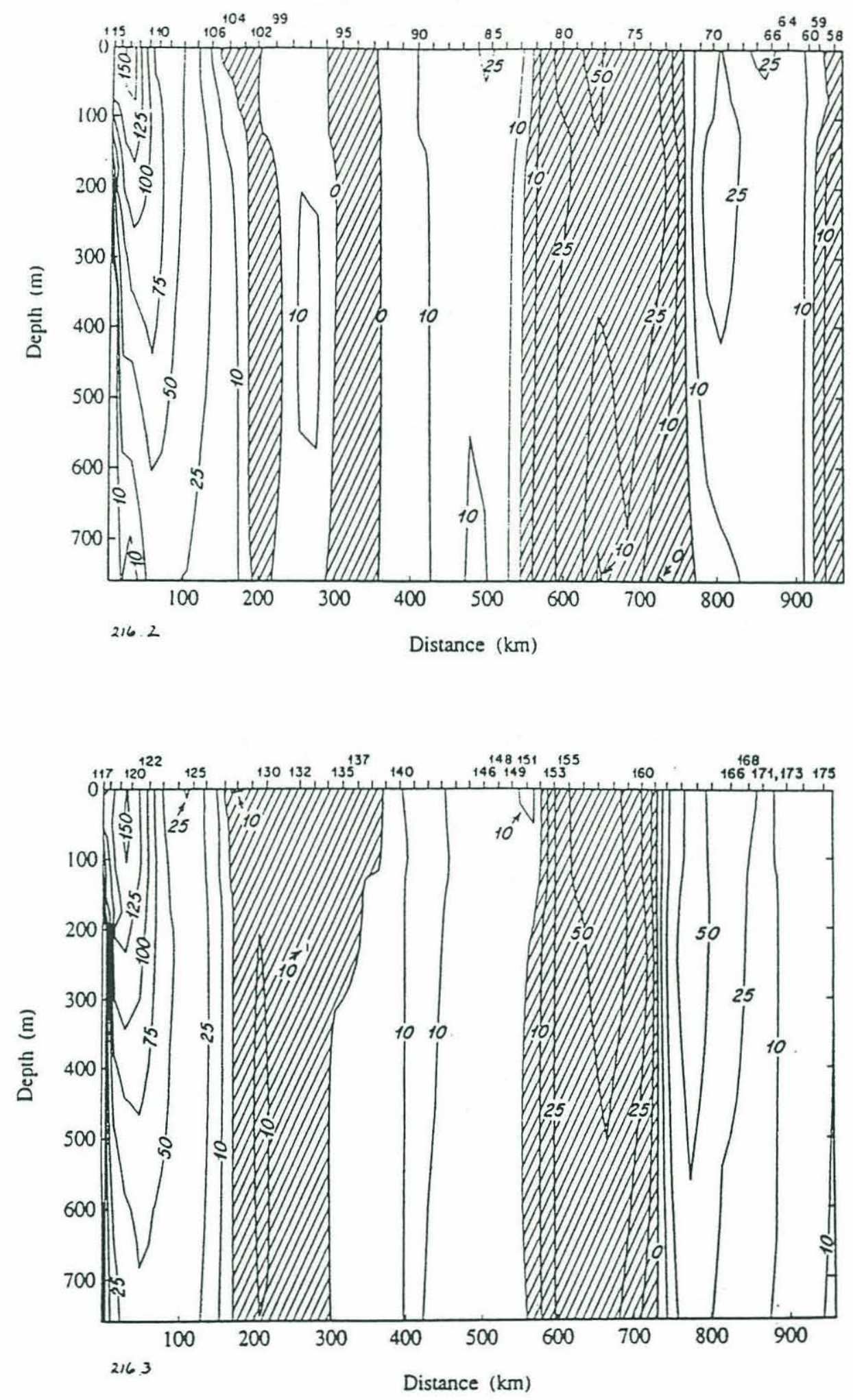

Figure 3.7. Velocity normal to ship's track for cruise OC216 sections 2 and 3 by direct combination of ADCP and geostrophic data. Distance is from the 200 meter isobath. Cross-hatched areas indicate negative velocity. 
OC216 Leg 1 Transport and Dynamic Heights

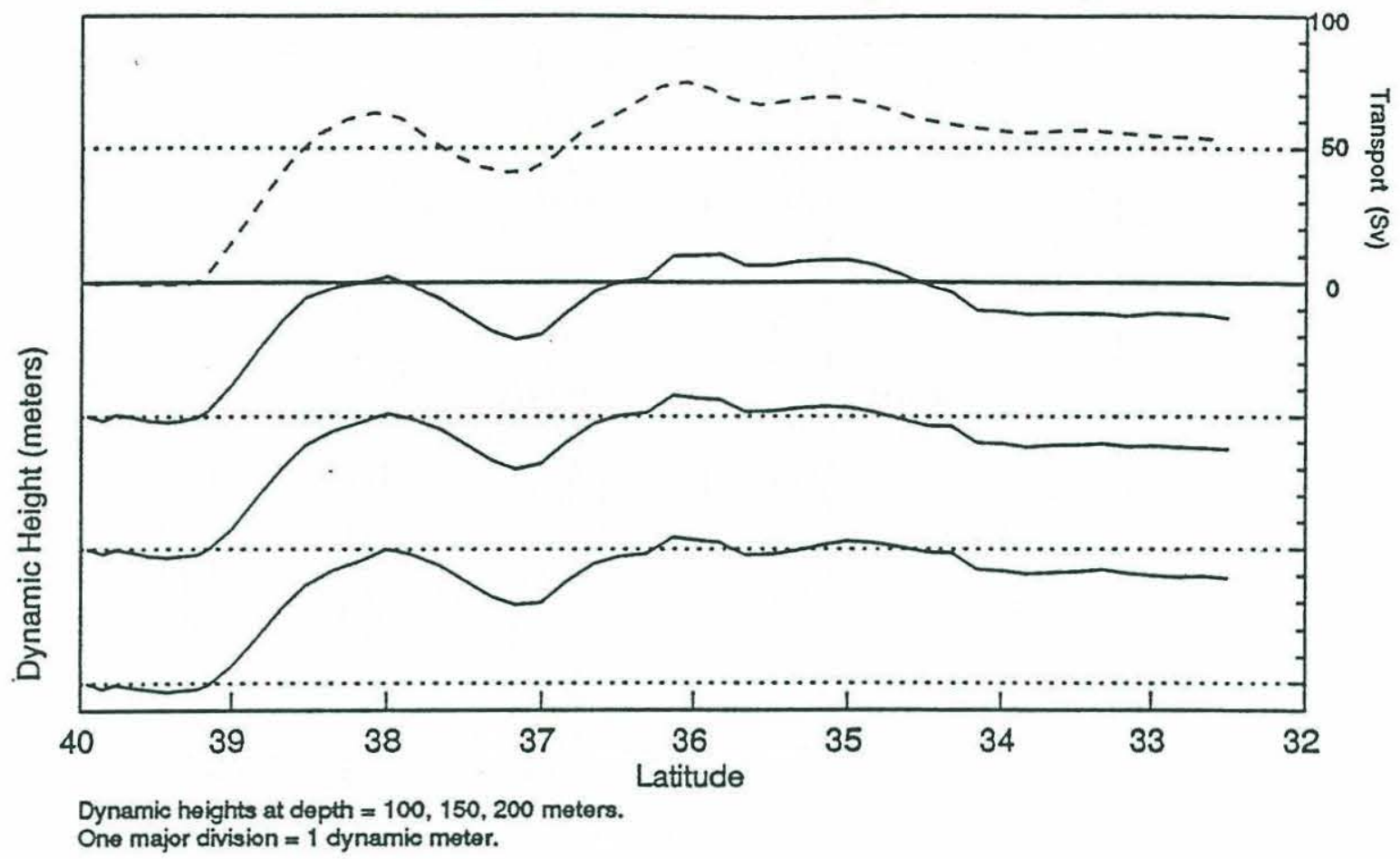

东

OC216 Leg 4 Transport and Dynamic Heights

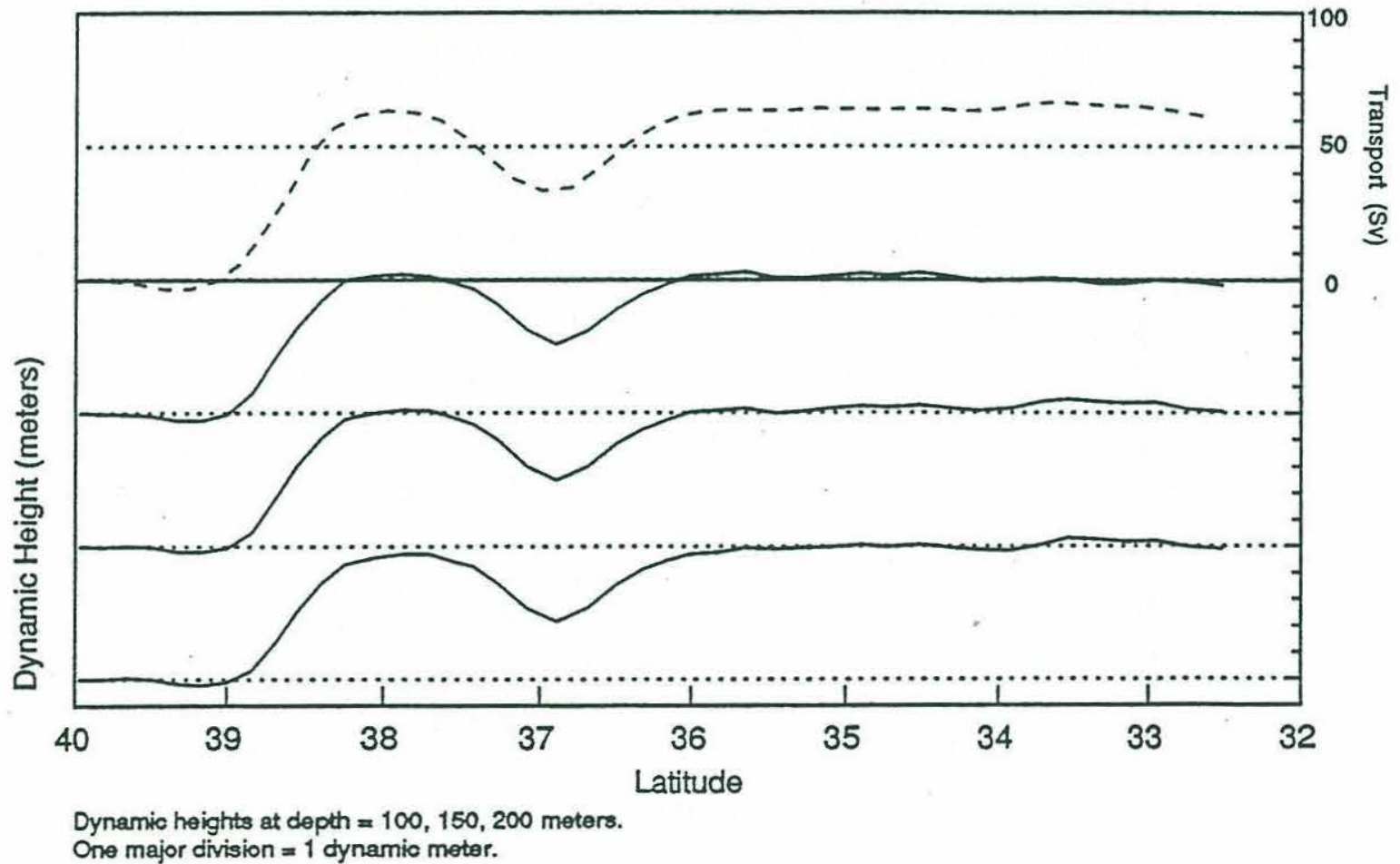

Figure 3.8. Transport and dynamic heights OC216 legs 1 and 4. 
OC216 Leg 2 Transport and Dynamic Heights

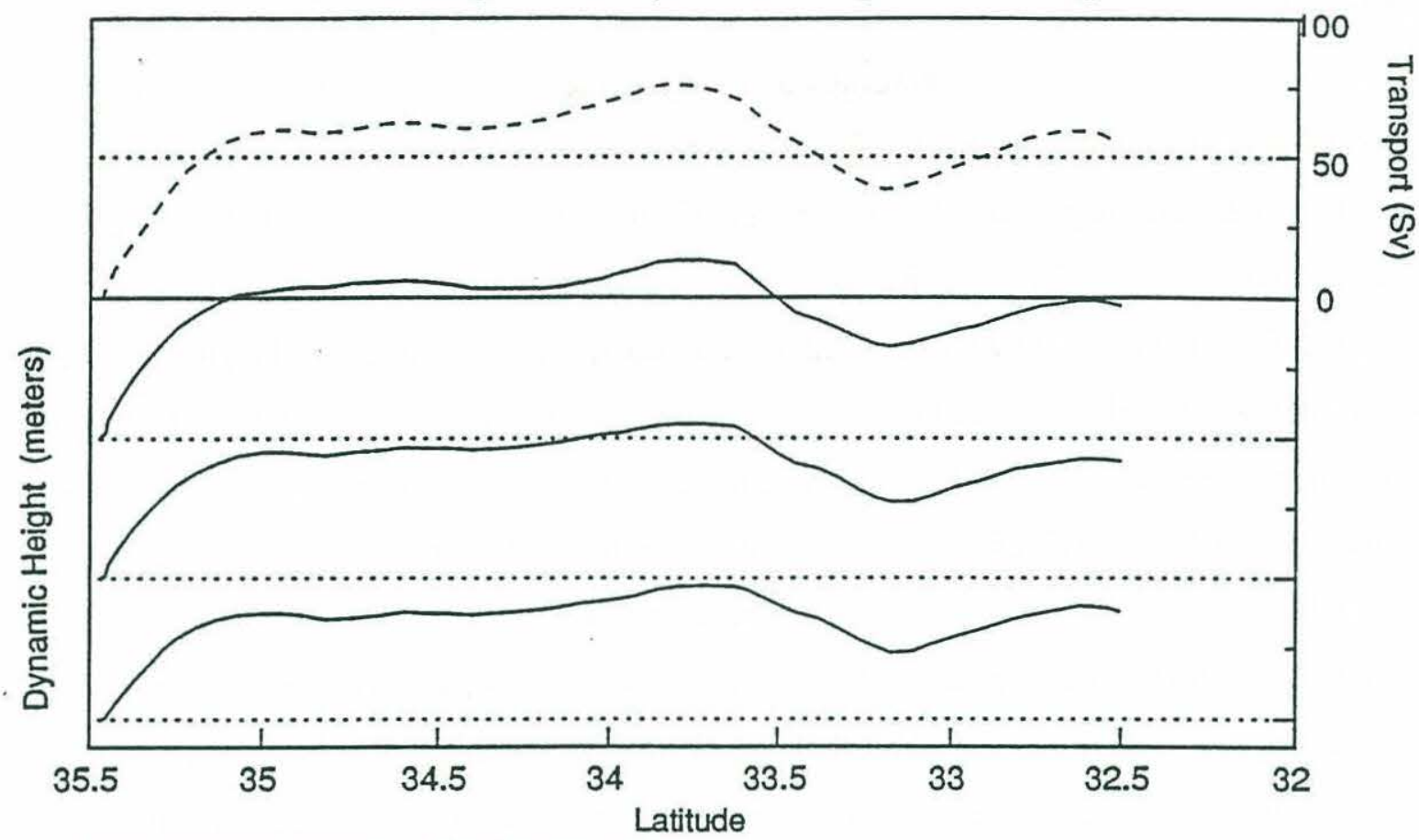

Dynamic Heights at depth $=100,150,200$ meters.

One major division $=1$ dynamic meter.

\section{OC216 Leg 3 Transport and Dynamic Heights}

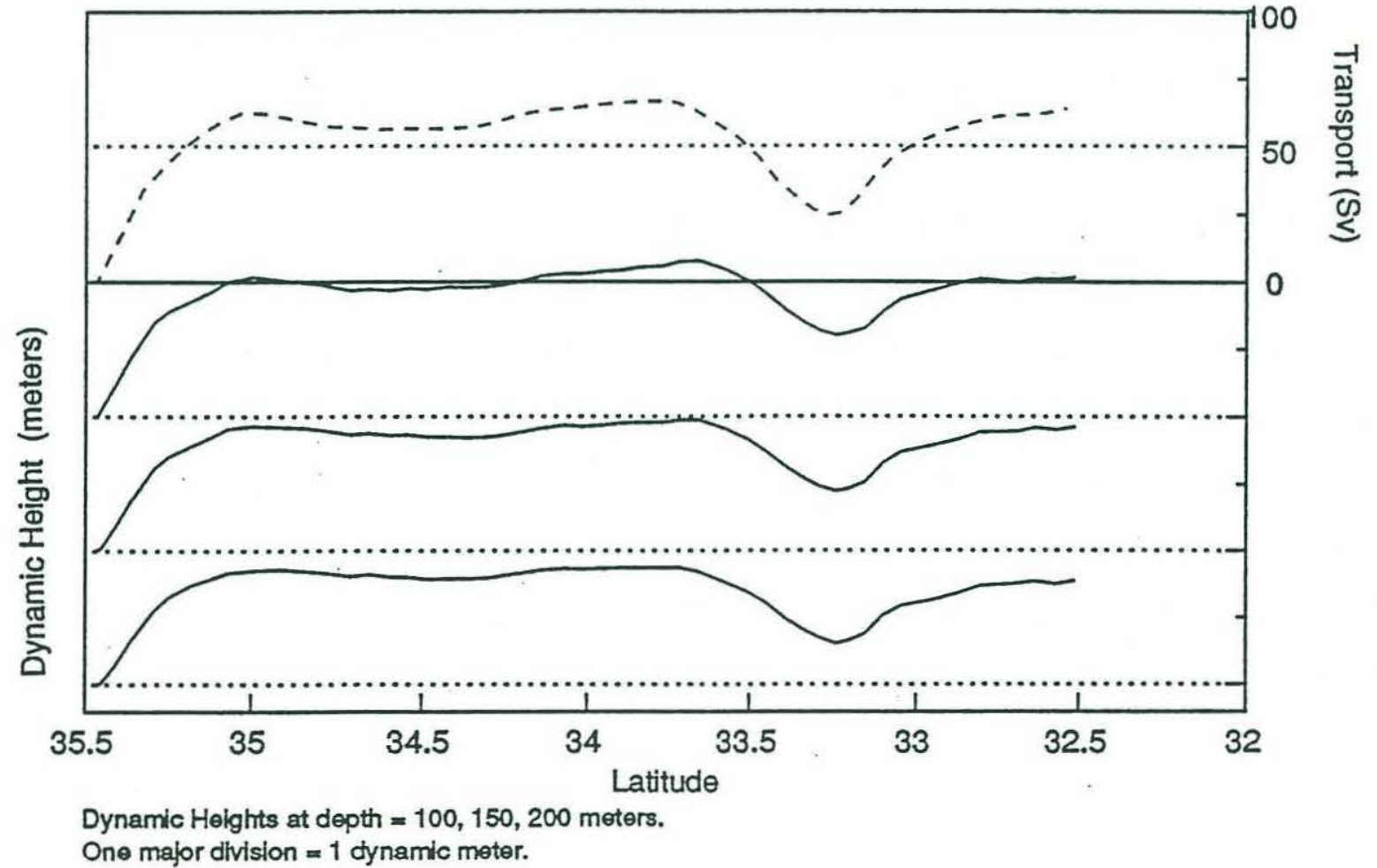

Figure 3.9. Transport and dynamic heights OC216 legs 2 and 3. 
Plots of transport and dynamic height vs. position for cruise OC216 are shown in Figure 3.8 and Figure 3.9. The Gulf Stream is somewhat stronger than during the April cruise, with a transport of 65 Sverdrups and a dynamic height difference at 100 meters depth of approximately 1.1 meter. The transport and height profiles for the two Cape Cod-Bermuda legs (legs 1 and 4) are very consistent, the major difference being a steady drop in transport on leg 1 at the southern end of the track, which causes the total transport to be 8 Sverdrups less than leg 4 . The transports and dynamic heights for the two Bermuda-Cape Hatteras legs show quite a difference in transport due to the large cold core ring between $32.5^{\circ} \mathrm{N}$ and $33.5^{\circ} \mathrm{N}$. On leg 3 , the height and transport lost in the northern half of the ring are retumed by the southern half of the ring, as would be expected. During leg 2, only about half of the transport removed by the northern half of the ring is returned. This appears to be an edge effect. The ring's cross-section is much wider during leg 2 than leg 3, and its center is further to the east. It appears that during leg 2, the ship's track did not extend to the end of the ring. By leg 3, the ring had moved so that the whole width of the ring was within the track, and the transport was balanced between the northern and southern halves of the ring. The apparent change in the ring's diameter is most likely due to a southward movement of the ring such that leg 2 cut nearly through the center of the ring, while leg 3 crossed the ring nearer its northern edge.

It is also necessary to examine the vertical structure of the transport. This is done by dividing the sections into layers defined by surfaces of constant potential density, as described by Joyce et. al. (1986). If we assume that the flow is along surfaces of constant potential density, then the transport within each layer should be in balance as well as the total transport. The data for both cruises were divided into six layers chosen in an attempt to resolve the major water mass features. These layers are the same as those contoured in the density sections shown in chapter 2. The layer transports using the reference velocities with bias corrections for both cruises are listed in Table 3.3.

We can see from the table that there are significant differences between layer transports, as well as the total transport for the different sections. Although a small 
Table 3.3 List of isopycnals and layer transports. Transport units: $10^{9} \mathrm{~kg} / \mathrm{s}=10^{6} \mathrm{~m}^{3} / \mathrm{s}$.

Individual layer transports for cruise 0C205

\begin{tabular}{|c|c|c|c|c|c|c||}
\hline $\begin{array}{c}\text { Layer } \\
\text { number }\end{array}$ & $\sigma_{\theta}$ & Leg 1 & Leg 3 & Leg 4 & Leg 6 & Leg 7 \\
\hline 1 & $<26.3$ & 25.83 & 24.91 & 17.69 & 14.57 & 20.84 \\
\hline 2 & $26.3-26.6$ & 14.37 & 15.74 & 10.16 & 5.80 & 10.77 \\
\hline 3 & $26.6-26.9$ & 8.58 & 10.28 & 10.88 & 8.93 & 7.36 \\
\hline 4 & $26.9-27.2$ & 9.33 & 8.59 & 8.59 & 10.21 & 9.52 \\
\hline 5 & $27.2-27.6$ & 3.27 & 2.14 & 6.39 & 6.55 & 4.55 \\
\hline 6 & $>27.6$ & -2.58 & 0.29 & 0.31 & -1.58 & 0.15 \\
\hline Total & & 58.80 & 61.59 & 54.01 & 44.48 & 54.56 \\
\hline \hline
\end{tabular}

Individual layer transports for cruise OC216

\begin{tabular}{|c|c|c|c|c|c||}
\hline $\begin{array}{c}\text { Layer } \\
\text { number }\end{array}$ & $\sigma_{\theta}$ & Leg 1 & Leg 2 & Leg 3 & Leg 4 \\
\hline 1 & $<26.3$ & 22.00 & 22.83 & 22.33 & 26.23 \\
\hline 2 & $26.3-26.6$ & 9.24 & 11.26 & 14.59 & 12.64 \\
\hline 3 & $26.6-26.9$ & 8.36 & 9.29 & 11.65 & 8.88 \\
\hline 4 & $26.9-27.2$ & 6.86 & 6.95 & 8.95 & 7.56 \\
\hline 5 & $27.2-27.6$ & 5.31 & 5.13 & 5.38 & 4.58 \\
\hline 6 & $>27.6$ & -1.44 & 0.50 & 0.83 & 1.25 \\
\hline Total & & 53.32 & 55.96 & 63.74 & 61.14 \\
\hline \hline
\end{tabular}

amount of cross-isopycnal flow is expected, the vertical velocities required to balance the layer flows between legs are too large to be physically realistic. In order to better balance the total and individual layer transports, inverse techniques will be used. 


\subsection{Transport Variability}

Prior to using individual layer and total section mass constraints to bring the sections closer into balance, it is important to examine why the section transports are different and how much change would be expected in the transports in the time required to complete the sections. Watts (1983) states that the velocity in the upper 800 meters in the Gulf Stream is more variable than is apparent looking only at the density field and concludes that this variability is due to a changing barotropic component of the flow. From Table 3.1 (page 29) we see that the baroclinic portion of the transport during cruise OC205 varies from 22.3 to 30.4 Sverdrups. The barotropic part of the transport, which is a function of the reference velocities, ranges from 22.3 Sverdrups (leg 6) to 36.4 Sverdrups (leg 3), a range of over 14 Sverdrups, which is almost twice as much as the variation in the baroclinic transport. There does not appear to be any direct correlation between the size of the baroclinic and barotropic components. Leg 5 has the smallest amount of both baroclinic and barotropic transport, but leg 3, which has the second smallest baroclinic transport, has the greatest barotropic component.

Looking at the repeated tracks between Bermuda and Cape Cod (legs 1, 4, and 7), we can see how much of this variability is due to changes in the Gulf Stream itself, and how much is due to changes in the flow field outside the Gulf Stream. The "Gulf Stream transport" for legs 1,4 , and 7 , determined by measuring the region of rapidly increasing transport (Figure 3.4), is 59.4 Sverdrups for leg 1, 56.8 Sverdrups for leg 4, and 57.0 Sverdrups for leg 7. Choosing the limits of the Gulf Stream is somewhat arbitrary, especially for leg 7, which does not have a sharp leveling off of the transport increase south of the Gulf Stream. The transport for Leg 1 is approximately 2.5 Sverdrups higher in the Gulf Stream, and approximately 5.5 Sverdrups higher overall than legs 4 and 7 . Separating the transports for these legs into baroclinic and barotropic components, the baroclinic part of the transport varies by less than 3 Sverdrups, (Table 3.1) whereas the barotropic part varies by nearly 8 Sverdrups between leg 1 (31.5 Sv.) and leg 4 (23.6 
Sv.). This seems to indicate the presence of some large scale rapid changes which could be due to Rossby waves.

For cruise OC216, we can compare the Gulf Stream transport for each of the two sets of repeated tracks (Figures 3.8 and 3.9). The Cape Cod-Bermuda legs have Gulf Stream transports of 64.7 Sverdrups (leg 1), and 67.6 Sverdrups (leg 4). The difference of approximately 3 Sverdrups between legs one week apart is similar to the change seen during cruise OC205. The Cape Hatteras tracks have Gulf Stream transports of 67.1 Sverdrups (leg 2), and 67.0 Sverdrups (leg 3). The transports are nearly identical, which is not surprising considering the small elapsed time between the two tracks. (The two Gulf Stream crossings were completed in just over one day.)

The major cause of variability in the OC216 legs is caused by the cold core ring near Bermuda, which which moved to the south-west during the cruise. The average transport for legs 3 and 4 is approximately 8 Sverdrups higher than for legs 1 and 2 due to edge effects caused by the movement of this ring between legs 2 and 3 . The change in transport due to this edge effect is barotropic. In fact, the baroclinic part of the transport is somewhat smaller for legs 3 and 4 than it is for legs 1 and 2 (Table 3.2, page $35)$.

In summary, the following types of variability are seen in the data:

- Variability in Gulf Stream transport between Bermuda and Cape Cod of order 3 Sverdrups in a one week period.

- Variability due to edge effects of approximately 8 Sverdrups, caused by the motion of a cold core ring during cruise OC216.

- Large scale barotropic variability between Cape Cod and Bermuda of order 8 Sverdrups in one week. 
The inverse models of the next chapter will use mass balance constraints to balance the flow between sections. The sources of variability listed above must be taken into consideration when making the models. For cruise OC216, there is a large change in transport between legs 2 and 3 due to edge effects which should not be removed by attempting to balance all four legs together. Therefore, the inverse model for cruise OC216 will involve only balancing leg 1 with leg 2 and leg 3 with leg 4 . If we examine the legs two at a time, the transport differences between legs 1 and 2 are small, as are the differences between legs 3 and 4 . We can use a fairly tight constraint on the total transport when conducting the two leg balances.

For cruise OC205, a three leg balance will be conducted, applying mass constraints to balance the flow in legs 3,4 , and 6 . The time from the start of leg 3 to the end of leg 6 was 9.5 days, while the average time for legs 1-2 and legs 3-4 of cruise OC216 was less than six days. Due to the much larger initial imbalances in transport for the three legs, as well as the longer period of time involved, less weight will be given to the total mass balance constraints when constructing the inverse model for cruise OC205. 


\section{Chapter 4}

\section{Velocity by Combined Inversion Techniques}

\subsection{The Inverse Problem}

The inversion technique combines the acoustic doppler velocities with the geostrophic profiles while at the same time attempting to satisfy certain other physical constraints within some estimated errors. All the constraint equations are set up in a linear matrix, which is solved using least squares techniques, specifically the Singular Value Decomposition (SVD), which yields information on the resolution of each equation and unknown. These inversion procedures were first applied to oceanographic data by Wunsch (1978). The procedures here closely follow Joyce, et. al. (1986), and Pierce and Joyce (1988) who applied the inverse technique to a combination of ADCP and hydrographic data. There are several differences between the current model and previous models. Due to the limits on XBT depth, only the transport in the upper 765 meters is being balanced. Also, the bias levels discussed in chapter 3 have been removed to make an initial correction to the total transports prior to performing the inverse calculations.

The model parameter matrix is made up of equations chosen to satisfy the following physical constraints: 
- The 760 meter velocities are consistent with those determined by the differences between the $A D C P$ and geostrophic velocity profiles and corrected for bias errors.

- The total mass transport in the upper 760 meters is conserved for the triangular areas between Bermuda and the shelf.

- Mass is conserved within each density layer.

The model is written in matrix format as

$$
A x=b \text {, }
$$

where $\mathrm{A}$ is the matrix of model parameters, $\mathrm{b}$ is a vector of observations, and $\mathrm{x}$ is the vector containing the unknowns. (Throughout the text, vector quantities will be denoted by boldface small letters, and matrices will be denoted by boldface capital letters.) The unknowns in our model will be the horizontal reference $(765 \mathrm{~m})$ velocities for each station pair, and the cross-isopycnal velocities associated with the chosen density surfaces. The number of unknowns, therefore, will be equal to the number of XBT pairs in the legs being balanced, plus the number of isopycnal interfaces. The concept of cross-isopycnal flow is discussed in Wunsch et. al. (1983). The horizontal reference velocities will be denoted as $x_{j}$ where $j=1$ to nsta, the number of station pairs in the legs being balanced. The cross-isopycnal velocities will be denoted by $w_{i}^{*}$, where $\mathrm{i}$ is the number of the interface between density layers. Since we have divided the sections into six density layers, there will be five interfaces for each area used in the transport balance.

The condition that reference level velocity is consistent with the $A D C P$ measurements is expressed as 


$$
\alpha_{j}=q_{j} \pm \varepsilon_{j}, \quad j=1, \text { nsta }
$$

where $q_{j}$ is the true reference velocity, $\alpha_{g}$ is the initial estimate of reference velocity as determined in the previous chapter, and $\varepsilon_{\mathrm{j}}$ represents the error in the acoustic doppler velocity. As discussed previously, the expected random error in the acoustic doppler velocities is $\pm 5 \mathrm{~cm} / \mathrm{s}$.

The transport constraints are expressed as equations balancing the inflow and the outflow of mass in any given layer, or the whole section.

$$
\sum_{j=1}^{n \text { sta }} a_{i j}\left(q_{j}+v_{i j}\right)+h_{i} w_{i}^{*}-h_{i-1} w_{i-1}^{*}=0 .
$$

We define $a_{i j}$ as the vertical area of layer $i$ within station pair $j$ multiplied by the density of layer $i$, and $h_{i}$ as the horizontal area of interface $i$ between two ship's tracks multiplied by the density. The quantity $\left(q_{j}+v_{i j}\right)$ is the sum of the reference and baroclinic velocity components in area ij. There will be one mass conservation equation for each layer, and one for the total section mass transport. We can express this set of equations as

$$
A_{1} x-b_{1} \approx 0,
$$

where $A_{1}$ is a matrix made up of the elements $a_{1 j}$ and $h_{1},-b_{1}$ is the initial imbalance between layer transports due to the baroclinic component of velocity, and $\mathbf{x}$ is the set of unknowns

$$
x=\left|\begin{array}{c}
q \\
--- \\
w
\end{array}\right| \text {. }
$$


The approximately equal sign in equation (4.4) represents the fact that mass is conserved only to within some level of error. Equation (4.4) represents the pure geostrophic inverse problem, where property conservation properties are used to solve for reference velocities. The set of equations (4.2) can be added to the matrix, combining the ADCP constraints with the mass balance constraints. The problem can now be stated:

$$
\left|\frac{I_{n s t a}: 0}{A_{1}}\right| x=\left|\frac{\alpha}{b_{1}}\right| \text {, }
$$

or simply $A x=b$. Solving for the unknowns is called the inverse problem, because it involves inverting the matrix $\mathrm{A}$.

$$
x=A^{-1} b .
$$

Prior to solving the inverse problem, the equations must be weighted. A row weighting factor is introduced for each equation which is inversely proportional to the estimated error in the constraint for that equation. When all the equations are multiplied by their weighting factors, the expected error in each equation is normalized. The equations are now non-dimensional. Column weighting is also imposed on the A matrix in the interest of numerical stability. There is an artificial tendency for the solution to favor the terms in the equation with the largest magnitudes. Therefore, any station pairs which were closely spaced or shallow would be less resolved than those spaced farther apart or deeper. Additionally, the horizontal interface areas are orders of magnitude larger than the vertical areas, and the horizontal velocities $q_{j}$ are much larger than the vertical velocities $w_{i}^{*}$. The column weighting scales the size of each unknown.

Let the row weighting matrix be $R$, a diagonal matrix with elements $r_{i j}=\sigma_{j}$, the expected error in the jth equation. With row weighting, equation (4.1) becomes 


$$
R A x=R b .
$$

To weight the columns, define another diagonal matrix $\mathrm{C}$, such that the diagonal elements $c_{i 1}$ are equal to the area of the station pair or layer associated with column i. $\mathrm{C}$ has a square root $\mathrm{C}^{1 / 2}$, and $\mathrm{C}^{-1 / 2} \mathrm{C}^{1 / 2}=\mathrm{I}$, the identity matrix. With column and row weighting, equation (4.1) becomes

$$
R A C^{-\frac{1}{2}} C^{\frac{1}{2}} x=R b,
$$

which we can rewrite in the form of equation (4.1) as

$$
\boldsymbol{A}^{\prime} \boldsymbol{x}^{\prime}=\boldsymbol{b}^{\prime},
$$

where $A^{\prime}=R_{A C}^{-1 / 2}, x^{\prime}=C^{1 / 2} x$, and $b^{\prime}=R b$. In the subsequent discussion the primes will be dropped, and the unprimed values will refer to the weighted matrix.

Our system will generally have more equations than unknowns, therefore the problem is formally overdetermined. The conventional method for solving an overdetermined problem is to use the least squares approach. The least squares solution is

$$
\hat{x}=\left[A^{T} A\right]^{-1} A^{T} b,
$$

where $A^{T}$ is the transpose of the data matrix $A$. The least squares solution gives the best estimate of the solution in the sense that the sum of the square differences between $\mathrm{Ax}$ and $\mathbf{b}$ is minimized. Although our A matrix is formally overdetermined, the equations in the matrix may not be independent. If the number of independent equations is less 
than the number of unknowns, the problem is underdetermined. In solving the system, we use a solution technique which is equivalent to the least squares technique, but is equally adept at handling the overdetermined and underdetermined cases.

\subsection{The Singular Value Decomposition}

The Singular Value Decomposition (SVD) of a matrix is a very powerful tool for evaluating the resolution and variance of the solution when solving the inverse problem. The Singular Value Decomposition decomposes the matrix A into two sets of orthonormal eigenvectors and a set of eigenvalues. The value of this decomposition is the ease with which it lends itself to qualitative ranking of the information content of the system. The SVD solution simultaneously minimizes the misfit in each equation and the deviation from the initial model. In this case, the magnitude of the reference velocity corrections and of the cross-isopycnal velocities is minimized. Thorough discussions of the Singular Value Decomposition are found in Lanczos (1961), Wiggins (1972), and Wunsch (1978).

The Singular Value Decomposition of $\mathrm{A}$ can be written as

$$
\underset{m \times n}{A}=\underset{m \times m}{U} \quad \underset{m \times n}{\Lambda} \underset{n \times n}{V^{T}},
$$

where $\mathrm{U}$ is composed of $m$ orthonormal column vectors $\mathrm{u}_{\mathrm{p}}$, and $\mathrm{V}$ is composed of $n$ orthonormal columnvectors $v_{i}$. The matrix $\Lambda$ is a diagonal matrix with elements $\lambda_{1}$, called the singular values of the matrix. The $\mathrm{U}$ and $\mathrm{V}$ matrices form a coupled eigenvalue problem:

$$
A A^{T} U=\lambda^{2} U, \quad A^{T} A V=\lambda^{2} V
$$


In general the number of rows $m$ is not equal to the number of columns $n$. The number of non-zero singular values, $k$ is known as the rank of the matrix $\mathrm{A}$ and represents the number of independent equations in the matrix. The singular values, which are all positive, are arranged from largest to smallest such that $\lambda_{1+1}<\lambda_{q}$. The rank of the matrix is always less than or equal to the smaller of $m$ and $n$. As will be shown below, the smallest singular values can introduce large variance into the solution. This effect can be eliminated by setting to zero all singular values smaller than some cutoff, thereby reducing the rank of the system.

The SVD solution of the inverse problem is given by

$$
\hat{x}=V \Lambda^{-1} U^{T} b .
$$

This solution is equivalent to the least squares solution, and also satisfies the constraint that it minimizes the sum of the squares of the solution parameters (i.e., $\hat{\mathbf{x}}^{\mathrm{T}} \hat{\mathrm{x}}$ is as small as possible). Equation (4.14) can be rewritten as a sum of the eigenvectors

$$
\hat{x}=\sum_{i=1}^{k} \frac{u_{i} \cdot b}{\lambda_{i}} v_{i} .
$$

From this expression, it is easy to see that the smallest values of $\lambda$ will have the largest effects on the solution. Choosing the cutoff below which the eigenvalues will not be kept in the summation is the problem of determining the rank of the system. Wiggins (1972) and Lawson and Hanson (1974) discuss several approaches to making this decision. As more and more eigenvalues are kept, the residual norm \|A $\hat{x}$ - bll decreases while the solution norm $\left\|\hat{\mathbf{x}}^{\mathrm{T}} \hat{\mathbf{x}}\right\|$ increases. The best choice of rank is one for which the residuals have been made acceptably small, but the solution has not been made too large. 


\subsection{Resolution and Variance}

The $\mathrm{U}$ and $\mathrm{V}$ matrices provide useful information about the contributions from the equations and the resolution of the unknowns. Since the eigenvectors are orthogonal,

$$
U U^{T}=I_{m}, \quad V V^{T}=I_{n},
$$

where $\mathrm{I}_{\mathrm{m}}$ is the $m x m$ identity matrix, and $\mathrm{I}_{\mathrm{n}}$ is the $n x n$ identity matrix. If the rank $k$ is less than $m$ or $n$, only the first $k$ columns of $\mathrm{U}$ and $\mathrm{V}$ are used by the SVD. If we denote the matrices made of the first $k$ columns of $U$ and $V$ as $U_{k}$ and $V_{k}$, we find that $U_{k} U_{k}^{T} \neq I_{m}$ and $V_{k} V_{k}^{T} \neq I_{n}$. It can be shown that the diagonal elements of $V_{k} V_{k}^{T}$ give the resolution of the $n$ unknowns of the model. At rank $n$, all the diagonal elements of $\mathrm{V}_{\mathbf{k}} \mathrm{V}_{\mathbf{k}}^{\mathrm{T}}$ are 1 and all the unknowns are perfectly resolved. At a lower rank, some of the diagonal elements of $V_{k} V_{k}^{T}$ will be less than 1 and the corresponding unknowns will be less than perfectly resolved. The sum of the diagonal elements of $\mathrm{V}_{\mathbf{k}} \mathrm{V}_{\mathbf{k}}^{\mathrm{T}}=k$.

The $U_{k} U_{k}^{T}$ matrix gives similar information about the contributions of each of the equations to the solution. The $m$ diagonal elements of $U_{k} U_{k}^{T}$ give the contribution of the $m$ equations to the solution. A diagonal element of 1 means the corresponding equation contributes fully to the solution. A diagonal element of $U_{k} U_{k}^{T}$ near zero means that the corresponding equation is not independent of the other equations and is not contributing to the solution. The sum of the diagonal elements of $\mathrm{U}_{\mathbf{k}} \mathrm{U}_{\mathbf{k}}^{\mathrm{T}}$ also equals $k$.

The SVD solution also provides a formal estimate of the uncertainty in the solution $\hat{x}$ due to random errors in the data (Wunsch, 1978). The relative variance of the $\mathrm{j}$ 'th unknown is given by 


$$
\left\langle\hat{x}_{j}^{2}\right\rangle=\sigma^{2} \sum_{i=1}^{k} \frac{v_{j i}^{2}}{\lambda_{i}^{2}},
$$

where $\left\langle\hat{\mathrm{x}}_{\mathrm{j}}^{2}\right\rangle$ is the solution variance, $v_{\mathrm{ji}}$ is the element in the $i_{\mathrm{th}}$ column and $j_{\mathrm{th}}$ row of the $V$ matrix, and $\sigma^{2}$ is the a priori problem variance. Note that this illustrates the trade-off between resolution and variance, in that as $k$ is increased, smaller and smaller values of $\lambda_{1}$ are kept in the summation, the unknowns become more well resolved but the solution variance increases.

\subsection{Inverse Results for Cruise OC216}

The inverse model for the December cruise, OC216 is simpler than the one used for the April cruise, and will be presented first. Two inverse calculations were made, one to balance the flow between legs 1 and 2 and the other to balance the flow between legs 3 and 4 . In chapter 3 we noted a large ( $7 \mathrm{~Sv}$ ) imbalance between legs 2 and 3 which was deemed to be due to edge effects caused by the large cold-core ring on the track near Bermuda. The magnitude of this change in transport is similar to that reported by Halkin and Rossby, who saw shifts in Gulf Stream transport of order $10 \mathrm{~Sv}$ in a 7 day period. Because we believe this change in transport was due to short-term variability, no attempt was made to balance the four leg transports together.

The error terms used in the row weighting for cruise OC205 were estimated to be $5 \mathrm{~cm} / \mathrm{s}$ for the individual reference velocities, $.2 \mathrm{~Sv}$ for the overall mass transport, $1 \mathrm{~Sv}$ for the lower 4 layer transports, $3 \mathrm{~Sv}$ for the top layer, and $1.5 \mathrm{~Sv}$ for the second layer. The shallower layers were assigned larger errors since ageostrophic velocity components are largest near the surface. 


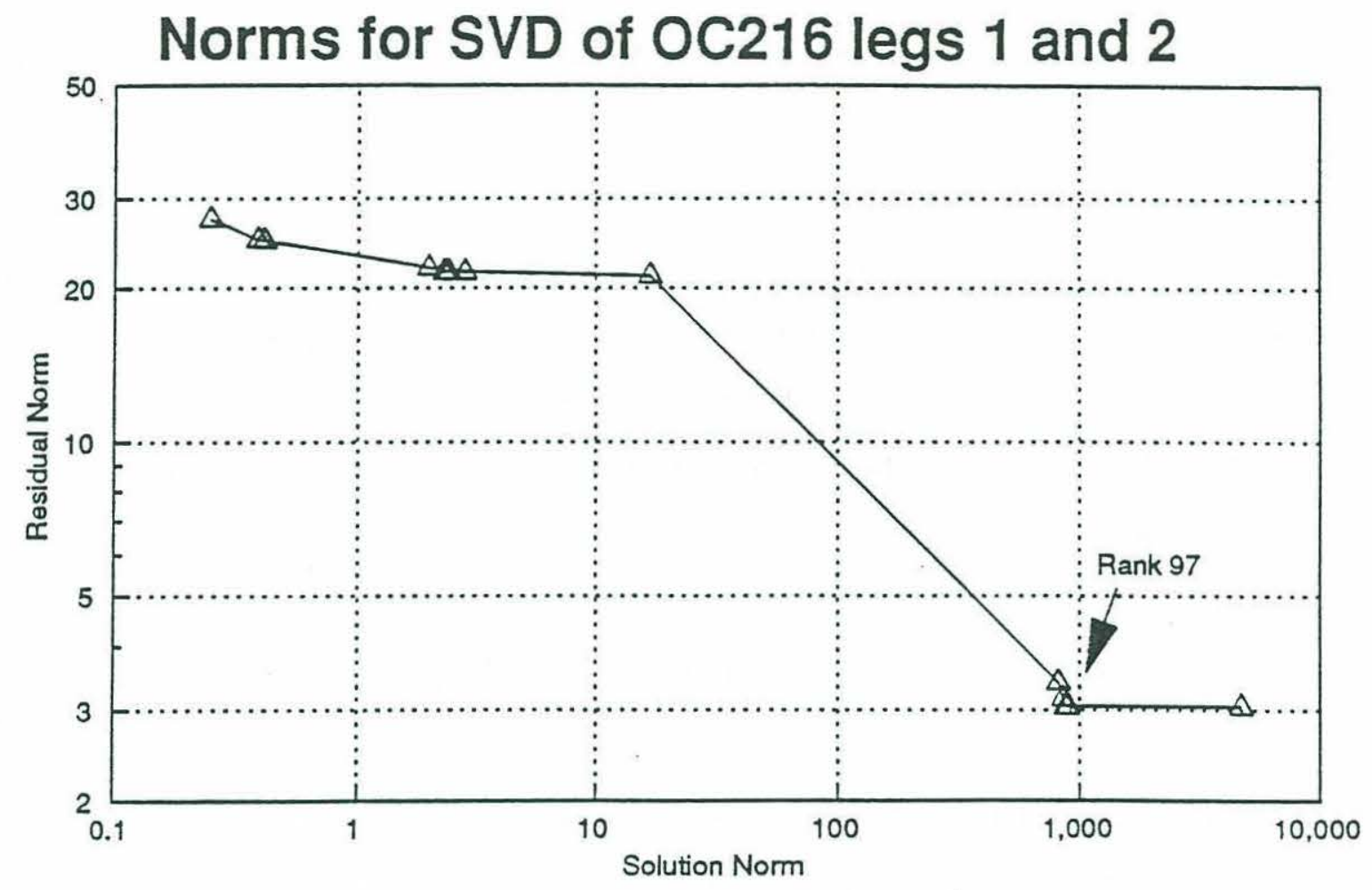

Eigenvalues for SVD of OC216 legs 1 and 2

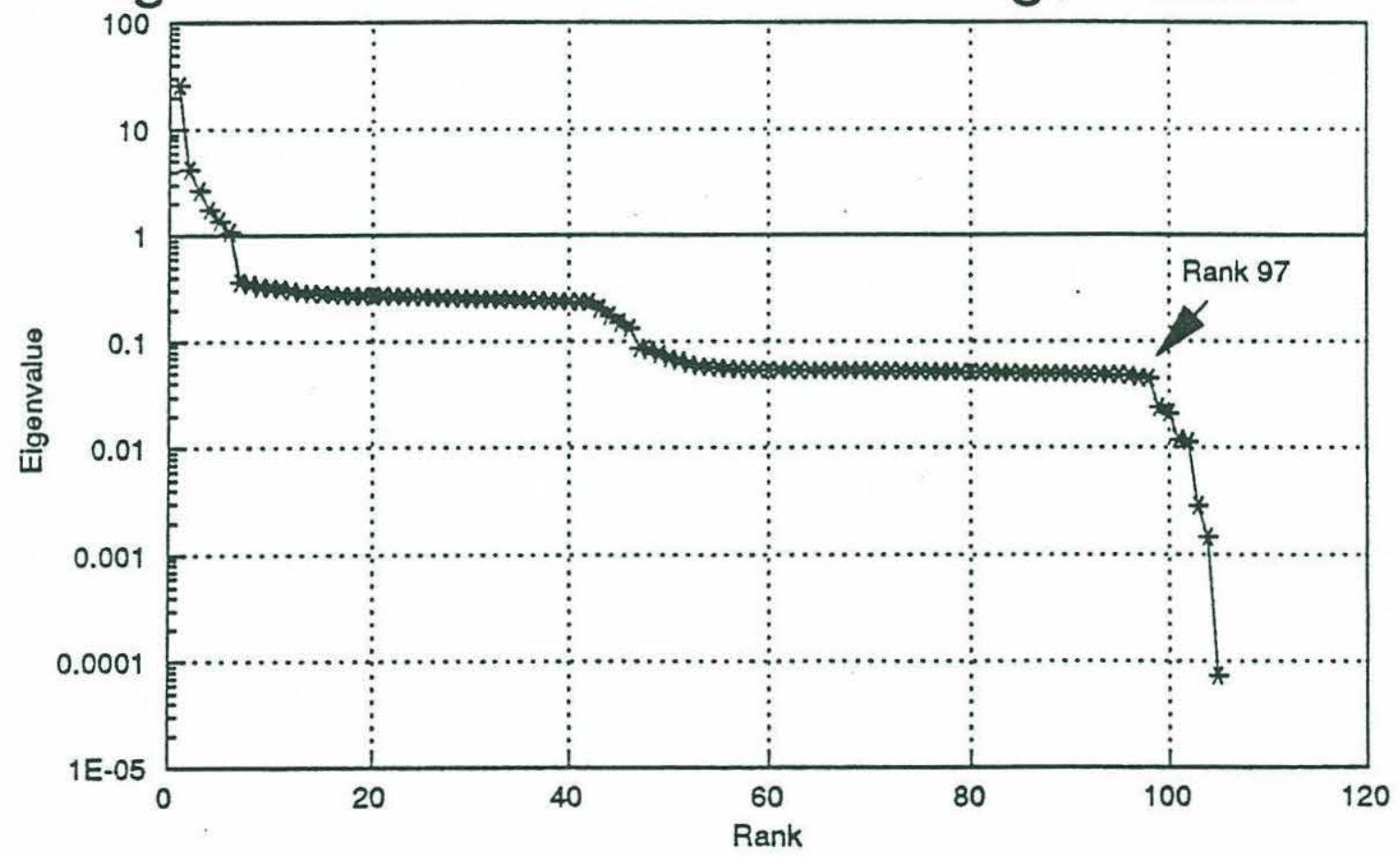

Figure 4.1. (a) Plot of residual norm vs. solution norm for determining solution rank for legs 1 and 2 of cruise OC216. (b) Plot of eigenvalues vs. rank for the same problem. 


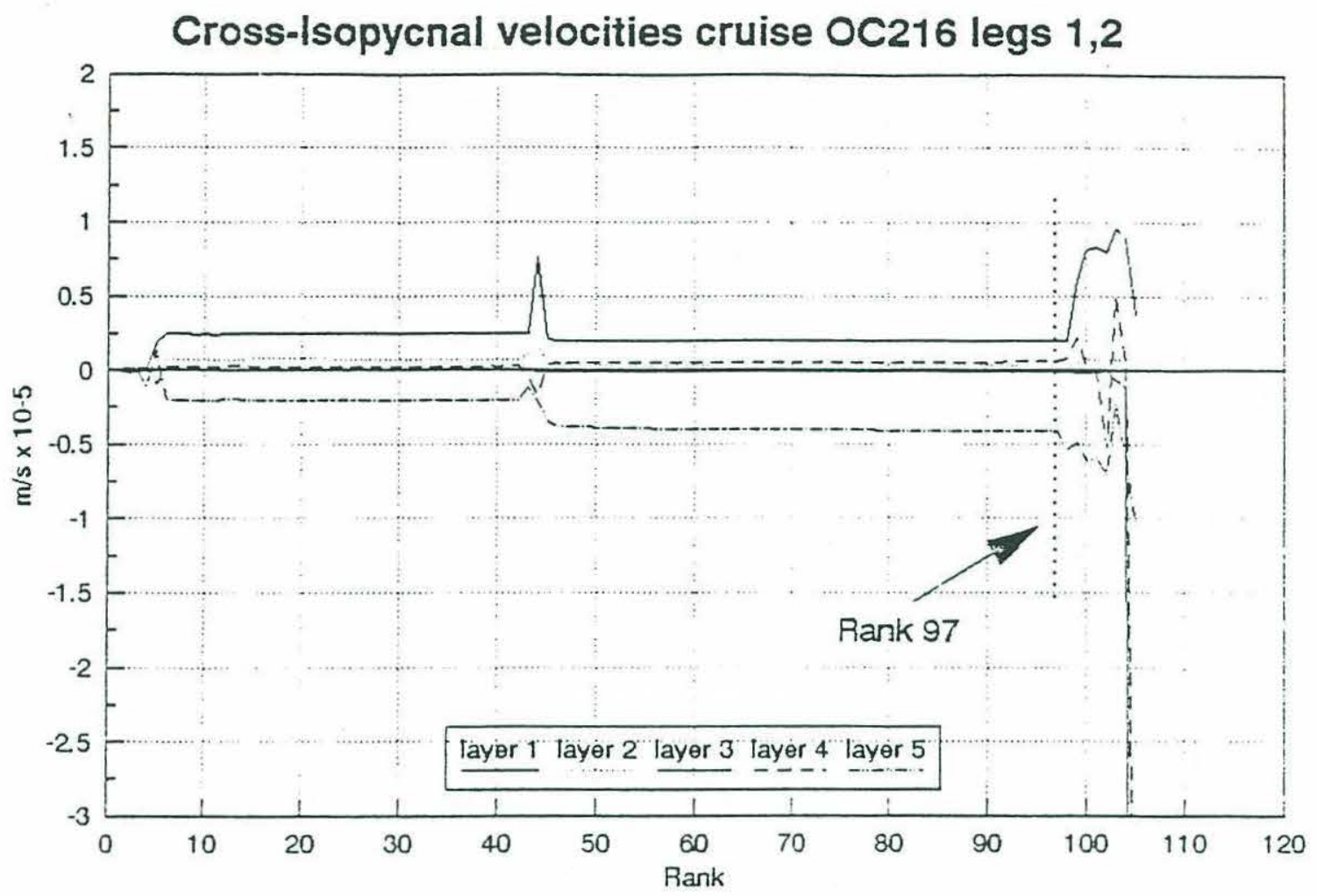

Figure 4.2. Cross-isopycnal velocity $w_{1}^{*}$ vs. rank for cruise OC216 legs 1 and 2.

In order to obtain the "best" solution using the SVD, the rank of the system must be estimated. The desired rank is one that minimizes the residual norm without making the values of the individual velocity corrections too large. One method of choosing the optimum rank is the Levenberg-Marqardt stabilization method (Lawson and Hanson, 1974), which plots the residual norm vs. the solution norm for each rank. The SVD representation of the Levenberg-Marquardt diagram for legs 1 and 2 of cruise OC216 is shown in Figure 4.1 along with a plot of the eigenvalues as a function of rank. The optimum rank is the point above which the solution norm increases sharply without a corresponding drop in residuals. This should correspond to a drop in the magnitude of the eigenvalues. The rank of this problem appears to be approximately 97 or 98 . In order to further evaluate the effect of rank on the solution, the cross-isopycnal velocities, $w_{1}^{*}$ were plotted vs. rank. Figure 4.2 shows that the magnitude of the cross-isopycnal 



Figure 4.3. (a) Plot of residual norm vs. solution norm for legs 3 and 4 of cruise OC216. (b) Plot of eigenvalues vs. rank for the same problem. 
velocities increases dramatically above rank 97 . Rank 97 was chosen as the optimum rank of the system based on keeping the cross-isopycnal flow small while balancing the layer and total transports as closely as possible. A similar analysis of the inverse model for legs 3 and 4 yields an optimum rank of 90 (Figure 4.3 and Figure 4.4).

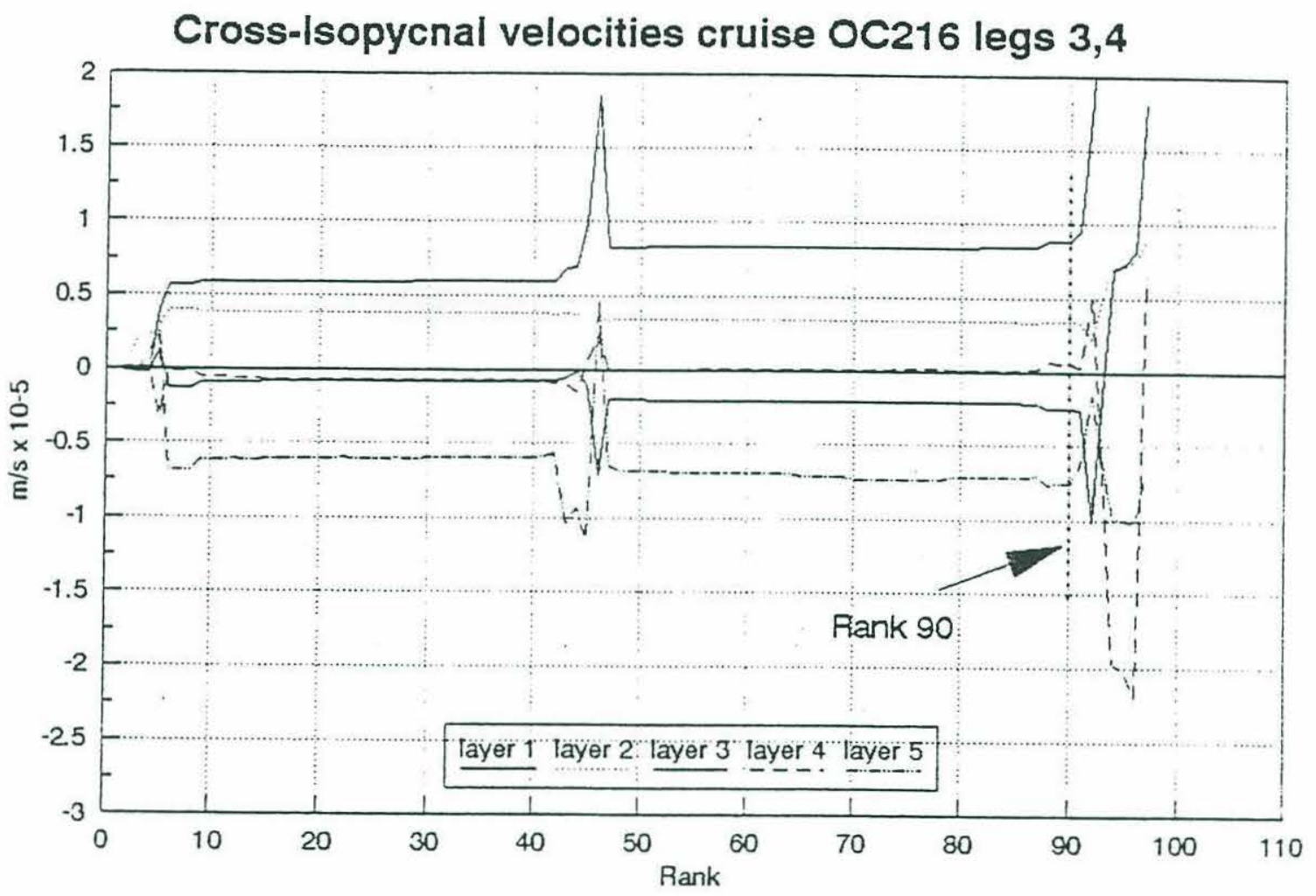

Figure 4.4. Cross-isopycnal velocity wi vs. rank for cruise OC216 legs 3 and 4.

The velocity corrections for the rank 97 solution for legs 1 and 2 and the rank 90 solution for legs 3 and 4 are shown in Figure 4.5 with error bars. As discussed by Joyce et al. (1986), the error bars have two contributors: (1) that due to noise in the data and (2) that due to failure to resolve the individual value of $q_{\mathrm{i}}$ or $w_{1}^{*}$. In order to determine the resolution of the unknowns, we must look at the diagonal elements of the resolution matrix, $\mathrm{V}_{\mathbf{k}} \mathrm{V}_{\mathbf{k}}^{\mathrm{T}}$. These values are plotted vs. unknown in Figure 4.6. For the leg 1 and 2 model, the first 100 unknowns are the individual reference velocity corrections, $q_{\mathrm{i}}$, and the last six unknowns are the cross-isopycnal velocities $w_{1}^{*}$. We can see that most of the 

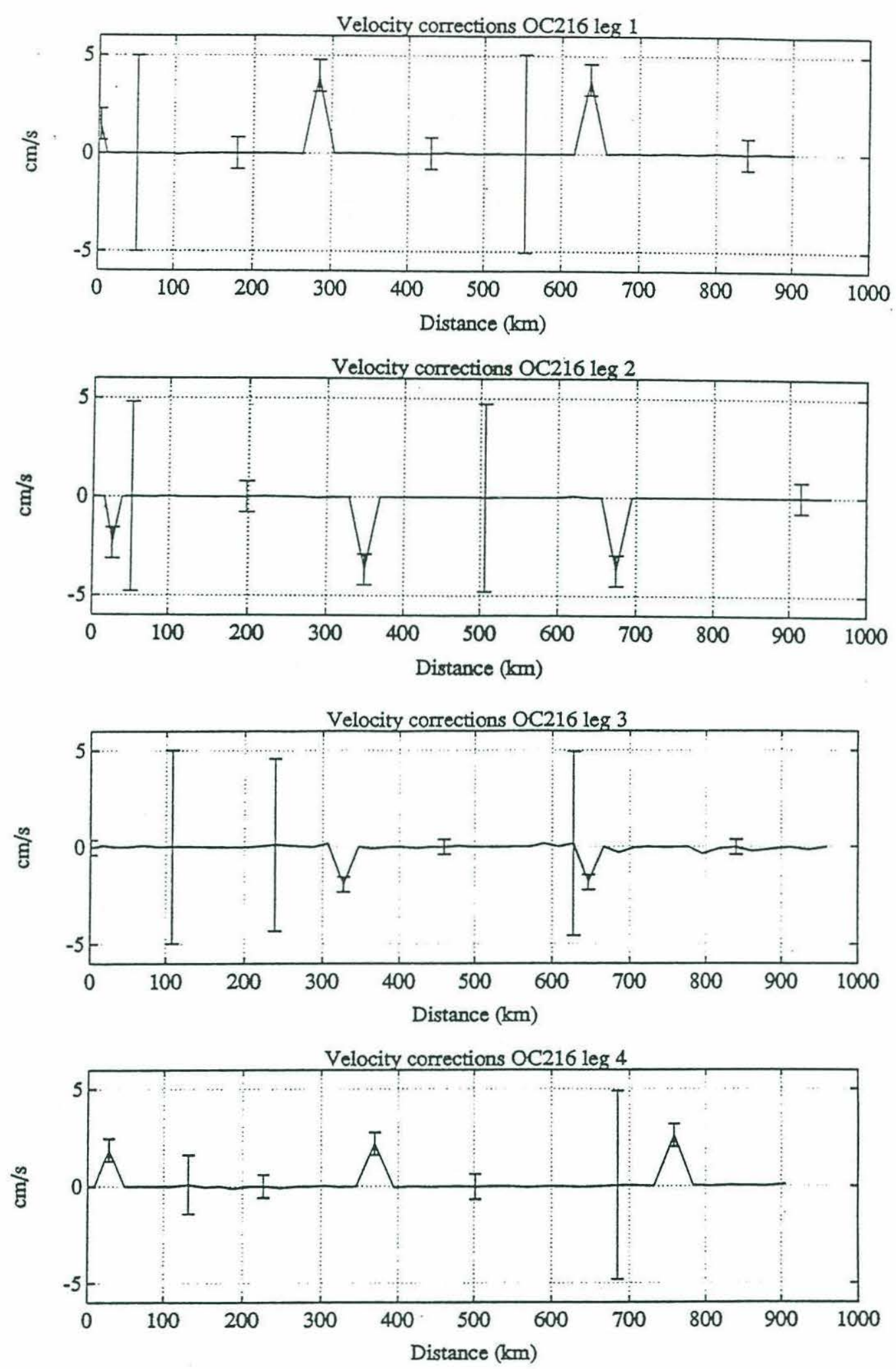

Figure 4.5. Reference velocity corrections for cruise OC216. Distances are measured from the $200 \mathrm{~m}$ isobath. Some representative error bars are provided. The error bars have two components, data noise and failure to resolve. Note that the velocities which received significant corrections are well resolved. The poorly resolved velocities (large error bars) have a correction of zero. 
$q_{\mathrm{i}}$ are well resolved, but five of the velocities are poorly resolved. Four of the five $w_{\mathrm{i}}^{*}$ are poorly resolved. The velocity corrections required to balance the transports are much smaller than the a priori estimate of $\pm 5 \mathrm{~cm} / \mathrm{s}$ would suggest. For each leg, significant adjustments were required for only two or three of the reference velocities. The largest error bars in Figure 4.5 correspond to the velocities which have not been resolved by the inverse model. The rank 90 solution for legs 3 and 4 yields similar results. Again, most of the $q_{i}$ are well resolved, with the $w_{i}^{*}$ in general being less well resolved.
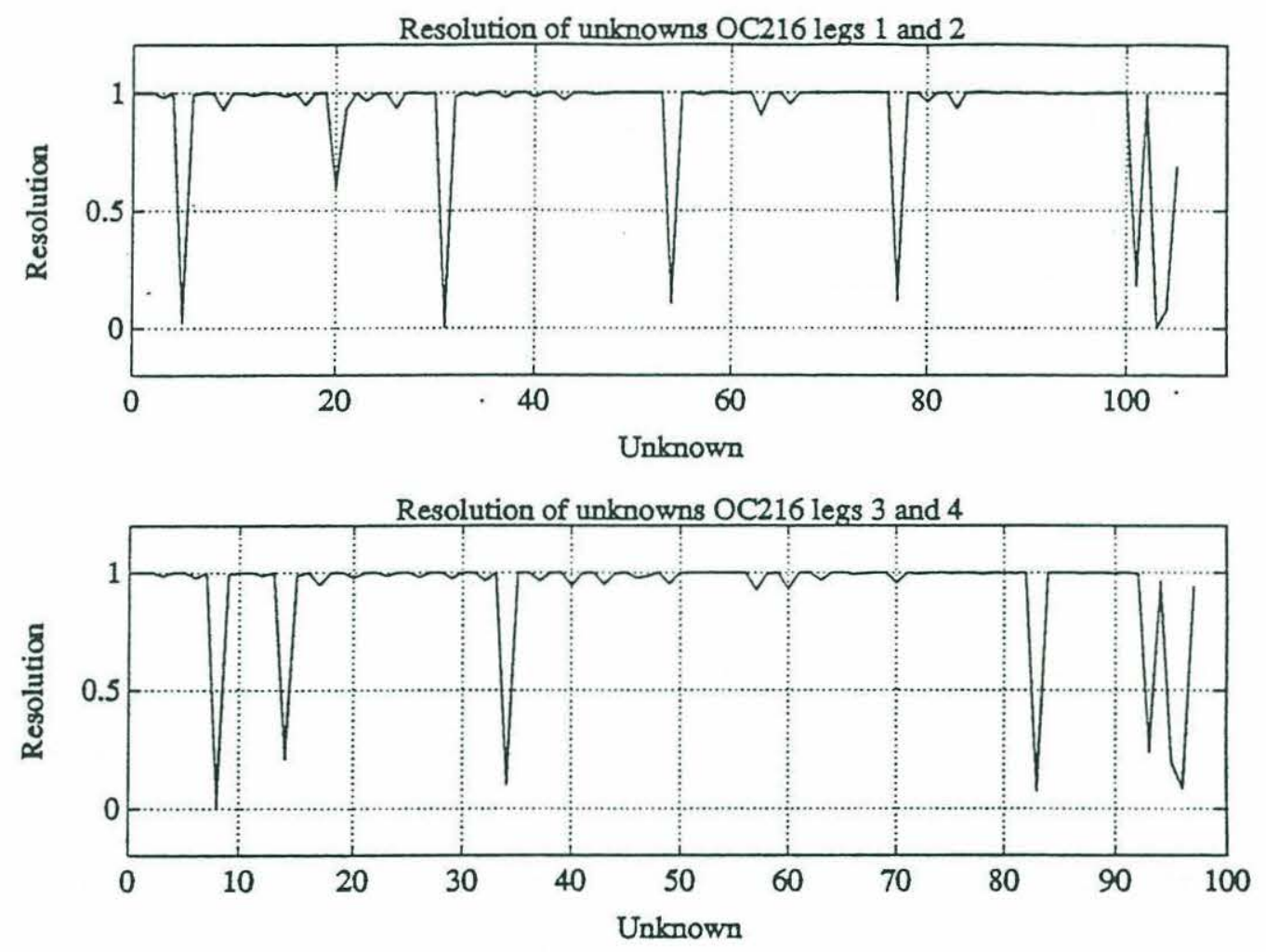

Figure 4.6. Diagonal elements of $\mathrm{V}_{\mathbf{k}} \mathrm{V}_{\mathbf{k}}^{\mathrm{T}}$ for legs 1 and 2 rank 97 (top), legs 3 and 4 rank 90 (bottom).

Examining the diagonal elements of the $U_{k} U_{k}^{T}$ matrices, we find that for the leg 1 and 2 model, the 100 equations for the reference velocities contribute 90.15 of the total rank (97). The 6 layer transport balance equations contribute 5.87, and the total transport 

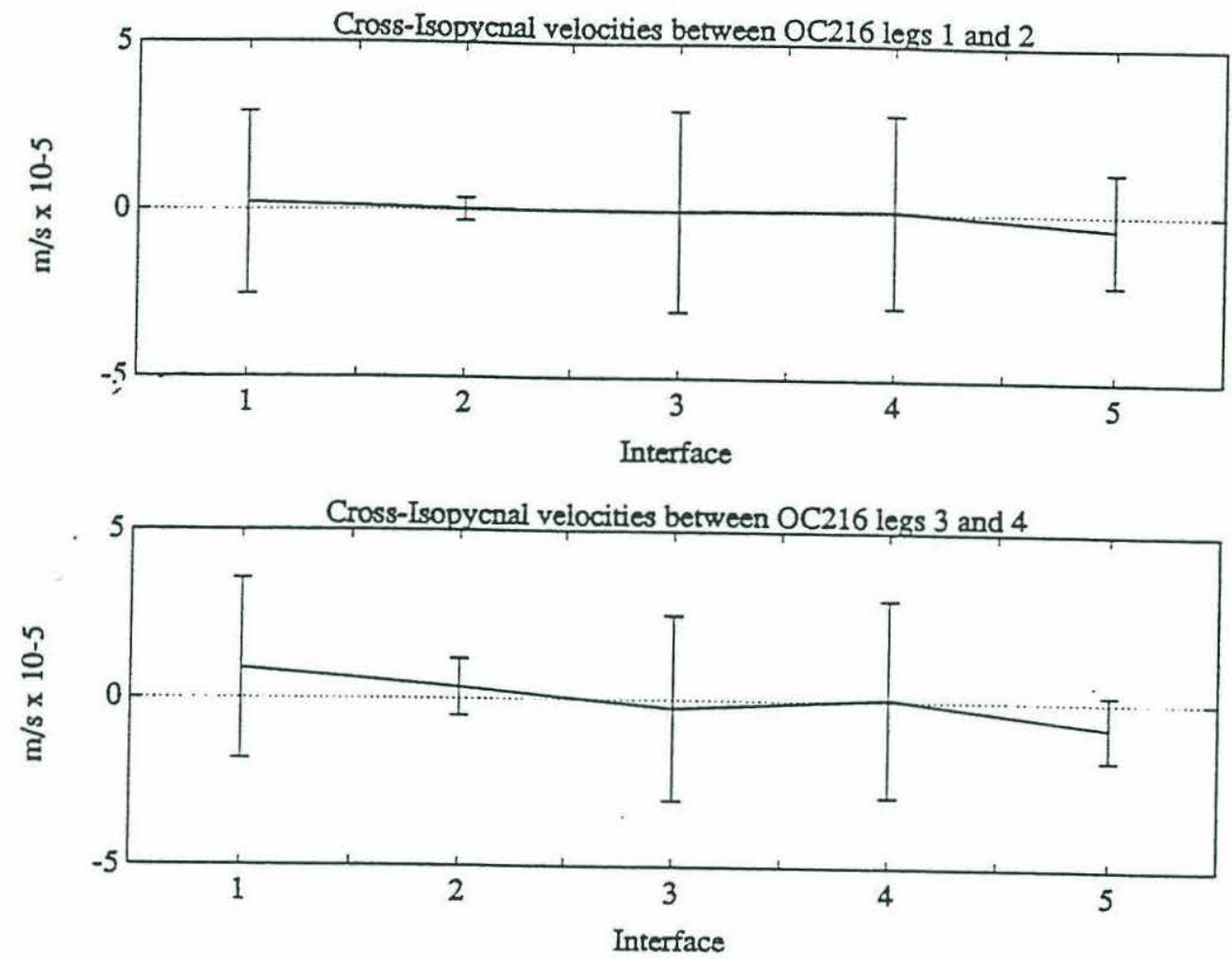

Figure 4.7. Cross-isopycnal velocities.

equation contributes .98 . This means that the layer and total mass transport balance equations are contributing nearly their maximum allowable contributions to the model, and that some of the reference velocity equations are not contributing. The results of the model for legs 3 and 4 are similar, with the 92 equations for the $q_{\mathrm{i}}$ contributing 83.1, the 6 layer balance equations contributing 5.91, and the total mass balance equation contributing .99 to the total rank of 90 .

The values of $w_{1}^{*}$ for the five interface areas between legs 1 and 2 and between legs 3 and 4 are plotted in Figure 4.7. Due to the small values and the lack of resolution, the error bars are large enough so that the values of $w_{1}^{*}$ are not statistically 
distinguishable from zero. The transport between layers due to these velocities is very small compared to the horizontal transports across the sections.

The resulting individual layer and total transports are given in Table 4.1. The difference between these values and the values given in chapter 3 are small, but the formal error in the transport calculations has been reduced from $\sim 5$ Sverdrups to less than $\sim 1$ Sverdrup for the transports. The total transports for each leg are $54.45 \pm .81 \mathrm{~Sv}$ for leg $1,54.67 \pm .32 \mathrm{~Sv}$ for $\operatorname{leg} 2,63.07 \pm .40 \mathrm{~Sv}$ for leg 3, and $62.39 \pm .62 \mathrm{~Sv}$ for leg 4 .

Plots of accumulated transport as a function of distance from the 200 meter isobath are given in Figure 4.8, comparing the results of the inverse model with the transports computed from the direct addition of reference velocity to the geostrophic profiles in chapter 3. Due to the small changes in the reference velocities, the changes in accumulated transport across the sections are quite small, but were enough to balance the overall transport between section 1 and 2 and between sections 3 and 4 to within 1 Sverdrup. 
Table 4.1. Transports for cruise OC216 from inverse model.

OC216 Layer and Total Section Transports

\begin{tabular}{|c|c|c|c|c||}
\hline \hline Layer & Leg 1 & Leg 2 & Leg 3 & Leg 4 \\
\hline 1 & 22.449 & 22.420 & 22.132 & 26.531 \\
\hline 2 & 9.554 & 10.869 & 14.355 & 12.864 \\
\hline 3 & 8.572 & 9.027 & 11.495 & 9.096 \\
\hline 4 & 7.033 & 6.816 & 8.880 & 7.717 \\
\hline 5 & 5.397 & 5.063 & 5.376 & 4.798 \\
\hline 6 & 5.063 & 0.476 & 0.833 & 1.388 \\
\hline Total & 54.451 & 54.670 & 63.071 & 62.393 \\
\hline
\end{tabular}

Rank 97 inverse solution for legs 1,2.

Rank 90 inverse solution for legs 3,4 .

Cross-isopycnal Transport

\begin{tabular}{|c|c|c|c|c||}
\hline \hline Interface & $w_{\mathrm{i}}^{*} 12$ & $\operatorname{Tran} 12$ & $w_{\mathrm{i}}^{*} 34$ & $\operatorname{Tran} 34$ \\
\hline 1 & 0.198 & 0.06 & 0.882 & 0.28 \\
\hline 2 & 0.032 & 0.01 & 0.343 & 0.11 \\
\hline 3 & -0.005 & -0.002 & -0.251 & -0.08 \\
\hline 4 & 0.056 & 0.005 & 0.059 & 0.006 \\
\hline 5 & -0.412 & -0.03 & -0.757 & -0.06 \\
\hline
\end{tabular}

$w_{\mathrm{i}}^{*}$ in $\mathrm{m} / \mathrm{s} \times 10^{-5}$

Transport in Sverdrups $\left(\mathrm{kg} / \mathrm{s} \times 10^{9}\right)$

Cross-isopycnal transports computed by multiplying the cross-isopycnal velocity $w_{i}^{*}$ by the area of the interface. 

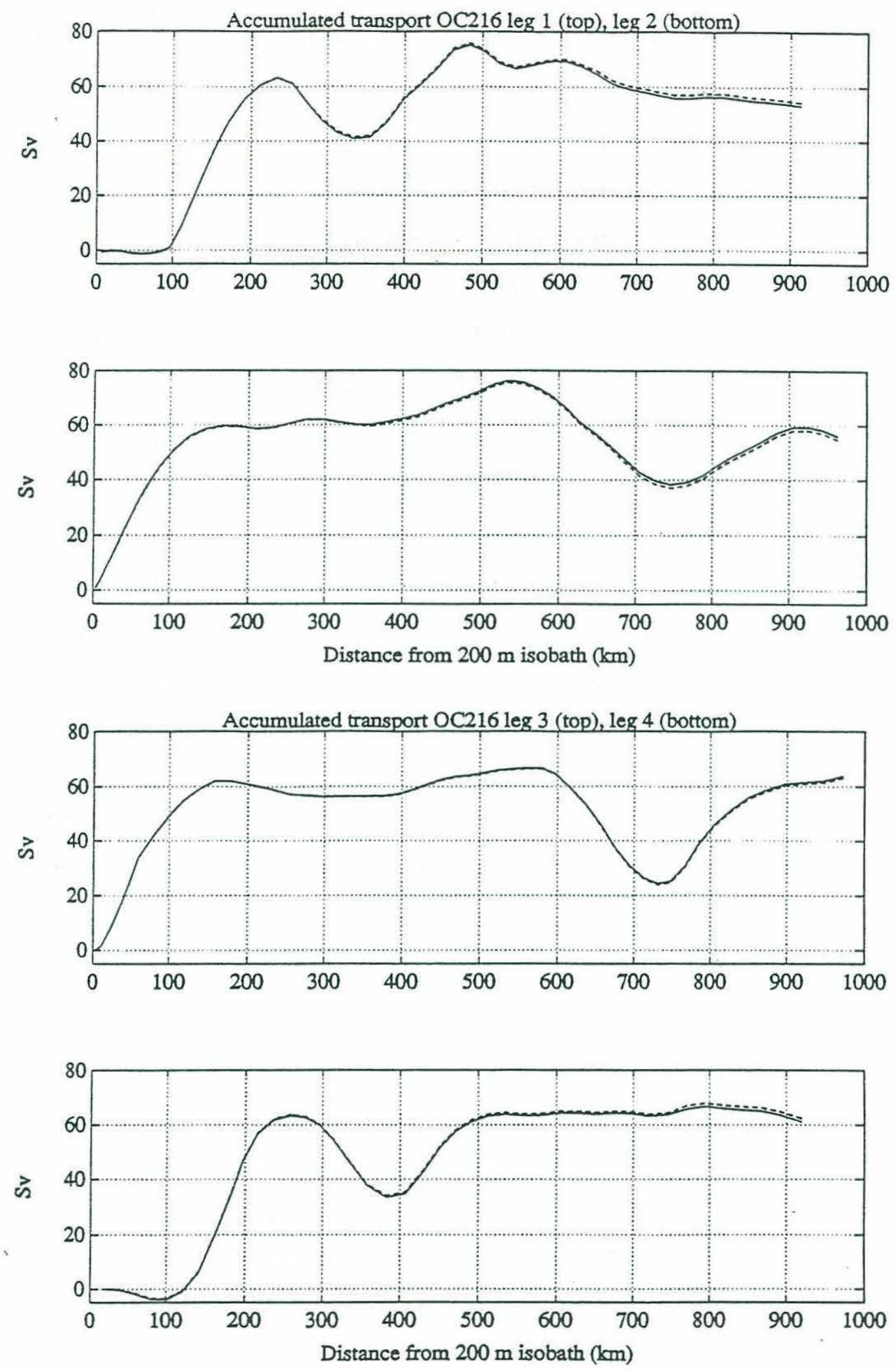

Figure 4.8. Transport as a function of distance for the four sections of cruise $0 \mathrm{C2} 216$. The solid lines are transports from direct combination of $\mathrm{ADCP}$ and geostrophic data. The dotted lines are the result of the inverse models. 


\subsection{Inverse Results for Cruise OC205}

The geometry of the April cruise allows us to balance the mass transport between three legs. For the center track between Bermuda and Cape Cod, the second transit (leg 4) was chosen to balance with legs 3 and 6 , since it is the leg closest in time to legs 3 and 6. In this model there is a set of equations balancing the flow in leg 3 with the flow in leg 4 , and another set of equations relating the flow in leg 4 to the flow in leg 6 . The unknowns in this case are the reference velocities $q_{i}$ for the three legs, and the crossisopycnal velocities $w_{i}^{*}$ for the areas between legs 3 and 4 and between legs 4 and 6 . The number of equations for this model is 166 , with 152 equations for the reference velocities, 12 individual layer balance equations ( 6 for the leg 3-6 balance, and 6 for the leg 4-6 balance), and 2 total section mass balance equations. The number of unknowns is 162 (152 reference velocities +10 cross-isopycnal velocities). The initial mass transports for this model are significantly more out of balance than the ones for the OC216 cruise. The row weighting was changed for this model, allowing an error in total transport of $\pm 7 \mathrm{~Sv}$, while holding the individual transports to $\pm 3 \mathrm{~Sv}$ for the top layer, $\pm 1.5 \mathrm{~Sv}$ for the second layer, and $\pm 1 \mathrm{~Sv}$ for the bottom 4 layers. As we will see when examining the $U_{k} U_{k}^{T}$ elements, this reduces the weight of the total transport equations. By evaluating the Levenberg-Marquardt diagram, the plot of eigenvalues vs. rank, and the plot of crossisopycnal velocity vs. rank, (Figure 4.9 and Figure 4.10 ), the optimum rank for the SVD of this model was chosen to be 152 .

Examining the resolution matrix (Figure 4.11), we find that the reference level velocities $q_{i}$ are nearly fully resolved, while the $w_{i}^{*}$ are essentially unresolved. The velocity corrections (Figure 4.12) are much larger than those seen in the OC216 models. In order to balance the transports, the model has added additional bias to each leg, as well as changing individual velocities. The the mean values of the velocity corrections in

Figure 4.12 are $-1.23 \mathrm{~cm} / \mathrm{s}$ for leg $3,-.32 \mathrm{~cm} / \mathrm{s}$ for leg 4 , and $+.85 \mathrm{~cm} / \mathrm{s}$ for leg 6 . Examining the values of $w_{\mathrm{i}}^{*}$ (Figure 4.13), we find that since the cross-isopycnal velocities 


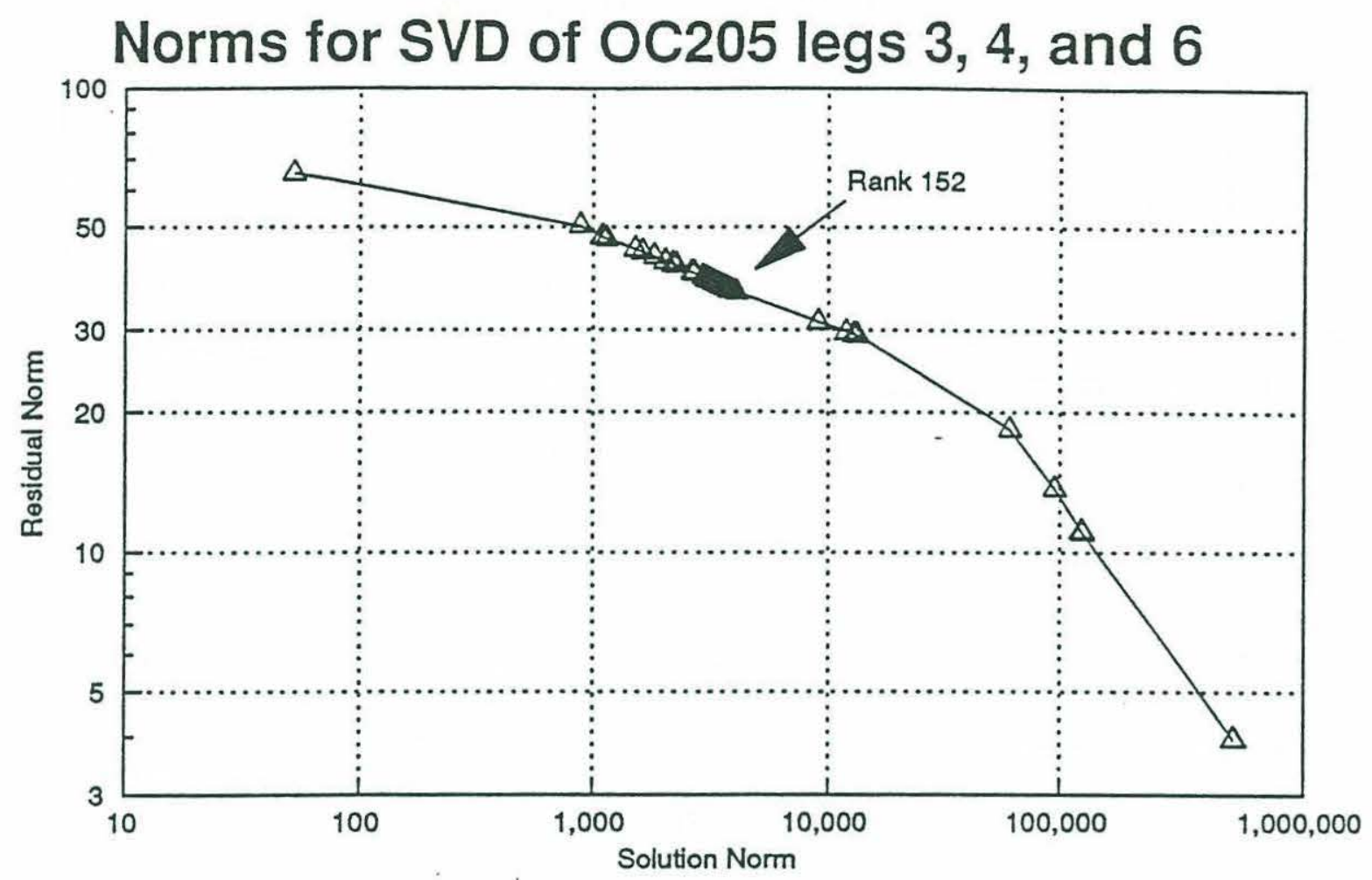

Eigenvalues for SVD of OC205 legs 3, 4, and 6

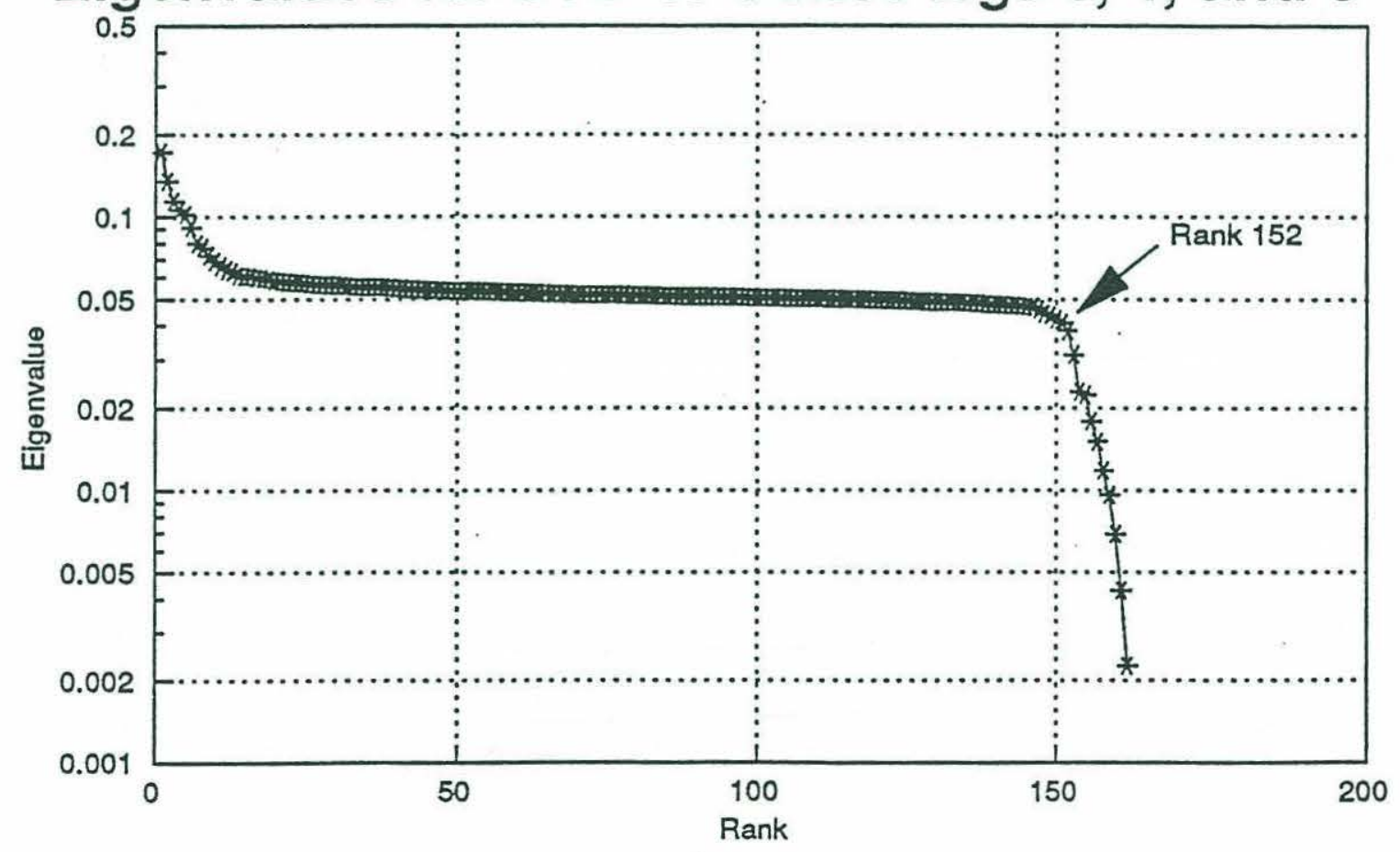

Figure 4.9. (a) Levenberg-Marquardt diagram for 3 leg inversion model for cruise 0C205. (b) Plot of eigenvalue magnitude vs. rank for the same model. 

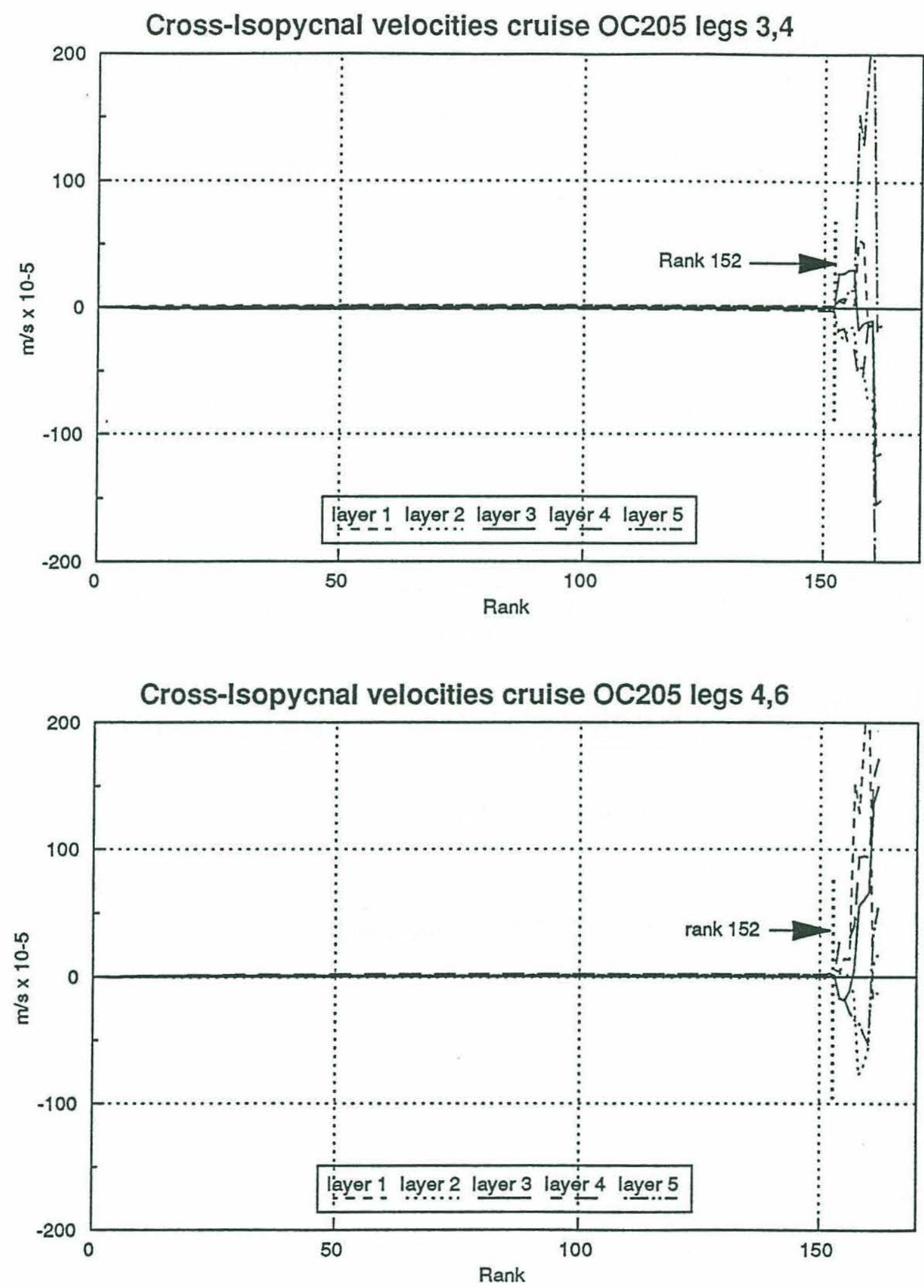

Figure 4.10. Cross-isopycnal velocities vs. rank. 




Figure 4.11. Diagonal elements of resolution matrix $\mathrm{V}_{\mathbf{k}} \mathrm{V}_{\mathrm{k}}^{\mathrm{r}}$ for Rank 152 .

have not been well resolved, the error bars are much larger than the velocities themselves. The $w_{i}^{*}$ are therefore indistinguishable from zero.

The diagonal elements of $\mathrm{U}_{\mathbf{k}} \mathrm{U}_{\mathbf{k}}^{\mathrm{T}}$ show that the contribution of the equations to the solution is different from the OC216 model. The 152 reference velocity equations contribute 147.94, the 12 equations for the layer transports (six for legs $3-4$, six for legs 4-6) contribute 3.60 , and the two total mass balance equations contribute .46 to the rank of 152 . In this case, little weight was put on the total mass balance equations due to the large errors allowed for these equations. The individual layer equations also contribute only fractionally to the solution, with most of the rank coming from the reference velocity equations.

The individual layer and total transports for the inverse rank 152 solution are summarized in Table 4.2. Despite the low weight on the total transport constraint, the model has lowered the total transport differences to 4 Sv. between legs 3 and 4 and 2 Sv. between legs 4 and 6 . The total transports are now $54.56 \pm 1.3 \mathrm{~Sv}$. for leg 3, $50.7 \pm .87$ Sv. for leg 4 , and $49.69 \pm 1.29 \mathrm{~Sv}$. for leg 6 . The cross-isopycnal velocities are of order $10^{-5} \mathrm{~m} / \mathrm{s}$, which is an order of magnitude higher than seen in the OC216 solutions, but 



Figure 4.12. Velocity corrections for cruise OC205 Rank 152. Error bars include error due to noise, and error due to failure to fully resolve.

still small enough that cross-isopycnal velocity causes only small changes of order $.5 \mathrm{~Sv}$ in layer transport between legs. 

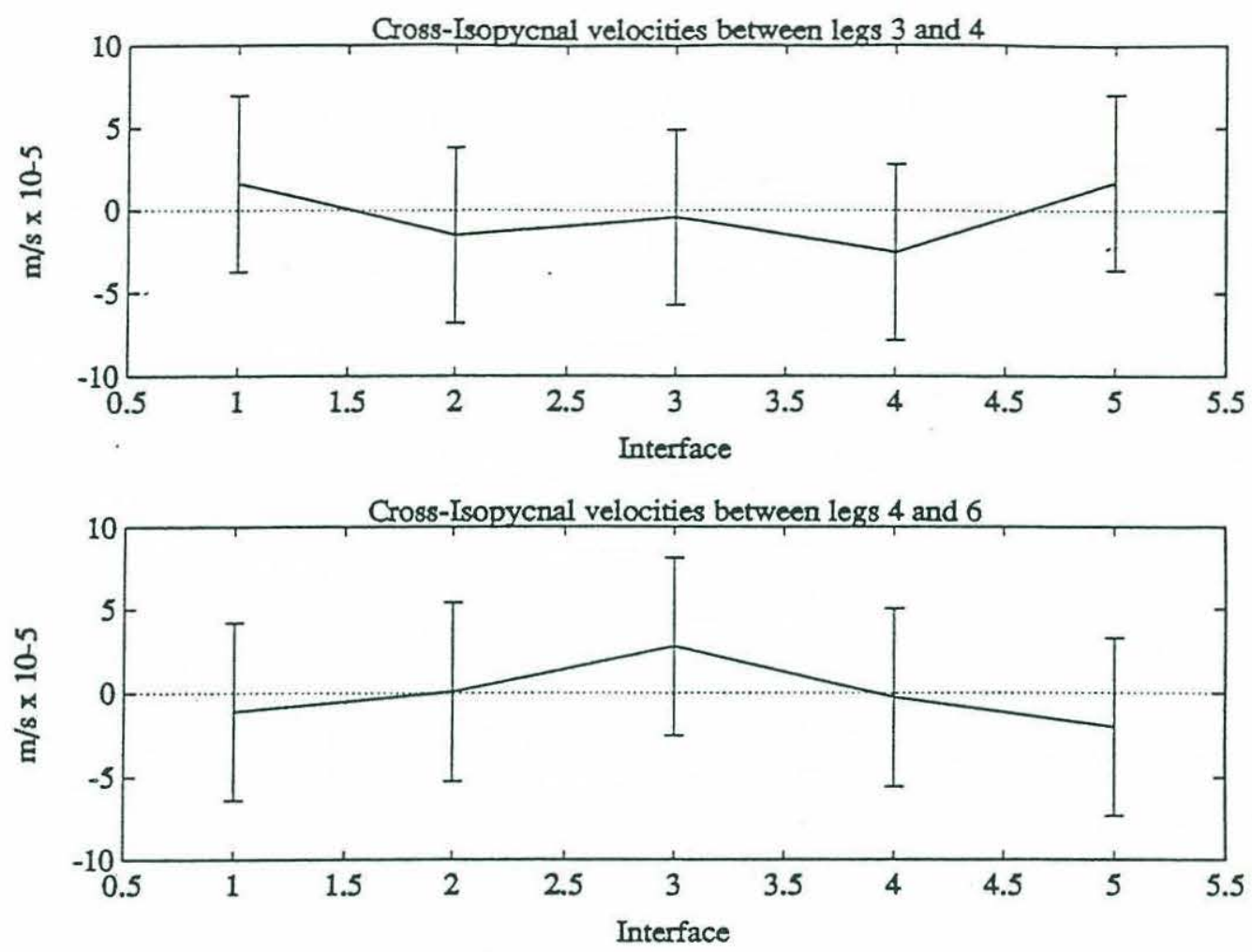

Figure 4.13. Cross-isopycnal velocities cruise OC205 rank 152.

The transports calculated from the inverse model are shown compared with the transports calculated in chapter 3 in Figure 4.14. The changes in transport introduced by the inverse solution are significantly larger than those produced for the OC216 cruise, since the initial transports had much larger differences than the inputs to the OC216 model. Leg 4 required the smallest amount of change, which is not surprising, since its transport was initially between the other two legs. The transport for leg 3 has been - reduced, and the transport for leg 6 increased to more nearly match leg 4 . The variability of the transport near Bermuda can be seen by plotting the transports of the three legs vs. distance from the Bermuda vertex (Figure 4.15). The tracks diverge with distance from Bermuda, but might all be expected to have the same type of transport change with distance near the point where the tracks meet. We can see that this is not the case, indicating the currents near Bermuda have changed during the time between legs. 
Table 4.2. Transports for cruise OC205 legs 3, 4, and 6 from inverse model.

\section{OC205 Layer and Total Section Transports}

\begin{tabular}{|c|c|c|c||}
\hline Layer & Leg 3 & Leg 4 & Leg 6 \\
\hline 1 & 22.36 & 17.48 & 16.53 \\
\hline 2 & 12.70 & 10.02 & 7.93 \\
\hline 3 & 8.62 & 10.40 & 10.04 \\
\hline 4 & 8.08 & 8.19 & 10.34 \\
\hline 5 & 2.49 & 5.35 & 6.19 \\
\hline 6 & 0.31 & -0.74 & -1.33 \\
\hline Total & 54.56 & 50.70 & 49.69 \\
\hline
\end{tabular}

Inverse model rank 152

Transports in Sverdrups $\left(\mathrm{kg} / \mathrm{s} \times 10^{-9}\right)$

Cross-Isopycnal Transport

\begin{tabular}{|c|c|c|c|c||}
\hline \hline Interface & $w_{\mathrm{i}}^{*} 34$ & $\operatorname{Tran} 34$ & $w_{\mathrm{i}}^{*} 46$ & $\operatorname{Tran} 46$ \\
\hline 1 & 1.62 & 0.59 & -1.10 & -0.21 \\
\hline 2 & -1.51 & -0.55 & 0.07 & 0.01 \\
\hline 3 & -0.42 & -0.15 & 2.80 & 0.54 \\
\hline 4 & -2.54 & -0.50 & -0.27 & -0.04 \\
\hline 5 & 1.69 & 0.20 & -2.02 & -0.21 \\
\hline
\end{tabular}

$w_{i}^{*}$ in $\mathrm{m} / \mathrm{s} \times 10^{-5}$

Transports in Sverdrups $\left(\mathrm{kg} / \mathrm{s} \times 10^{-9}\right)$

Cross-isopycnal transports computed by multiplying $w_{1}^{*}$ by the interface area. 

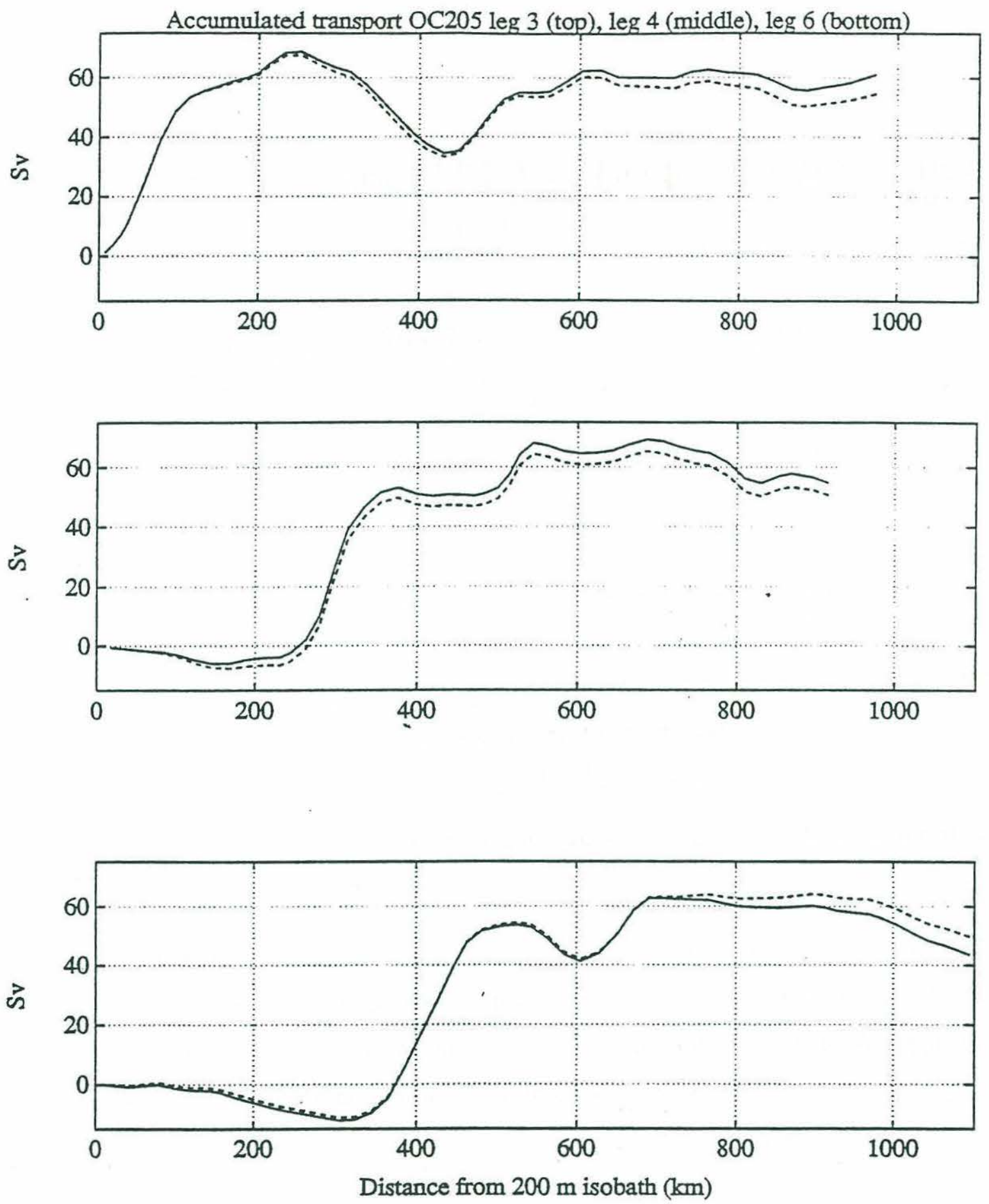

Figure 4.14. Transport as a function of distance for $0 C 205$ legs 3,4 , and 6 . The solid lines are transport from direct combination of $\mathrm{ADCP}$ and geostrophic data from chapter 3. The dotted lines are the result of the inyerse model. 


\section{Accumulated Transports OC205 legs 3, 4, and 6}

Inverse solution rank 152

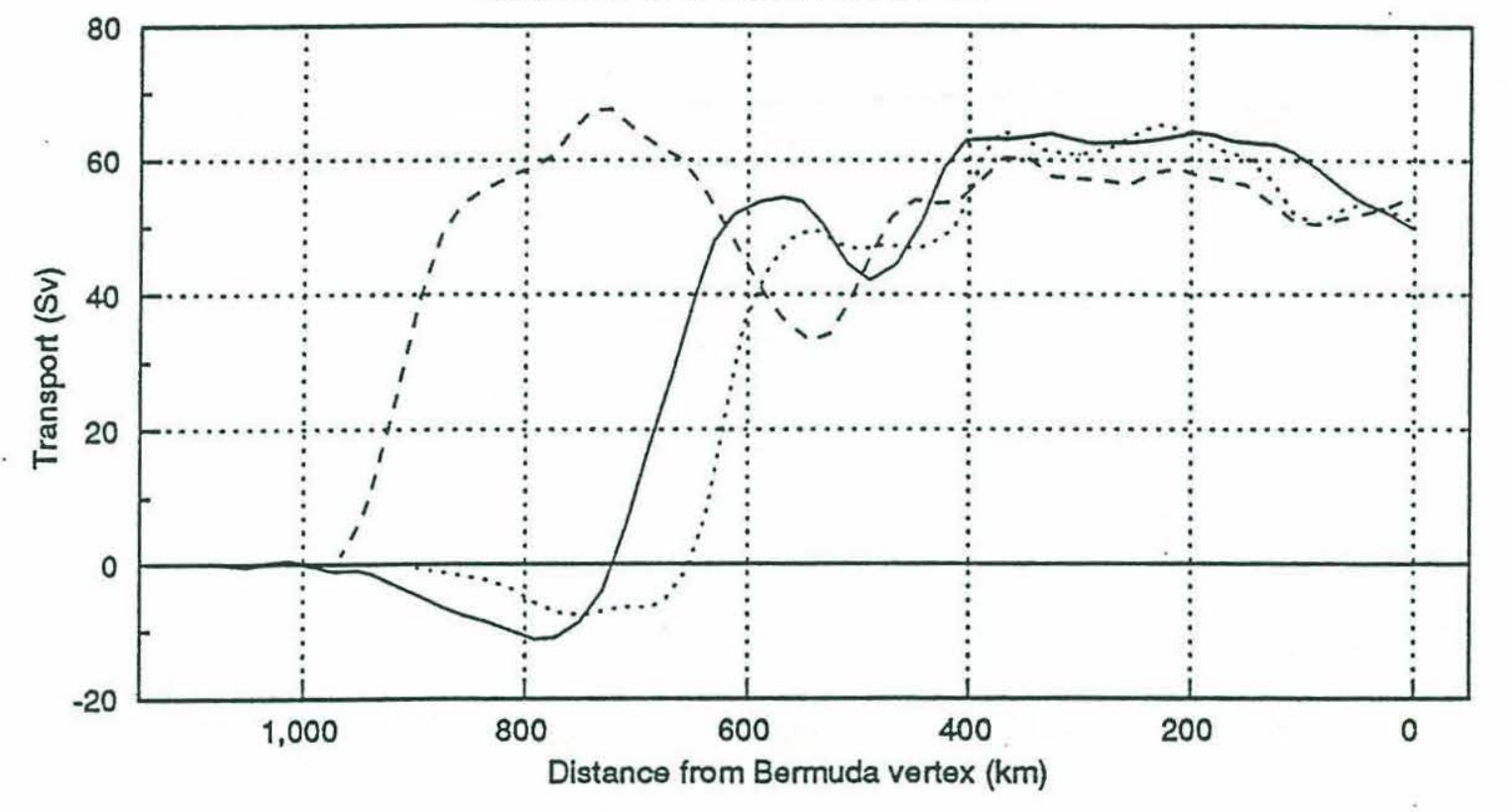

Leg 3 . Leg 4 Leg 6

Figure 4.15. Transports 0 C205 legs 3, 4, and 6 vs. distance from Bermuda.

This graph also illustrates the change in the Gulf Stream transport as it moves downstream. The sharp rise in transport from the Gulf Stream provides approximately $55 \mathrm{~Sv}$. in the upper 765 meters for both legs 3 and 4, but has increased to 65 Sv. by leg 6. These estimates are very sensitive to the definition of what portion of the sections constitutes the "Gulf Stream". 


\section{Chapter 5}

\section{Temporal Variability between Bermuda and Cape Cod}

\subsection{Gulf Stream Variability}

The Acoustic Doppler Current Profiler (ADCP) allows us to compare velocity profiles computed using the dynamic method to directly measured velocity profiles. Since it measures both horizontal components of velocity, we can also directly calculate several of the terms in the horizontal momentum equations which are neglected when using the geostrophic approximation.

The Altimeter track between Bermuda and Cape Cod was traversed three times during the OC205 cruise, and twice during the OC216 cruise. By examining the ADCP velocities for the different legs along with $A V H R R$ sea surface temperature images, we can see how the Gulf Stream is changing during the cruises. During the April cruise, OC205, the Gulf Stream moved to the south and underwent a rotation in the clockwise direction during the cruise, due to the trough of a meander which crossed the track during the cruise. This rotation is seen in the 100 meter doppler vectors for the three tracks (Figure 5.1). The position of the meander relative to the track on various days can be seen in the AVHRR images (Figure 5.2). During the December cruise (OC216), a small southward shift in the position of the Gulf Stream was observed between legs 1 and 4, 


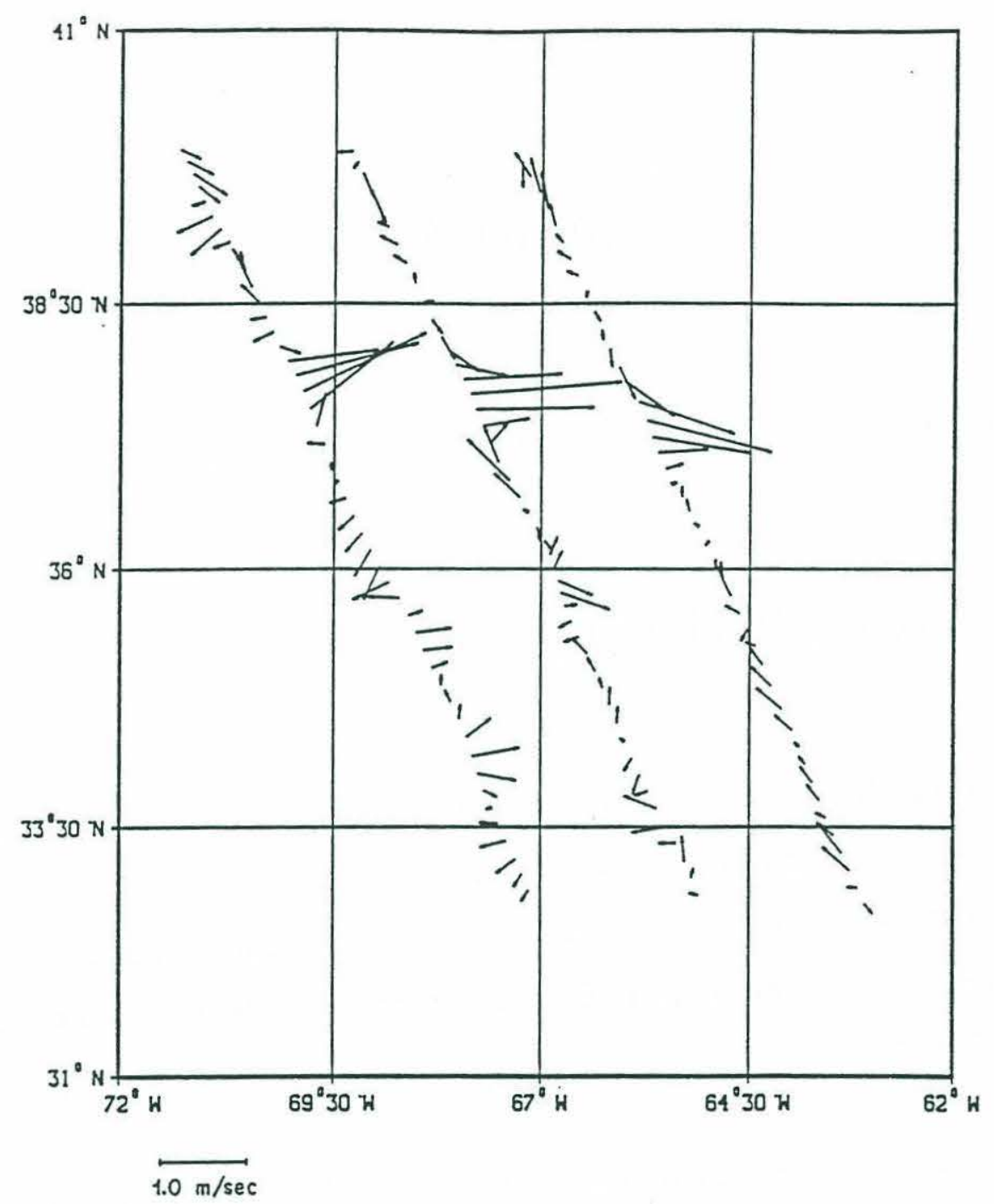

Figure 5.1. ADCP velocities at 100 meters depth, cruise $0 C 205$ legs 1,4 , and 7 . Leg 1 has been moved $2^{\circ}$ west, leg 7 has been moved $2^{\circ}$ east.

and additional variability was observed from a large cold-core ring which moved across the track (Figure 5.3). Unfortunately, due to heavy cloud cover, no AVHRR images of the sea surface are available for the December cruise. 


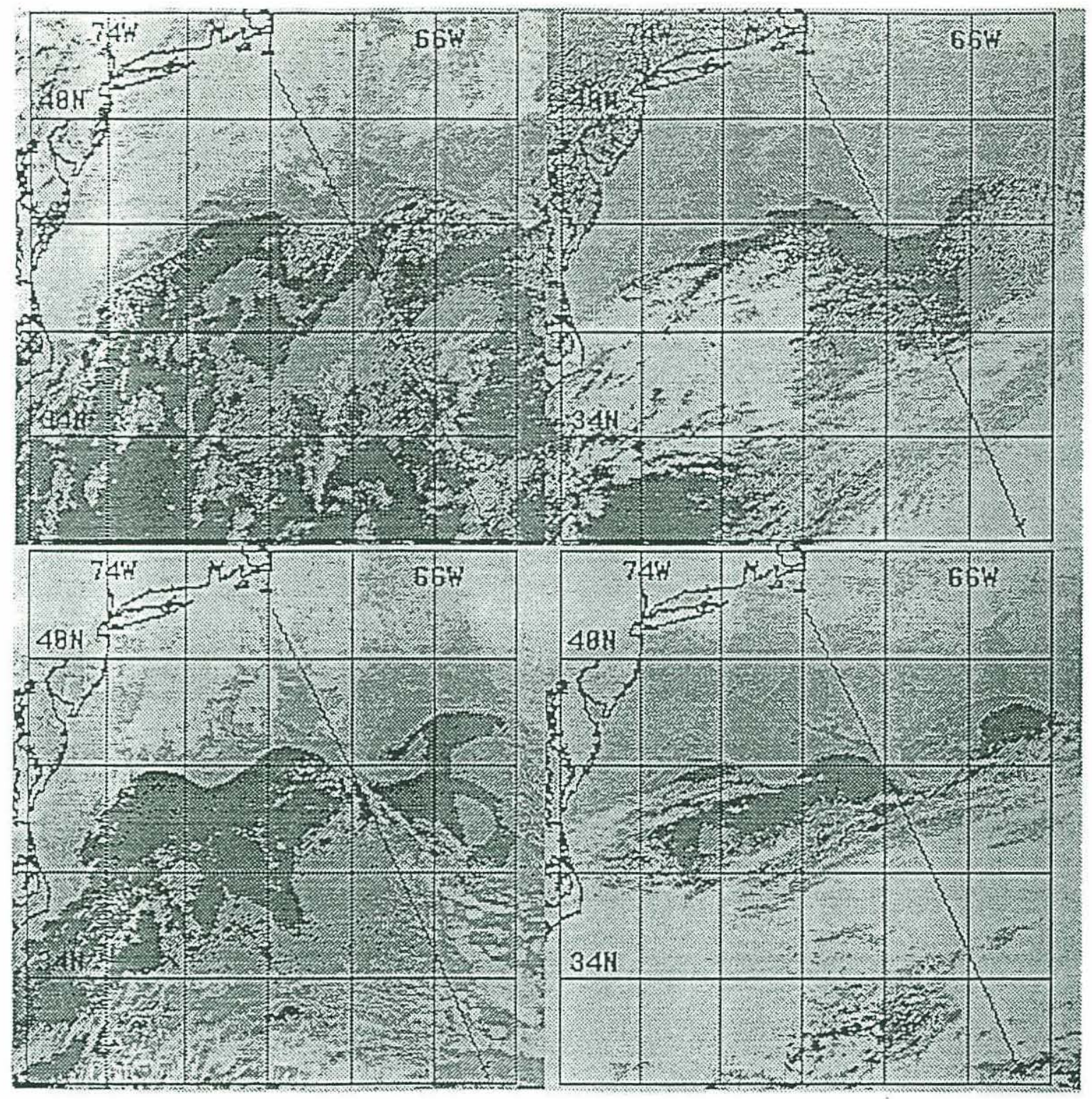

Figure 5.2. Infrared AVHRR images for days 94 (upper left), 102 (upper right), 108 (lower left), and 111 (lower right), with GEOSAT track. 


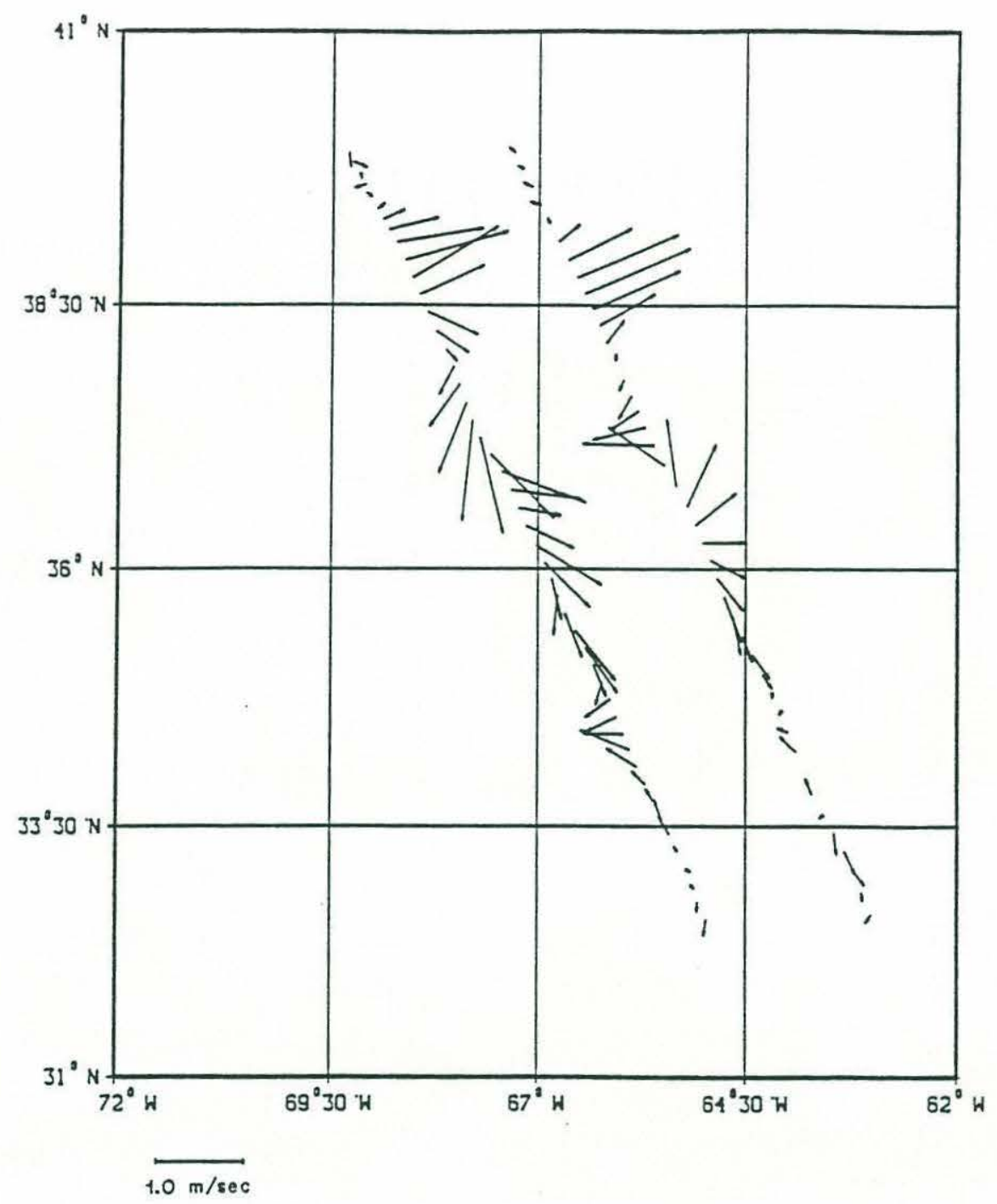

Figure 5.3. $A D C P$ velocities at 100 meters depth for cruise $O C 216$ legs 1 and 4 . Leg 4 has been shifted $2^{\circ}$ east.

\subsection{Ageostrophic effects}

The multiple crossings allow us to evaluate time as well as space derivatives of velocity along the Cape Cod-Bermuda track. Velocities and their derivatives were measured in a rotated coordinate system, where $\mathrm{x}$ is the across-track direction, and $\mathrm{y}$ is the along track direction. Velocity in the $\mathrm{x}$ direction is $u$ (positive to the Northeast) and 
velocity in the $\mathrm{y}$ direction is $v$ (positive to the Northwest). The y direction (ship's heading) is $334^{\circ}$.

The horizontal momentum equations in the rotated coordinate system are:

$$
\begin{aligned}
& u_{t}+u u_{x}+v u_{y}+w u_{z}-f v=-P_{x} \\
& v_{t}+u v_{x}+v v_{y}+w v_{z}+f u=-P_{y}
\end{aligned}
$$

In order to examine the terms in the equations at the same points in space, the $A D C P$ vectors were filtered onto a straight line track using a Gaussian filter with a filter half-width of $10 \mathrm{~km}$. A filtered velocity vector was generated every $10.2 \mathrm{~km}$ between $32^{\circ}-30^{\prime} \mathrm{N}$ and $40^{\circ} \mathrm{N}$. Local time derivatives were generated for each point by taking the difference in $u$ and $v$ between legs and dividing by the time between measurements. Spatial derivatives were obtained at the same points as the time derivatives using a centered difference scheme.

Spatial derivatives are only directly measurable in the along track direction. A quasi-geostrophic approximation (c.f. Pedlosky, 1979) can be used to justify neglect of the vertical velocity in the advection of horizontal momentum and in the divergence equation. However, in the Gulf Stream, vertical velocities can be quite large. Bower (1989) has shown that vertical velocity can be related to vorticity changes following a "Lagrangian" RAFOS float. Using the continuity equation, it is possible to estimate $u_{\mathrm{x}}$.

$$
u_{x}=-v_{y}-w_{z} \approx-v_{y}
$$

This approximation is justified (Joyce, Kelly, Schubert, and Caruso, 1990) using values for $w_{z}$ in the Gulf Stream of $10^{-6} \mathrm{~s}^{-1}$ from Bower and using measured values for $v_{y}$.

$$
\left[w_{z}\right] /\left[v_{y}\right]=10^{-6} / 10^{-5}=0.1
$$


The vertical advection term can also be shown to be small, using values for $w$ of $5 \times 10^{-4}$ $\mathrm{m} / \mathrm{s}$ from Bower and measured values for the remaining terms.

$$
\left[\mathrm{wu}_{\mathrm{z}}\right] /\left[\mathrm{vu}_{\mathrm{y}}\right]=2 \times 10^{-6} / 10^{-5}=0.2
$$

Using the above scaling, equation (1) can be rewritten as

$$
u_{t}+v u_{y}-u v_{y}-f v=-P_{x}-w u_{z}+u w_{z}
$$

where all the terms on the left-hand side can be directly measured, and the terms involving $w$ on the right-hand side are small.

During the last leg of cruise OC216, a short section was made perpendicular to the ship track. This allowed measurement of derivatives in the $\mathrm{x}$ direction, providing an opportunity to check the above scaling arguments at one point in the Gulf Stream. The cross-track was approximately $90 \mathrm{~km}$ long, and crossed the satellite track about five $\mathrm{km}$ south of the peak velocity point of the satellite track. At the point where the two tracks cross, a comparison can be made of $u_{x}$ and $v_{y}$. Using the same Gaussian filter described previously, the three values of $u_{\mathrm{x}}$ and $v_{\mathrm{y}}$ closest to the crossing point have been averaged at $50,100,150$, and 200 meters. The value of $w_{z}$ at each of these depths has been computed using the continuity equation. These values with standard deviations are tabulated in Table 5.1. 
Table 5.1. Velocity derivatives in the continuity equation.

\begin{tabular}{|c|c|c|c|c|c|c||}
\hline \hline Depth & $\mathrm{u}_{\mathrm{x}}$ & $\sigma_{\mathrm{x}}$ & $\mathrm{v}_{\mathrm{y}}$ & $\sigma_{\mathrm{y}}$ & $\mathrm{w}_{\mathrm{z}}$ & $\sigma_{\mathrm{z}}$ \\
\hline 50 & -1.239 & 2.442 & -5.015 & 1.568 & 6.254 & 2.902 \\
\hline 100 & 0.193 & 1.750 & -1.031 & 1.790 & 0.838 & 2.503 \\
\hline 150 & -1.734 & 2.819 & 0.005 & 1.642 & 1.729 & 3.262 \\
\hline 200 & 0.021 & 3.629 & -1.239 & 2.918 & 1.260 & 4.657 \\
\hline \hline
\end{tabular}

Depths are in meters, derivatives in $\mathrm{s}^{-1} \times 10^{-6}$.

Standard deviations in $\mathrm{x}$ and $\mathrm{y}$ directions are of the three data points closest to the point where the tracks cross.

$\sigma_{z}=\left(\sigma_{x}^{2}+\sigma_{y}^{2}\right)^{h}$

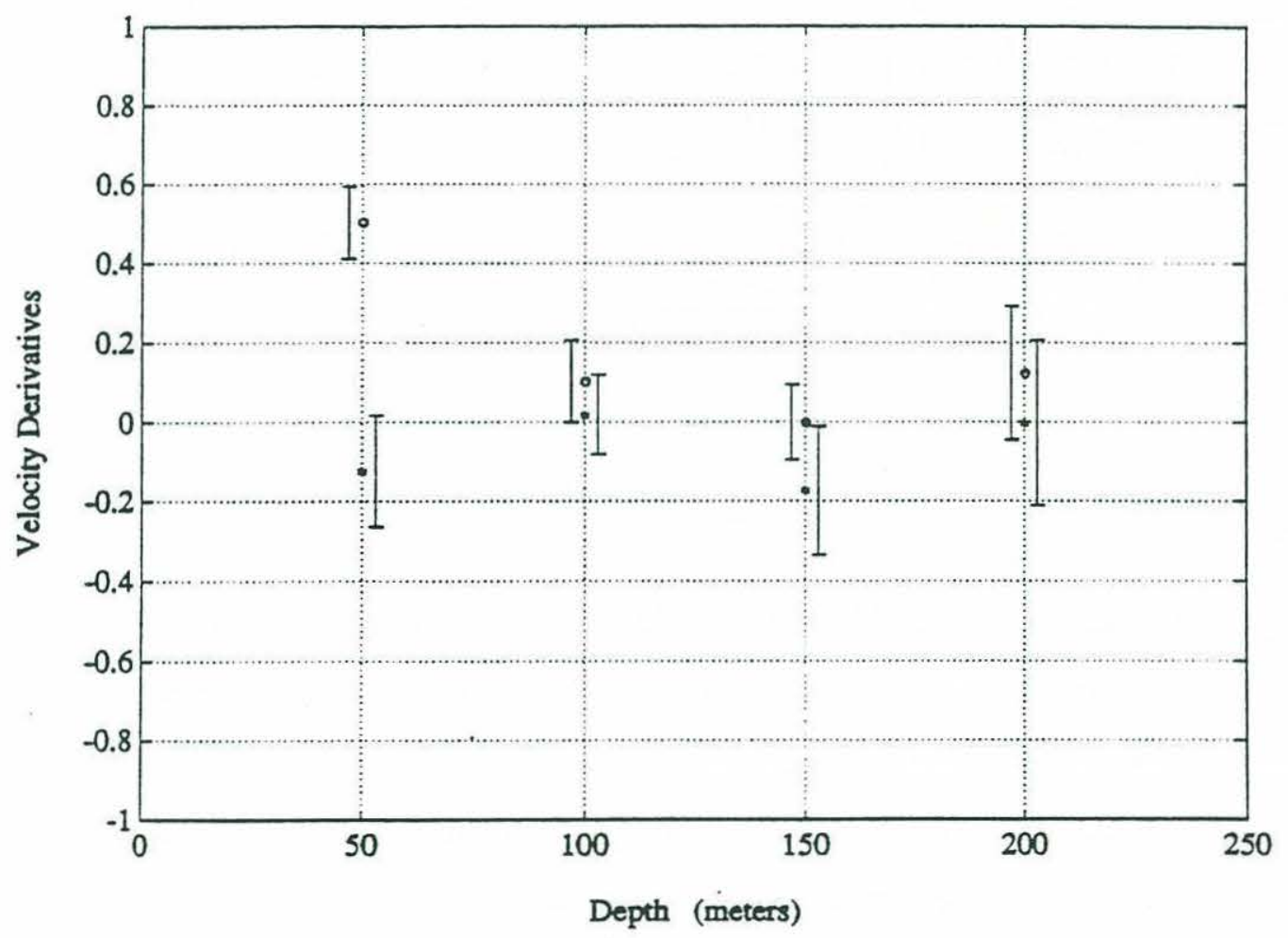

Figure 5.4. Velocity derivatives $\partial \mathrm{u} / \partial \mathrm{x}\left({ }^{*}\right)$ and $-\partial \mathrm{v} / \partial \mathrm{y}(0)$ at various depths. $\left(\sec ^{-1} \times 10^{-5}\right)$ 
Values of $u_{x}$ and $-v_{y}$ are plotted with error bars in Figure 5.4. For the 100 to 200 meter values, the difference between the values of $u_{x}$ and $-v_{y}$ falls within the error bars. There is a large difference between the terms at 50 meters, indicating that $w_{z}$ is measurably different from zero at shallow depths. This agrees with Bower's finding that $w_{z}$ tends to have larger values at shallower density surfaces.

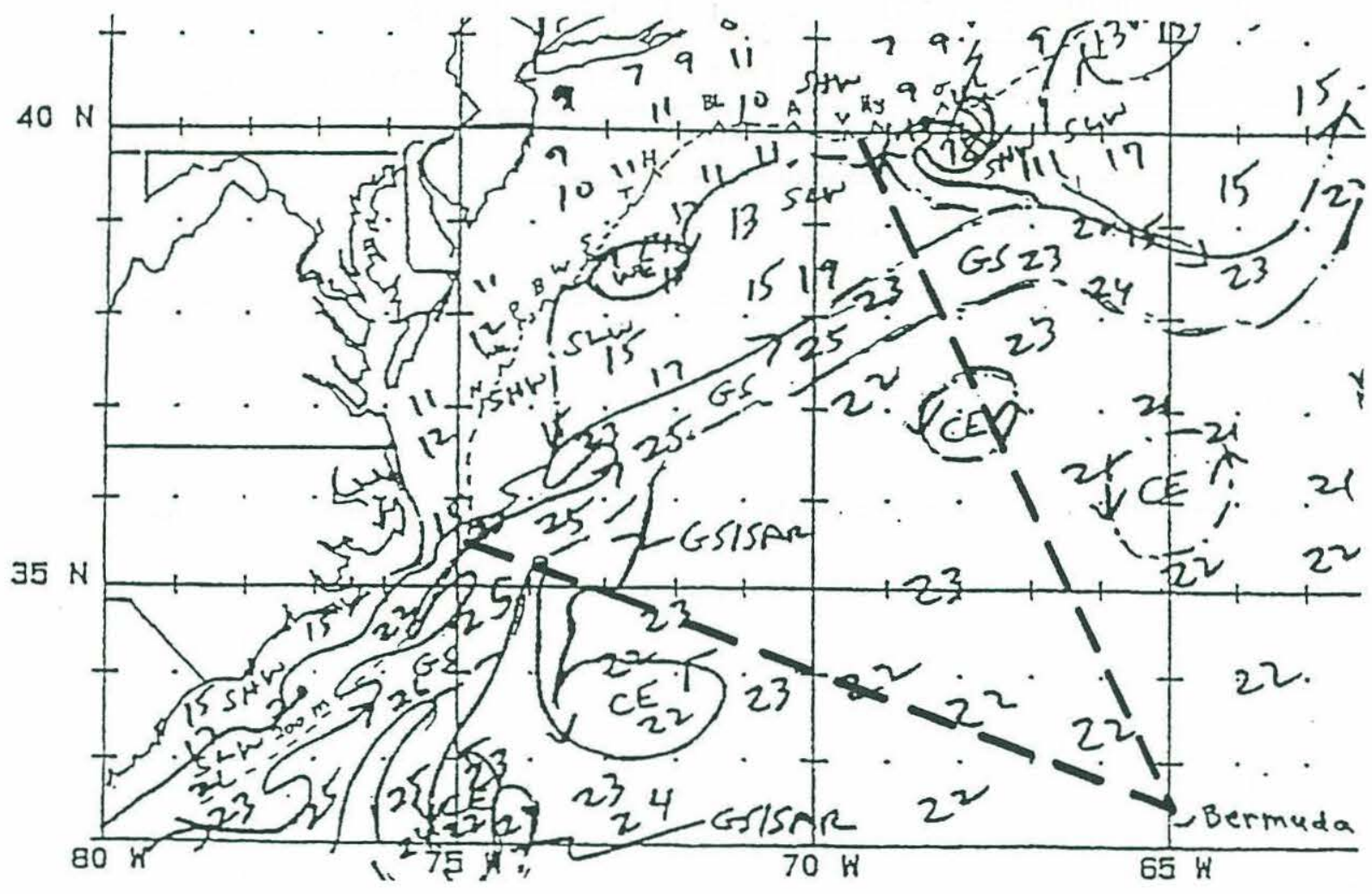

Figure 5.5. NOAA Oceanographic Analysis Chart dated 11 Dec 1989. The ship's tracks have been added as heavy dashed lines. The Gulf Stream is indicated by "GS'.

The positive value of $w_{z}$ at 50 meters indicates a horizontal divergence, which Bower found to occur in the right side of the stream when downstream of a trough, and on the left side of the stream when downstream of a meander crest. Our perpendicular section crossed the track to the south of the peak in Gulf Stream velocity, indicating that our data point for $w_{z}$ is in the right side of the stream, and therefore are downstream of a trough: There are no AVHRR images available to confirm the orientation of the Gulf 
Stream, however the weekly NOAA/National Ocean Service weekly Oceanographic analysis chart dated 11 Dec 1989 (Figure 5.5) indicates that the Gulf Stream upstream of the ship's track is relatively straight, unlike the situation in the April cruise.

Using the value of $w_{z}$ at 50 meters and assuming that $w=0$ at the surface, we can estimate the value of $w$ at 50 meters in the Gulf Stream.

$$
w_{s 0}=\frac{\partial w}{\partial z} \delta z=\left(6.254 \times 10^{-G}\right)(-50)=-3.1 \times 10^{-4} \mathrm{~m} / \mathrm{s}
$$

Actual measured values of $w$ in the Gulf Stream are of order $8 \times 10^{-4} \mathrm{~m} / \mathrm{s} \mathrm{rms}$ (Bower and Rossby, 1989) at depths between 300 and 700 meters. Our computed velocity is smaller than these values, but is measured at a much shallower depth.

If the sign of $w_{z}$ remains positive (although decreasing) with depth, the magnitude of $w$ would increase with depth. Hall (1986) estimates this depth of maximum $w$ to be 875 meters, based on estimates of vertical velocity at a moored current meter site. The above data do not support approximating $u_{x}$ by $-v_{y}$, since $w_{z}$ is of the same order of magnitude as the other terms. It is accurate to say that $u_{x}$ will be of the same order of magnitude as $v_{y}$ when deciding which terms to neglect in the momentum equations.

A clear picture of the relative magnitudes of the terms of the momentum equations can be made by simply graphing all of the measurable terms. Figure 5.6 contains graphs of the momentum equation terms at 100 and 200 meters for cruise OC205. The momentum equation terms for cruise OC216 at 50,100, 150, and 200 meters are shown in Figure 5.7. In each plot, the terms are average values for the crossings conducted on that cruise; three crossings for the first cruise, and two for the second cruise. The curves change little with depth, indicating that $u_{z}$ and $v_{z}$ are small. 

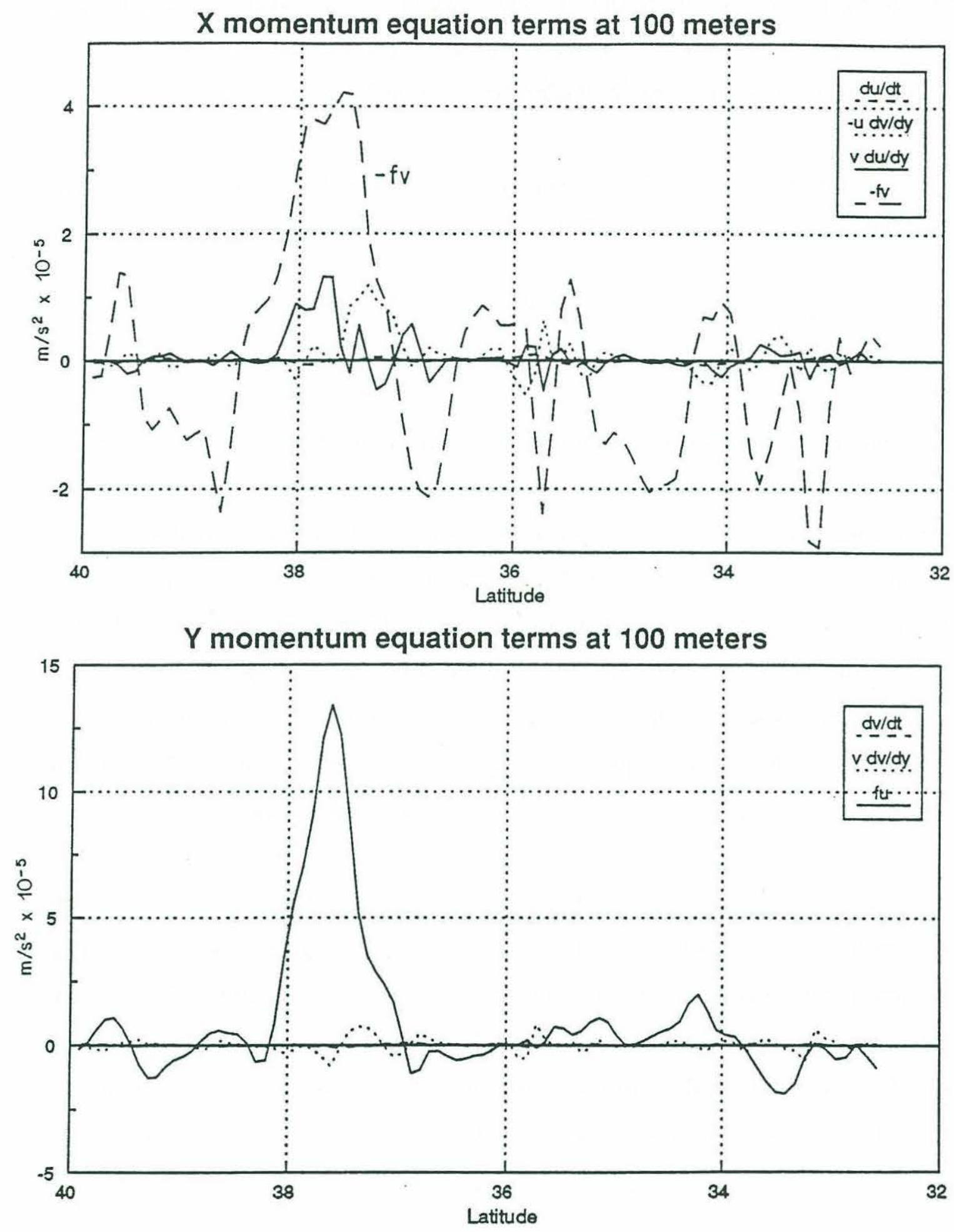

Figure 5.6. Momentum equation terms for cruise OC205. 

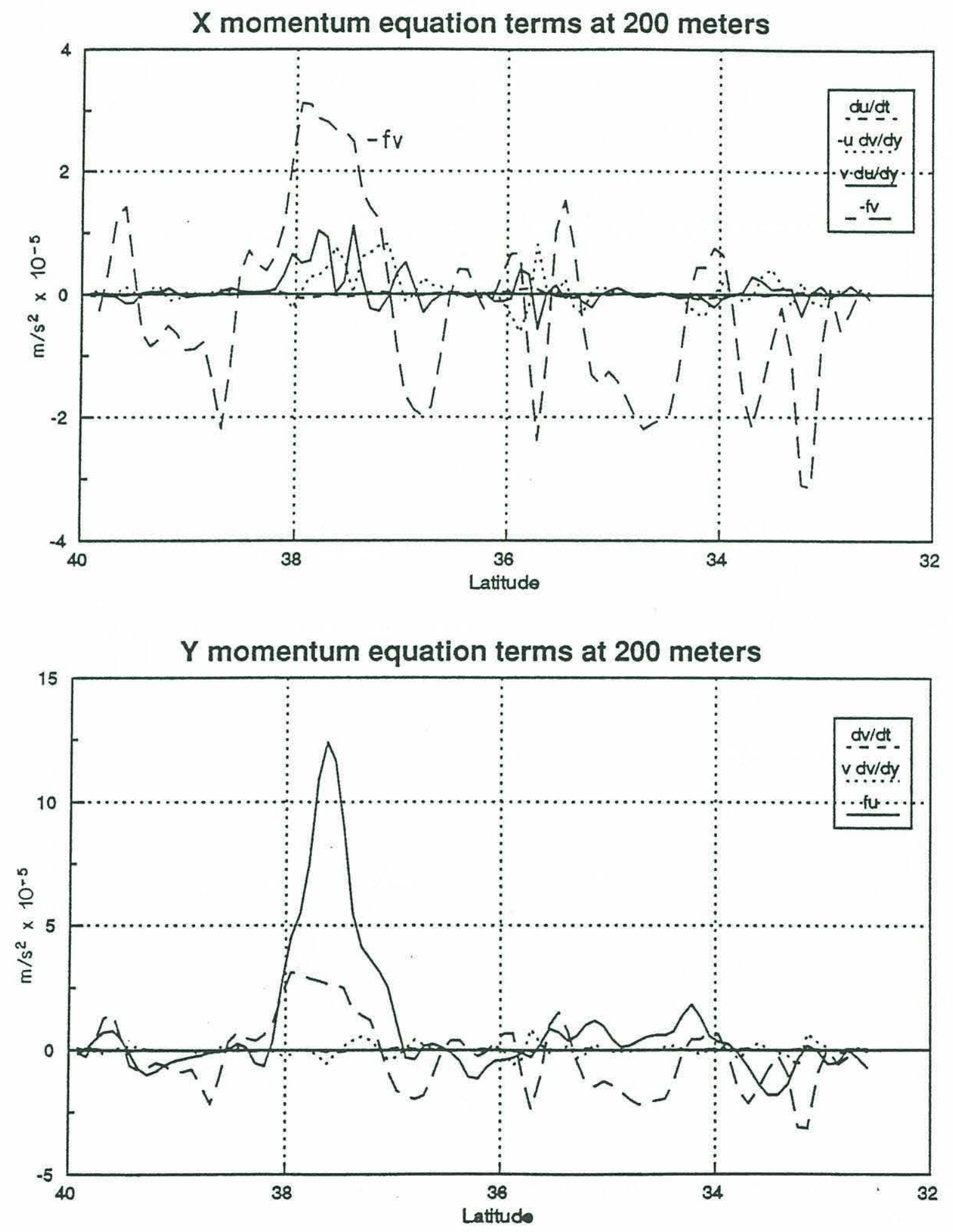

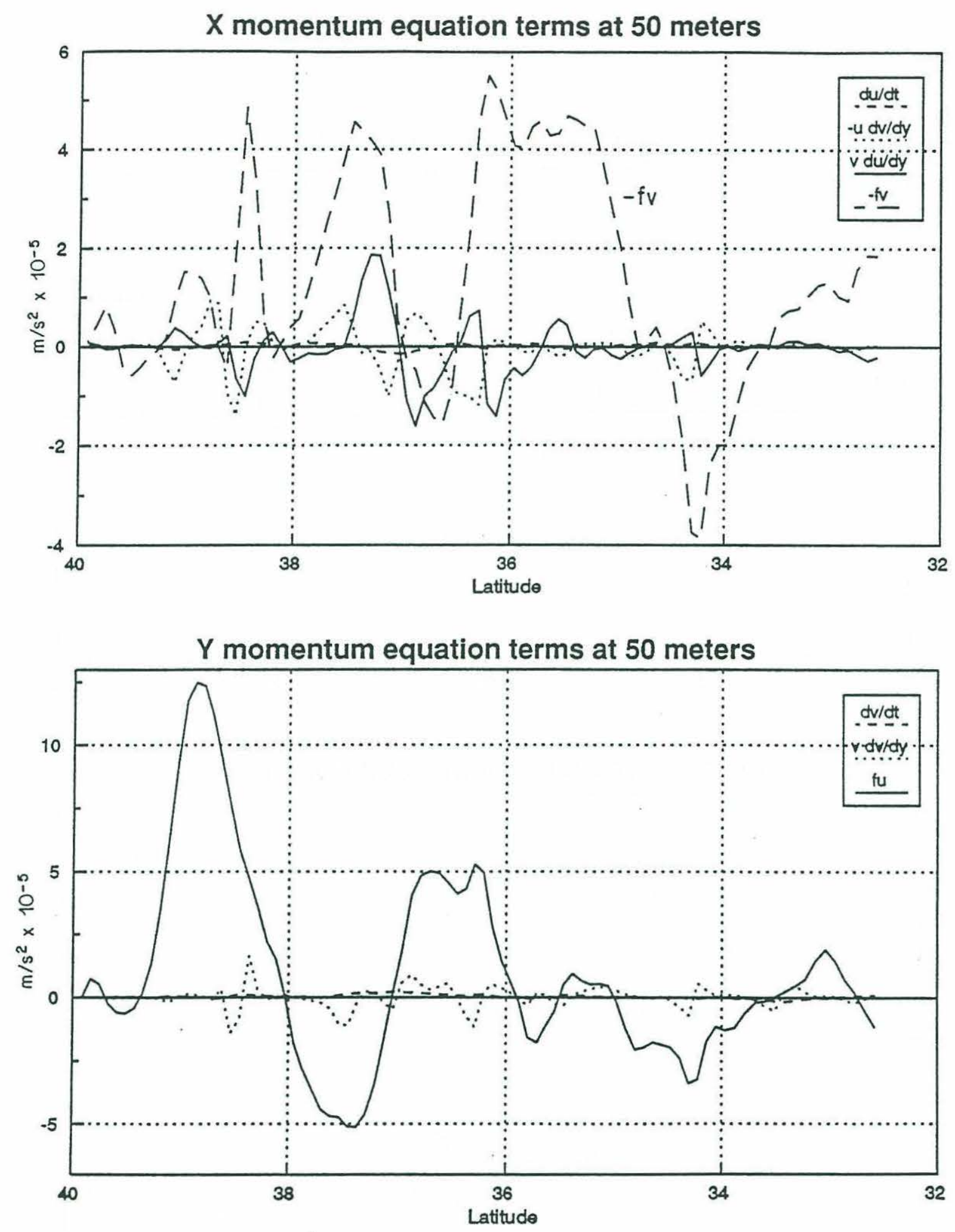

Figure 5.7. Momentum equation terms for cruise OC216. 

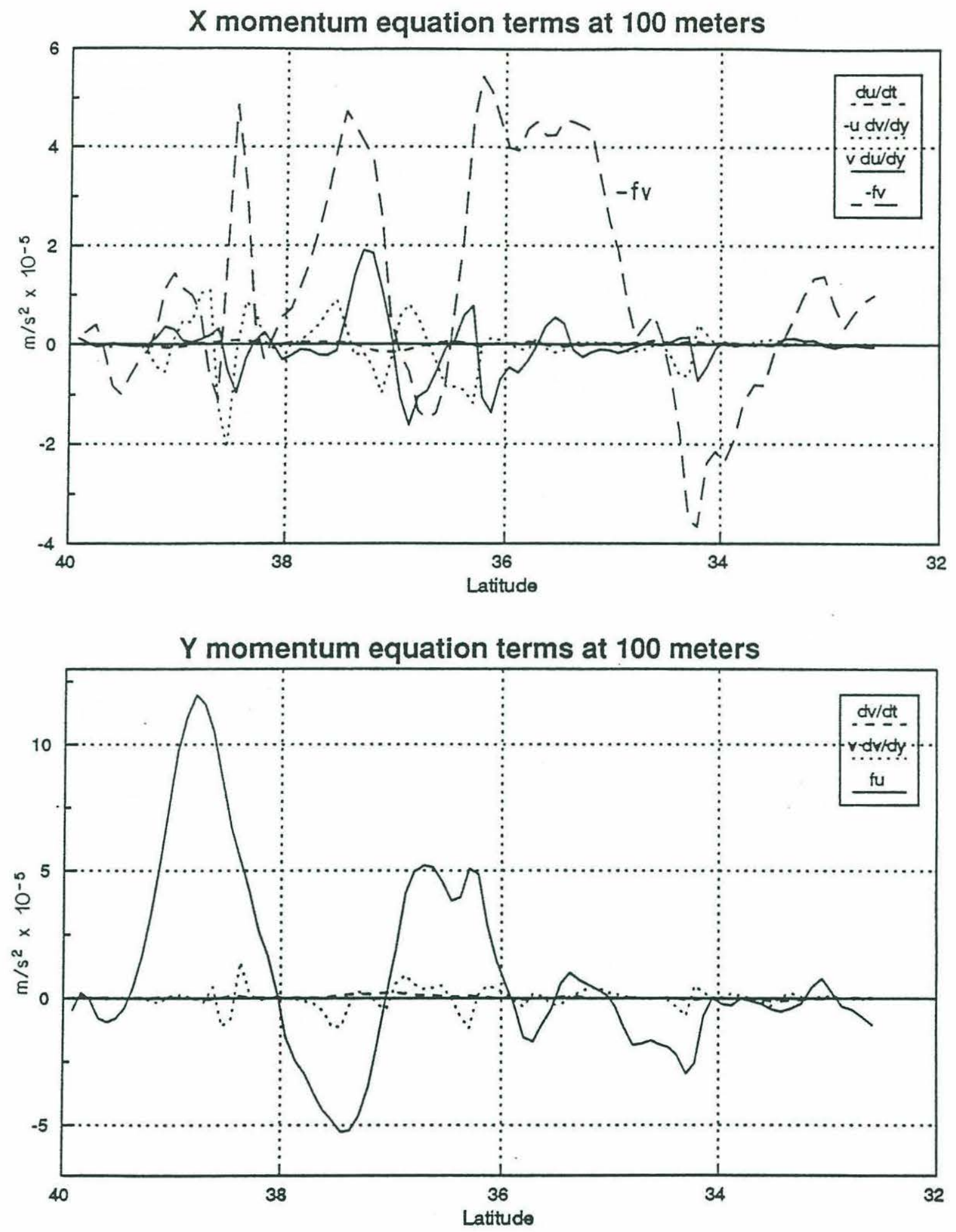

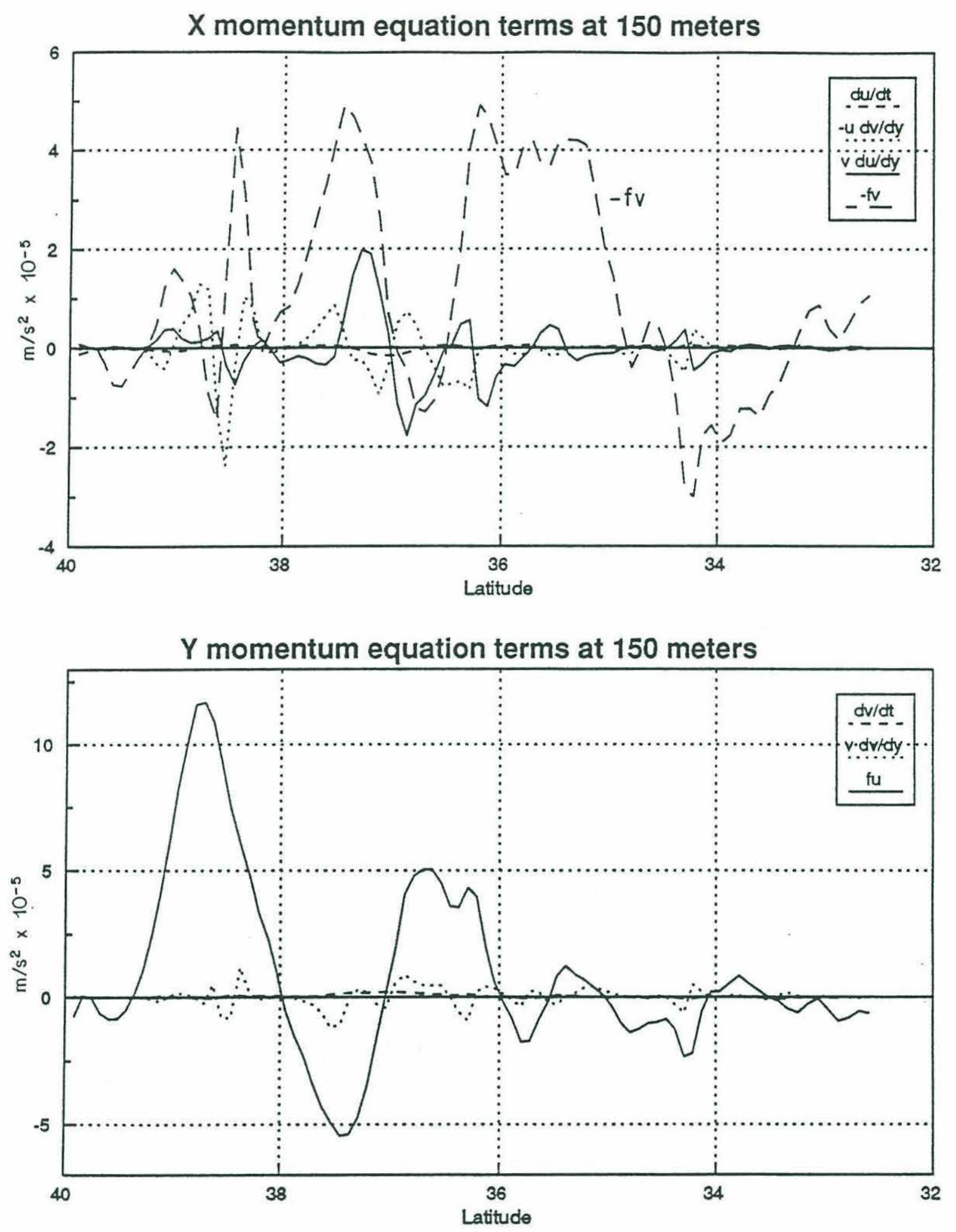

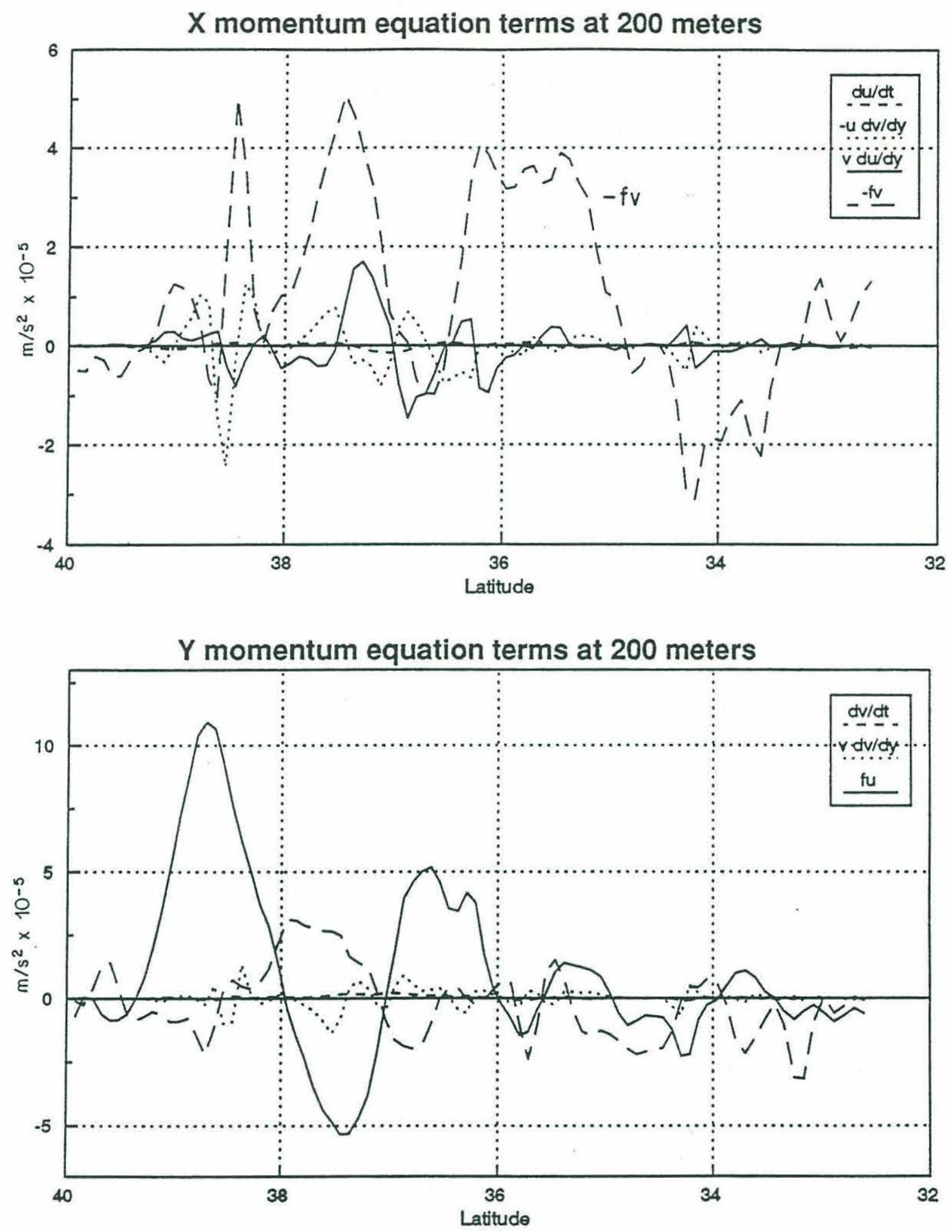
Looking at the relative magnitudes of the terms in the $\mathrm{x}$ equations, we see that the local acceleration term $u_{\mathrm{t}}$ is the smallest with magnitude $\approx 10^{-6} \mathrm{~m} / \mathrm{s}^{2}$. The convective acceleration terms $u v_{y}$ and $v u_{y}$ have maximum values of $1-2 \times 10^{-5} \mathrm{~m} / \mathrm{s}^{2}$, and the Coriolis term -fv has a maximum value of $5 \times 10^{-5} \mathrm{~m} / \mathrm{s}^{2}$. Using the geostrophic approximation in the cross-track direction would give velocity errors of 20 to 35 percent.

Adding all the measured ageostrophic terms together, we can get a feel for what the pressure gradient must be. The sums of $x$ momentum equation terms $u_{\mathrm{t}}-u v_{\mathrm{y}}+v u_{\mathrm{y}}$ and y momentum equation terms $v_{t}+v v_{y}$ with error bars are shown in Figure 5.8 for cruise OC205 and in Figure 5.9 for cruise OC216. For cruise OC205, the sum of $u_{\mathrm{t}}-u v_{\mathrm{y}}$ $+v u_{y}$ in the Gulf Stream (latitude $37^{\circ}-38^{\circ} \mathrm{N}$ in Figure 5.8) is positive, indicating that the pressure gradient in the $\mathrm{x}$ direction would have to be be larger than required to balance the Coriolis term. This additional pressure gradient, if not attenuated with depth would tend to push water to the south at speeds of approximately $10 \mathrm{~cm} / \mathrm{s}$ at depths where the non-linear terms decay, because the Coriolis term is not large enough in itself to balance the pressure gradient. This agrees with the findings of Bower and Rossby (1989) that cross-frontal velocity would be to the south downstream of the crest of a Gulf Stream meander.

Looking at the sum of the $\mathrm{x}$ momentum equation terms for cruise OC216, the results are less clear in the Gulf Stream. There is a large negative spike at $38.5^{\circ} \mathrm{N}$, right in the center of the Stream. The overall sense of the ageostrophic terms is small, which means the overall pressure gradient across the stream should be about the same as that required to balance the Coriolis term. Since it appears that on this cruise we crossed a fairly flat section of the stream, with no meander, this is consistent with Bower and Rossby.

The graphs of the y momentum equation terms show only three terms, $v_{t}, v v_{y}$, and $\mathrm{f} u$. The term which we are unable to measure, $u v_{\mathrm{x}}$ is known as the cyclostrophic term, 

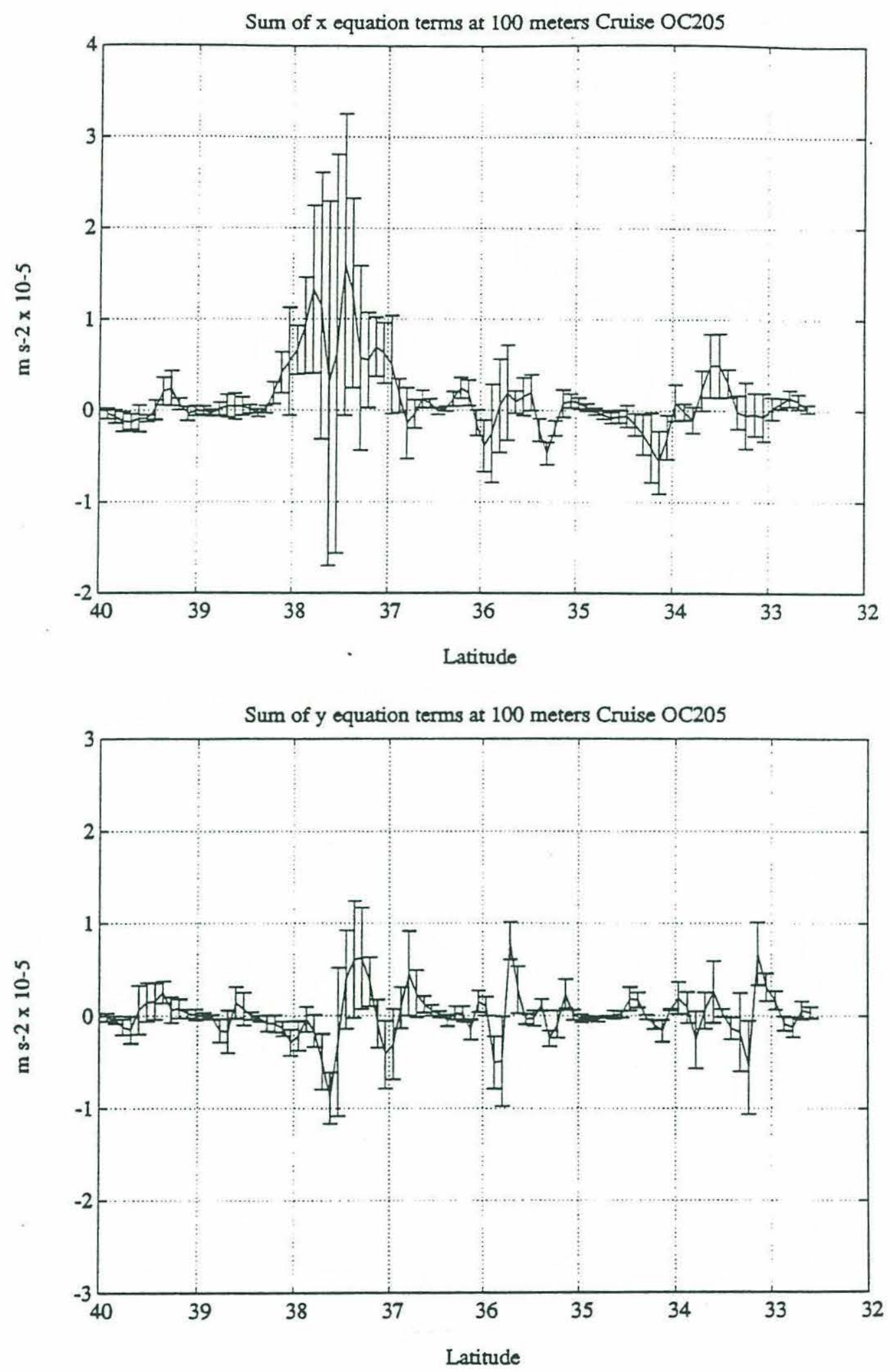

Figure 5.8. Sums of momentum equation terms at 100 meters, cruise OC205. Error bars are standard deviation of $u_{z}-u v_{y}+v u_{y}$ for the $x$ equation, and standard deviation of $v_{t}+v v_{y}$ for the $y$ equation. 

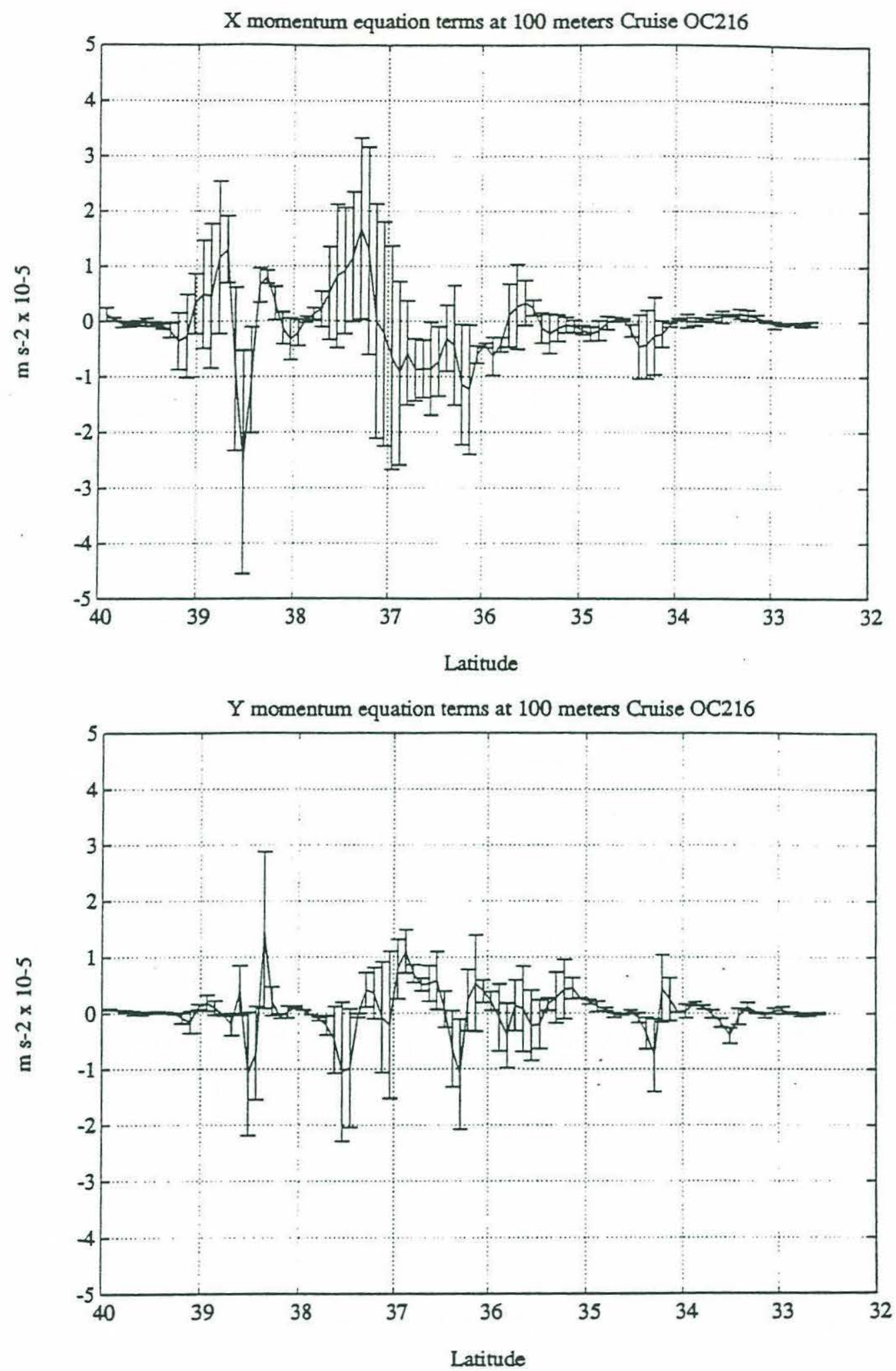

Figure 5.9. Sums of momentum equation terms at $100 \mathrm{~m}$ depth, cruise $0 C 216$. Error bars are standard deviation of $u_{t}-u v_{y}+v u_{y}$ for the $x$ equation, and standard deviation of $v_{t}+v v_{y}$ for the $y$ equation. 
which can be large if there is significant curvature in the Gulf Stream, which would cause $v_{\mathrm{x}}$ to be significant. From the AVHRR pictures during cruise OC205, we know that we are in a Gulf Stream meander, and can estimate $u v_{x}$ using the radius of curvature. For the curvature present during cruise OC205, the assumption of pure geostrophy causes $u$ to be overestimated by approximately $15 \%$ in the center of the Gulf Stream. A more detailed analysis of this effect for cruise OC205 is conducted in the next chapter.

For the OC216 cruise, a value of $u v_{x}$ can be determined for one point in the Gulf Stream using the data from the cross-track conducted during leg 4 . The value of $u v_{\mathrm{x}}$ at this point is $-2 \times 10^{-5} \mathrm{~m} / \mathrm{s}^{2}$ at a depth of 100 meters. Adding this term to the sum of $v_{t}$ $+v v_{y}$ shown in Figure 5.9, the sum of the ageostrophic terms in the y momentum equation would be of the order $1-2 \times 10^{-5} \mathrm{~m} / \mathrm{s}^{2}$ near the center of the Gulf Stream during cruise OC216. With values of $\mathrm{f} u$ in the Gulf Stream of order $1.3 \times 10^{-4} \mathrm{~m} / \mathrm{s}^{2}$, using geostrophy to compute cross-track velocity $u$ would result in errors of order $10 \%$. 


\title{
Chapter 6
}

\section{Comparison of Sea Surface Height and Velocity to}

\author{
Satellite Data
}

The GEOSAT altimeter measures collinear profiles of sea surface height every

seventeen days. By calculating dynamic height and sea surface velocity from the shipboard transits along one of the GEOSAT tracks, we are able to get an independent estimate of sea surface height to compare with the altimeter data. In order to compare the two data sets, the sea surface height variations due to the geoid must first be removed from the altimeter data. A mean sea surface topography is achieved by averaging many GEOSAT passes together. Unfortunately, subtracting out this mean signal from the height data also subtracts out the mean dynamic height. Kelly and Gille (1990) developed a method to add a synthetic mean Gulf Stream height profile back into the altimeter residual height data to produce a total dynamic height profile. The mean Gulf Stream is modeled with a Gaussian profile of the form

$$
u(y)=a \exp \left[-\frac{(y-b)^{2}}{2 c^{2}}\right]
$$


where $u$ is the downstream velocity as a function of cross-stream location (y), a is the peak velocity, $b$ is the location of the center of the stream, and $c$ is a width parameter. The dynamic height is then given by the integral

$$
h(y)=-\frac{f}{g} \int u(y) d y^{\prime} .
$$

The mean value of $h(y)$ when added to the residual height data from a particular satellite pass will give an estimate of the sea surface dynamic height for that pass. This height can be differentiated using the geostrophic relation to get a sea surface velocity profile. There are several errors introduced by using this method. First, the GEOSAT tracks are not exactly collinear. The satellite can deviate from its nominal track by one kilometer or more in the cross-stream direction. This means that when the mean sea surface topography is calculated, cross-stream spatial variations in sea surface height will show up as temporal variations. This effect is most pronounced near Bermuda, where there are strong cross-track gradients of the geoid.

Another restriction of the model is that mean values for flows outside the Gulf Stream are not modeled. The mean recirculation north and south of the Gulf Stream and any mean currents associated with rings are not taken into account.

The third source of error which affects the computed surface velocity comes from assuming geostrophy at the sea surface. As shown in the previous section, there are ageostrophic components in the momentum equations which are significant in the surface layer. In regions of significant curvature in the Gulf Stream, the "cyclostrophic" term should be included in the momentum balance.

Sea surface velocity profiles were generated from each of the three shipboard tracks from cruise OC205 and for the closest two GEOSAT passes. The ship's track surface velocities are from the combined doppler and geostrophic profiles. Unfortunately, 


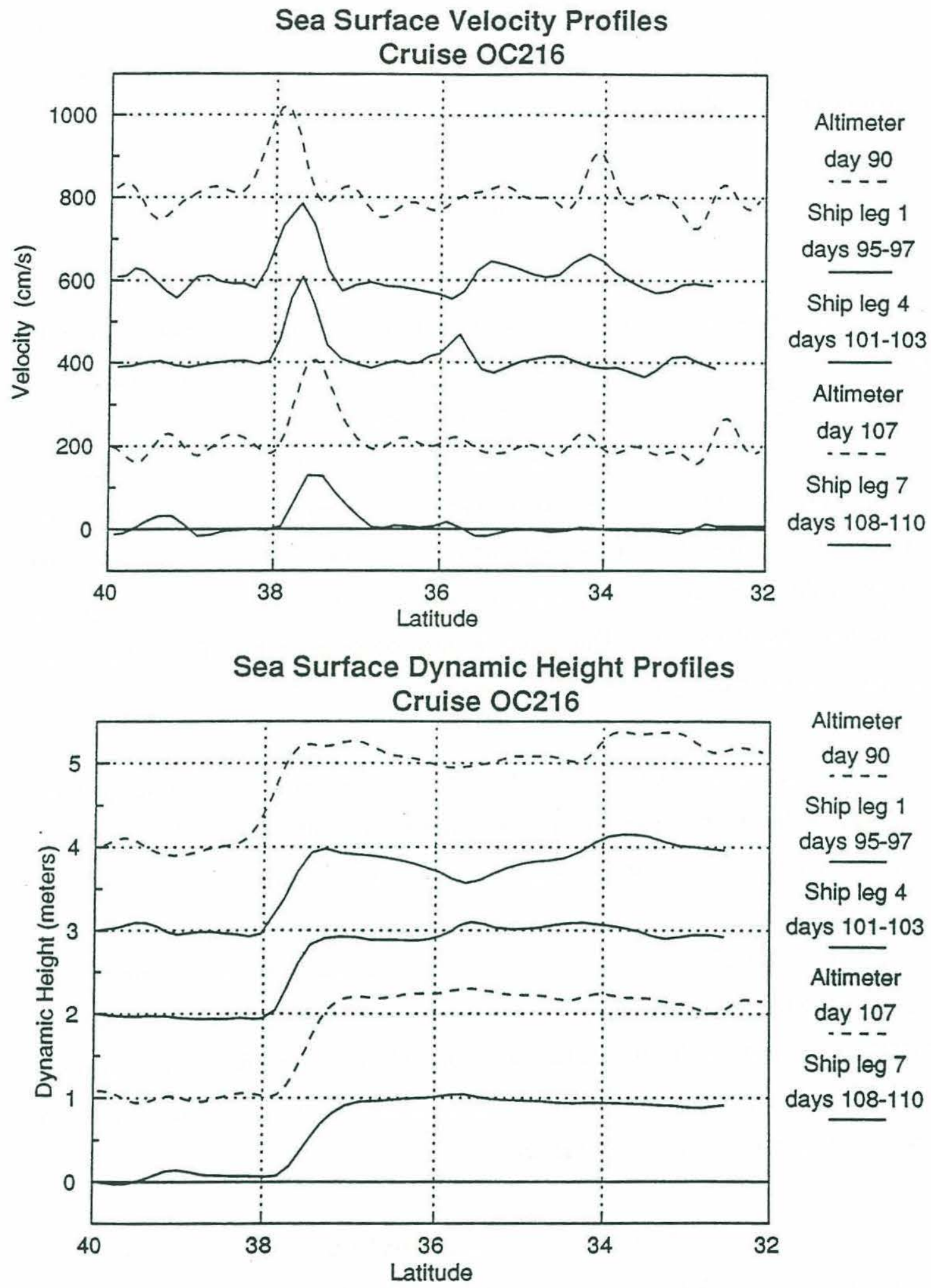

Figure 6.1. Sea surface velocities and sea surface heights for ship and satellite tracks between Bermuda and Cape Cod. 
none of the shipboard crossings of the Gulf Stream coincided in time with a satellite pass. The GEOSAT pass occurring during the cruise was on April 17, between legs 4 and 7 of the ship's track. These cross-track sea surface velocity profiles are presented as a time series in Figure 6.1. The satellite profiles and the shipboard profiles show a consistent picture of the Gulf Stream moving southward during the period of the cruise, with the peak cross-track velocity in the Gulf Stream decreasing towards the end of the cruise due to rotation of the Gulf Stream axis. The values of peak velocity (about $2 \mathrm{~m} / \mathrm{s}$ ) and width of the Gulf Stream are similar in both satellite and shipboard profiles, although the peak Gulf Stream velocities are somewhat higher in the satellite profiles. The Gulf Stream appears to have broadened and slowed down by leg 7 because the meander which was crossed on this leg has rotated the Gulf Stream axis to the south. The GEOSAT velocity profile for day 107 shows the broadening associated with this rotation, but not the dip in peak velocity. Part of this inconsistency may be due to omission of the cyclostrophic term in the momentum balance.

The AVHRR infrared satellite images presented in chapter 5 show the evolution of the Gulf Stream meander which was located on the satellite track at the time of the cruise. The meander moved from east to west and the trough of the meander deepened during the cruise. Due to the significant curvature in the Gulf Stream induced by this meander, the cyclostrophic term is significant in the momentum balance. The momentum balance, including the cyclostrophic term is

$$
\frac{u^{2}}{R}+f u=-g \frac{\partial h}{\partial n},
$$

where $u$ is the velocity in the direction tangent to the radius of curvature, and $n$ is distance normal to the radius of curvature. In the track oriented coordinate system the equation becomes: 


$$
\frac{u^{2}}{R \cos \theta}+f u=-g \frac{\partial h}{\partial y}=f u_{g},
$$

where $u_{r}$ is the cross-track velocity in the rotated system, $\theta$ is the angle between the downstream direction and the cross-track direction, and $u_{\mathrm{g}}$ is the velocity which would exist if the height gradient were due entirely to geostrophy.


Figure 6.2. Gulf Stream curvature at times of day 90 and day 107 GEOSAT passes.

At the time of the day 90 satellite pass, the radius of curvature was $\approx 170 \mathrm{~km}$ and the angle between the Gulf Stream direction and the normal to the satellite track was $3^{\circ}$. Using equation (6.4), the geostrophic peak velocity in the Gulf Stream of $2.2 \mathrm{~m} / \mathrm{s}$ corresponds to a peak velocity of $1.95 \mathrm{~m} / \mathrm{s}$ when the curvature is taken into effect. For the second satellite pass, using $R=130 \mathrm{~km}, \theta=33^{\circ}$, and $v_{\text {peak }}=2.05 \mathrm{~m} / \mathrm{s}$, the corresponding peak velocity including the cyclostrophic term is $1.74 \mathrm{~m} / \mathrm{s}$. (Figure 6.2) 
The surface velocity computed by differentiating the sea surface slope using geostrophy is about .25 to $.3 \mathrm{~m} / \mathrm{s}$ too high at the peak value in the Gulf Stream given the curvature seen at the time of the satellite passes. Since the shipboard velocities are referenced to directly measured $\mathrm{ADCP}$ velocities, the surface velocities computed from shipboard data should be close to the actual velocity, even though geostrophy was used to compute the velocity change from 100 meters to the surface.

Smaller scale variations in velocity also appear consistently between the altimeter and the shipboard profiles. A cold core ring centered at $35.6^{\circ} \mathrm{N}$ can be seen in both the day 90 GEOSAT and the leg 1 shipboard profile. The large fluctuations in the altimeter velocities south of $33^{\circ} \mathrm{N}$ are noise due to geoid spatial variability near Bermuda as discussed earlier.

More insight can be gained by examining a time series of sea surface heights. A time series of height profiles from the three ship crossings and two altimeter crossings are shown in the lower half of Figure 6.1 (page 99). In this case, the heights measured by the altimeter are the direct measurement, and the velocities measured from the ship are integrated to give a geostrophic dynamic height profile. The height differences across the Gulf Stream determined geostrophically from the shipboard data are low due to neglecting the cyclostrophic term. In order to see how close the best shipboard estimate of dynamic height would come to the altimeter height, the velocity data from legs 4 and 7 were interpolated to the time of the GEOSAT pass. A cyclostrophic correction was determined for each interpolated doppler vector using the component of velocity in the radial direction and the distance from each vector position to the center of the radius of curvature. The 100 meter doppler vectors were used, assuming that the cyclostrophic term would not be significantly different at 100 meters than at the surface. The cyclostrophic correction was then added to an interpolated surface velocity profile, and this velocity profile was integrated to produce a height profile for the time of the satellite pass based on shipboard data. The result is shown in Figure 6.3. Even when an estimate of the cyclostrophic term is added, the height difference across the Gulf Stream 
is about $12 \mathrm{~cm}$ less for the shipboard determined height profile than it is for the height profile measured by the altimeter. Interpolating the legs 4 and 7 velocity profiles tends to smooth out features, so the Gulf Stream and any other features will tend to be broader and with lower peak velocities than either of the velocity profiles individually. This would explain why the slope of the height curve is steeper for the satellite data than for the shipboard results, and why the curve is smoother than the altimeter curve, but does not account for the overall difference in height across the Gulf Stream. The total height difference across the Gulf Stream is should be the same for both curves within the expected errors for the two techniques.

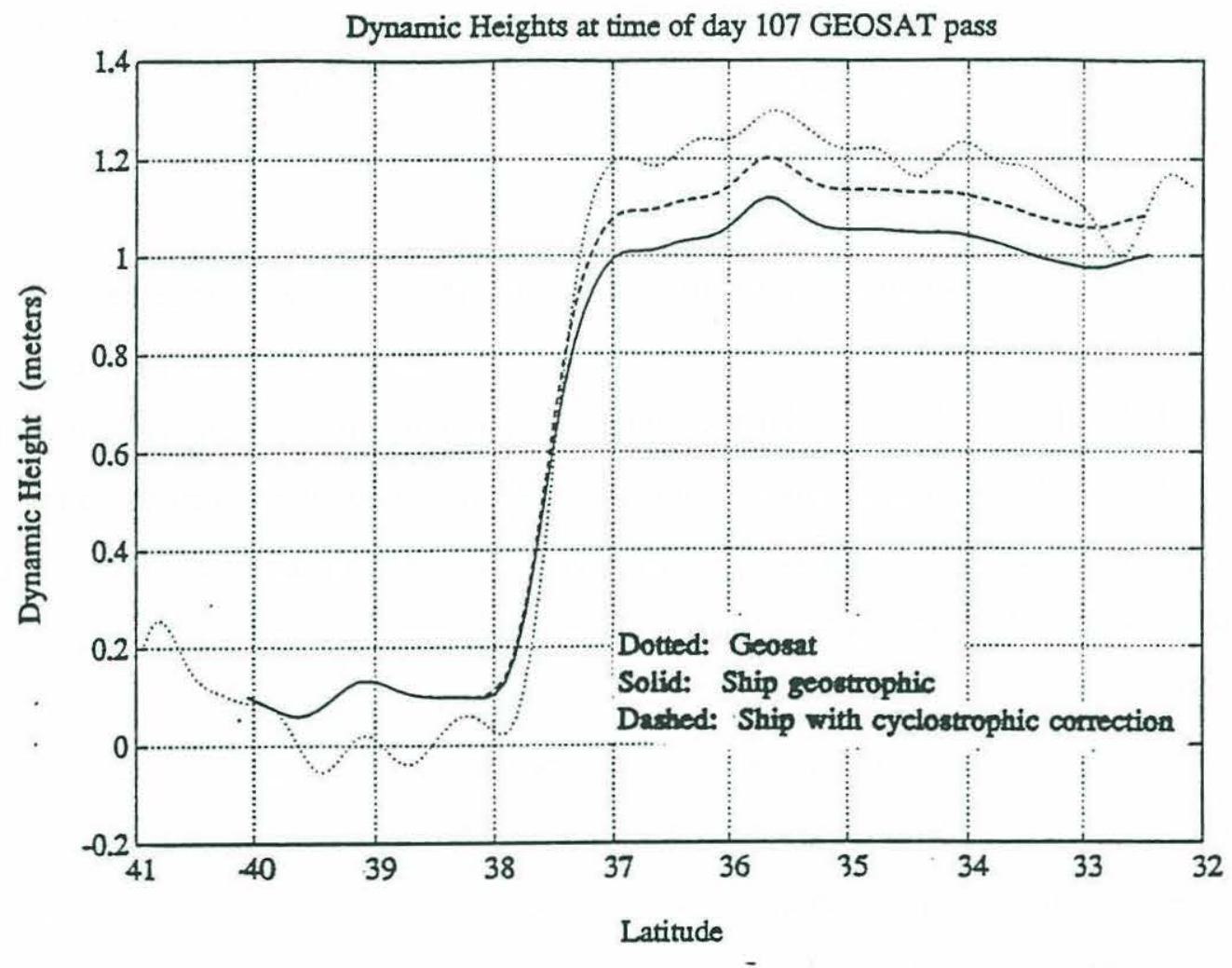

Figure 6.3. Sea surface height for the day 107 GEOSAT profile compared to height interpolated between ship's tracks for legs 4 and 7.

One source of error is the time difference between the altimeter measurements and the shipboard measurements. Interpolating between legs 4 and 7 to the time of the satellite pass is an attempt to reduce this problem. The height difference across the Gulf Stream is about $10 \mathrm{~cm}$ larger for leg 4 than for leg 7. Certainly the error introduced by 
the interpolation is less than $\pm 5 \mathrm{~cm}$. We have already seen how the ADCP velocities are prone to systematic bias errors. Assuming a maximum bias of no more than $2 \mathrm{~cm} / \mathrm{s}$ after balancing the leg mass transports gives a maximum error of $\pm 2.5 \mathrm{~cm}$ in dynamic height across the Gulf Stream.

The dynamic height computed from the altimeter data is also subject to several sources of error:

- The Kelly-Gille model for the mean Gulf Stream is based on processing 32 cycles of the satellite between November 1986 and April 1988. The rms height error across the Gulf Stream due to the height variance in the samples used to compute the mean is $6 \mathrm{~cm}$.

- The particular satellite pass is subject to errors caused by (1) uncertainty in the measurement of the travel time of the radar signal, and (2) uncertainty in the actual orbit position of the satellite. Height measurement errors are caused by variability of the moisture content of the troposphere and by variations in the free electron content in the ionosphere, which change the amount of refraction of the radar signal, and by errors induced by variations in wave height. Orbit errors are due to variations in the satellite height from its assumed orbit path. The expected error in height difference across the Gulf Stream due to these effects is $\pm 8 \mathrm{~cm}$ (Kelly, et al. 1990).

The total ms error in $\Delta h$ for the altimeter curve for all the effects described above is \pm 10 $\mathrm{cm}$.

The height profiles, despite the difference in $\Delta h$ across the Gulf Stream are remarkably similar, with several smaller scale features in the altimeter profile consistently reproduced by the ship's data, despite the temporal and spatial aliasing problems. More data are needed from future cruises to determine whether better agreement is achieved when there is not such a large cyclostrophic term in the momentum balance and when the shipboard and satellite data are taken at the same time. 


\section{Chapter 7}

\section{Conclusions}

Velocities measured using the acoustic doppler current profiler have been combined with geostrophic velocity profiles generated from XBT measurements to estimate the flow field on several tracks between Bermuda and the eastern coast of the American continent. The data were taken during two separate cruises, the first in April, 1989, and the second in December, 1989. A track between Bermuda and Cape Cod was chosen to correspond to an ascending subtrack of the GEOSAT altimeter, allowing comparison of velocities determined from shipboard measurements to velocities determined from altimeter data. This study has four main objectives:

- Demonstration of the use of XBT's and the ADCP system to measure upper ocean transport and variability over large areas in a short period of time.

- Use of repeated measurements along the Cape Cod-Bermuda track in order to examine short term variability along this track on time scales of order one to two weeks. 
- Use of the $A D C P$ velocities to compute and analyze ageostrophic terms in the horizontal momentum equations.

- Evaluation of the use of satellite altimetry for computing sea surface velocities by comparing altimeter results to shipboard measurements along the satellite track.

The time saving advantage of the $\mathrm{ADCP}-\mathrm{XBT}$ method is demonstrated by the large areas covered during the two cruises. In the April cruise, for example, the ship covered a distance of over 5000 kilometers in a period of less than three weeks while making continuous $\mathrm{ADCP}$ and hourly $\mathrm{XBT}$ measurements. This allowed measurements of the velocity field over a large area of the North Atlantic in a time period much shorter than that required for hydrographic measurements with CTD stations. The disadvantages of this method include limitation of measurements to the upper ocean and errors in the geostrophic velocity profiles introduced by the inability to directly measure salinity.

The repeat tracks between Bermuda and Cape Cod allowed measurement of rapid variability along this path. Sources of variability along this track included internal variability in the Gulf Stream, which caused changes in transport of up to 3 Sverdrups in the upper 765 meters in a one week period, and a rapid, large scale barotropic mode, which caused transport changes of up to 8 Sverdrups in one week. During the December cruise, the movement of a cold core ring onto the track caused a change in transport of 8 Sverdrups due to edge effects at the end of the track.

Measurements of horizontal velocity components along the repeated track using the $\mathrm{ADCP}$ system allowed computation of both temporal and spatial derivatives along the track. This allowed us to measure the size of some of the ageostrophic terms and to estimate the size of the errors introduced in using the geostrophic approximation. Measurement of the non-geostrophic terms indicates that the geostrophic approximation is reasonably good for computing the along-stream velocity (errors $\leq 10 \%$ ) but that 
geostrophy is a poor approximation for determining the cross-stream velocity component (errors 20-35\%).

Sea surface velocity measurements made from the GEOSAT altimeter, when compared to measurements made from the ship along the same track, show a consistent picture of the size, location, and motion of the Gulf Stream. Smaller scale features in the flow field are also reproduced consistently, despite some temporal and spatial aliasing. These measurements were taken in the trough of a large Gulf Stream meander, which introduced a significant cyclostrophic term into the momentum balance. This term was estimated using satellite imagery to compute the radius of curvature of the Gulf Stream, and subtracted from the shipboard data. The geostrophic GEOSAT velocities in the Gulf Stream exceeded the shipboard measurements by about $10 \%$, even after the cyclostrophic term was removed. The difference between the shipboard and altimeter estimates of dynamic height are attributed to errors in the altimeter height profile, caused by limitations of the model used to remove the mean Gulf Stream from the geoid, and by inaccuracies in computing the radar signal path and the orbit path of the satellite. Additional comparisons of shipboard and altimeter measurements for different conditions in the Gulf Stream are needed to further evaluate the accuracy of satellite altimetry for determining sea surface current velocities. 


\section{REFERENCES}

Armi, L. and N. A. Bray, 1982. A standard analytic curve of potential temperature versus salinity for the western North Atlantic. Journal of Physical Oceanography, 12, 384-387.

Beardsley, R. C. and W. C. Boicourt, 1981. On estuarine and continental-shelf circulation in the Middle Atlantic Bight. Evolution of Physical Oceanography, Scientific Surveys in Honor of Henry Stommel, B. A. Warren and C. Wunsch, eds.,The MIT Press.

Bower, A. S., 1989. Potential vorticity balances and horizontal divergence along particle trajectories in Gulf Stream meanders east of Cape Hatteras. Journal of Physical Oceanography, 19, 1669-1681.

Bower, A. S., and T. Rossby, 1989. Evidence of Cross-frontal Exchange Processes in the Gulf Stream Based on Isopycnal RAFOS Float Data. Journal of Physical Oceanography, 19, 1177-1190.

Hall, M. M., 1986. Horizontal and vertical structure of the Gulf Stream velocity field at $68^{\circ} \mathrm{W} . J$. Phys. Oceanogr., 15, 1439-1452.

Halkin, D. and T. Rossby, 1985. The structure and transport of the Gulf Stream at $73^{\circ} \mathrm{W}$, Journal of Physical Oceanography, 15, 1439-1452.

Joyce, T. M., 1988. On in-situ "calibration" of shipboard ADCP's. Journal of Atmospheric and Ocean Technology, 6, 169-172.

Joyce, T. M., J. A. Dunworth, D. M. Schubert, M. C. Stalcup and R. L. Barbour, 1988. Application of Acoustic-Doppler Current Profiler and Expendable Bathythermograph Measurements to the Study of the Velocity Structure and Transport of the Gulf Stream, Woods Hole Oceanog. Inst. Tech. Rept. WHOI-88-42, 27 pp.

Joyce, T. M., K. A. Kelly, D. M. Schubert, and M. J. Caruso, 1990. Shipboard and altimetric studies of rapid Gulf Stream variability between Cape Cod and Bermuda. Deep Sea Res., Submitted.

Joyce, T. M., C. Wunsch, and S. D. Pierce, 1986. Synoptic Gulf Stream velocity profiles through simultaneous inversion of hydrographic and acoustic doppler data, $J$. Geophys. Res., 91, 7573-7585. 
Kelly, K. A., and S. T. Gille, 1990. Gulf Stream surface transport and statistics at $69^{\circ} \mathrm{W}$ from the GEOSAT altimeter, Journal of Geophysical Research, 95, 3149-3161.

Kelly, K.,A., T. M. Joyce, D. M. Schubert, M. J. Caruso, and Z. Sirkes, 1990. The Geoid and mean dynamic height along the GEOSAT subtrack from Bermuda to Cape Cod. (in preparation)

Kennelly, M. A., 1984. The velocity structure of warm core ring 82B and associated cyclonic features, M. S. Thesis, MTT, Woods Hole Oceanog. Inst. Tech. Rept. WHOI-84-10, $100 \mathrm{pp}$.

Lanczos, C., 1961. Linear Differential Operators. Van Nostrand, London, 564 pp.

Lawson, C. L. and R. J. Hanson, 1974. Solving Least Squares Problems, Prentice-Hall, Englewood Cliffs, NJ, 340 pp.

Pedlosky, J., 1979. Geophysical Fluid Dynamics, Springer-Verlag, 710 pp.

Pierce, S. and T. M. Joyce, 1988. Gulf Stream velocity structure through inversion of hydrographic and acoustic doppler data. J. Geophys. Res., 93, 2227-2236.

Rosenfeld, L. K., R. L. Molinari, and K. D. Leaman, 1989. Observed and modeled annual cycle of transport in the straits of Florida and east of Abaco Island, the Bahamas $\left(26.5^{\circ} \mathrm{N}\right), J$. Geophys. Res., 94, 4867-4878.

Warren, B. A. and G. H. Volkmann, 1968. Measurements of volume transport in the Gulf Stream south of New England. J. Mar. Res., 26, 110-126.

Watts, D. R., 1983. Gulf Stream variability. Eddies in Marine Science, A. R. Robinson, Ed., Springer-Verlag 114-167.

Wiggins, R. A., 1972. The general linear inverse problem: implication of surface waves and free oscillations for earth structure. Rev. Geophys. Space Phys., 10, 251-285.

Wiggins, R. A., K. L. Lamer and R. D. Wisecup, 1976. Residual statistics analysis as a general linear inverse problem. Geophys., 41, 922-938.

Worthington, L. V., 1976. On the North Atlantic Circulation. The Johns Hopkins Oceanographic Studies, No. 6, $110 \mathrm{pp}$.

Wunsch, C., 1978. The general circulation of the North Atlantic west of $50^{\circ} \mathrm{W}$ determined from inverse methods. Review of Geophysics, 16, 583-620. 
Wunsch, C., D. Hu, and B. Grant, 1983. Mass, heat, salt, and nutrient fluxes in the South Pacific Ocean. J. Phys. Oceanogr., 13, 725-753. 